\title{
Pontos-quânticos: fotodetectores, localização-fraca e estados de borda contra-rotativos
}

\author{
Ivan Ramos Pagnossin
}

\section{Orientador:}

Prof. Dr. Guennadii Michailovich Gusev (IFUSP)

Banca examinadora:

Prof. Dr. Antônio Carlos Seabra (EPUSP)

Prof. Dr. Eliermes Arraes Meneses (UNICAMP)

Prof $^{a} \operatorname{Dr}^{a}$ Euzi Conceição Fernandes da Silva - Presidente (IFUSP)

Prof. Dr. Fernando Iikawa (UNICAMP)

Prof $^{a}$ Dr $^{a}$ Lucy Vitória Credidio Assali (IFUSP) 


\section{FICHA CATALOGRÁFICA \\ Preparada pelo Serviço de Biblioteca e Informação do Instituto de Física da Universidade de São Paulo}

Pagnossin, Ivan Ramos

Pontos-quânticos: fotodetectores, localização-fraca e estados de borda contra-rotativos - São Paulo, 2008.

Tese (Doutorado) - Universidade de São Paulo.

Instituto de Física - Depto. de Física dos Materiais e Mecânica

Orientador: Prof. Dr. Guennadii Michailovich Gusev

Área de concentração: Física

Unitermos: 1. Fotodetectores; 2. Efeito Hall quântico;

3. Física da Matéria Condensada. 
Dedico esta obra aos meus pais, à minha esposa, Fabiana, e ao meu filho, Giovani. 


\section{Agradecimentos}

Este trabalho não teria sido possível sem o apoio da minha esposa, Fabiana Aparecida Cagnotto de Farias, do meu filho, Giovani Cagnotto Pagnossin, e dos meus pais, Marco Antônio Pagnossin e Luci Andrade Ramos Pagnossin. Por este motivo agradeço-os todos e compartilho com eles, em cotas iguais, os méritos deste trabalho.

Agradeço à minha eterna orientadora e amiga, a profa Euzi Conceição Fernandes da Silva, por acreditar em mim (mesmo quando eu não merecia) e orientar-me sempre sobre tudo e mesmo de longe.

Ao meu orientador, prof. Guannadii Michailovich Gusev, por aceitar-me como seu aluno quando a prof. Euzi foi para os Estados Unidos e por me indicar "o caminho das pedras."

Aos amigos Alain André Quivy, Angela María Ortiz de Zevallos Márquez, Celso de Araújo Duarte, Francisco de Paula Oliveira, José Geraldo Chagas, Luis Enrique Gomez Armas, Márcia Ribeiro, Mônica Jimenez Clauzet, Niko Churata Mamani, Tatiana Lacerda e Tomas Erikson Lamas, agradeço pela preciosa amizade e pelos incontáveis auxílios.

À Rita (EPUSP), agradeço por dispôr-se sempre a executar a gravação da barra-Hall, em todas as amostras.

Ao professor Antônio Carlos Seabra (EPUSP) sou grato pelo acesso ao microscópio eletrônico utilizado neste trabalho; e às colegas Mariana Pojar e Simone Camargo Trippe, por ensinarem-me a utilizá-lo.

Ao professor Iouri Poussep (IFSC), pelo acesso ao seu laboratório; e ao seu aluno Haroldo Arakaki, por auxiliar-nos nos processos de litografia e evaporação de ouro. Processos similares foram feitos também no Instituto de Física da UNICAMP, pelos qual sou grato ao Antonio Augusto de Godoy Von Zuben (Totó).

I would like to thank prof. Ajit Kumar Meikap, who taugh me the principles of weak localization and with who I had trainning my spoken english skill before my trip to France; also for the colaboration on many studies.

Je remercie au prof. Jean-Claude Portal, pour m'admettre dans son équipe de travail en France, où j'ai établi contact avec d'autres paradigmes. De la même façon, je remercie aux collègues Vincent Renard et Sami Sassini, qui m'ont accueilli dans le pays et m'ont enseigné a conduire les équipements, sans rien demander en exchange.

Finalmente, sou grato à FAPESP, por ter disponibilizado importantes recursos públicos para este projeto, cujos resultados não podem ser representados em sua totalidade nessas poucas páginas, por mais que eu tente. 


\section{Resumo}

Apresentamos neste trabalho três estudos sobre o transporte de cargas em heteroestruturas contendo pontosquânticos. Para isso, efetuamos medidas dos efeitos Hall clássico e quântico inteiro, do Shubnikov-de Haas e da localização-fraca em baixas temperaturas (de 0,05 a $5 \mathrm{~K}$ ) e em campos magnéticos de até $15 \mathrm{~T}$.

No primeiro destes estudos utilizamos uma heteroestrutura de poço-quântico duplo (bicamada) com uma rede de pontos-quânticos hexagonal construída por litografia na superfície da amostra. Observamos, pela primeira vez (até onde sabemos), que quando o fator de preenchimento total é dois, os pontos-quânticos afetam a dinâmica dos elétrons no poço-quântico mais próximo da superfície, dando origem a um platô "Hall" com resistência diferente daquela prevista pelo efeito Hall quântico inteiro. Acreditamos que este fenômeno se deva à presença de estados de borda contra-rotativos, previstos em 1992 por Johnson et al [1].

No segundo estudo utilizamos o fenômeno da localização-fraca para determinar a influência de pontosquânticos de InAs auto-organizados no tempo de coerência da função de onda de um sistema bidimensional de elétrons (poço-quântico de InGaAs) próximo a eles. Observamos que, embora o acúmulo de tensão mecânica durante o crescimento epitaxial prejudique a mobilidade quântica desses elétrons, ele também aumenta o tempo de coerência. Concluímos daí que a tensão mecânica reduz o espaço de fases dos elétrons no poço-quântico.

Finalmente, determinamos as propriedades básicas do transporte de cargas em heteroestruturas contendo pontos-quânticos e visando sua utilização na fabricação de fotodetectores de infravermelho. Observamos que o empilhamento de pontos-quânticos auto-organizados pode ser organizado de modo a maximizar a mobilidade e, com isso, melhorar as características operacionais de um tal dispositivo. No entanto, é importante observar que, por questões de infra-estrutura, não foi nosso objetivo fabricar esses dispositivos.

\section{Abstract}

In this work we present three studies about the transport of charges in heterostructures with quantumdots. For this, we made measurements on the classical and quantum Hall effects, Shubnikov-de Haas and weak-localization at low temperatures (from 0.05 to $5 \mathrm{~K}$ ) and magnetic fiels up to $15 \mathrm{~T}$.

In the first one we used a double quantum-well structure (bilayer) with an array of hexagonal lithographic quantum-dots at the surface. We observed, for the first time (up to our knowledge), that when the total filling factor is two, the quantum-dots change the electron dynamics on the quantum-well closer to the surface, giving rise to a "Hall" plateau different from that predicted by the integer quantum Hall effect. We believe this phenomenon is due to the presence of counter-rotating edge-states, first predicted by Johnson et al [1].

In the second study, we used the weak-localization effect to determine the influence of self-organized InAs quantum-dots on the coherence time of the wave function of electrons close to them (in a InGaAs quantumwell). We observed that, though the mechanical strain accumulated during the epitaxial growth degrades the quantum mobility, it also increases the coherence time. We concluded that the strain reduces the phase space of the electrons on the quantum-well.

Finally, we determined the basic charge transport properties of heterostructures containing quantum-dots to be used on the fabrication of quantum-dots infrared photodetectors. We observed that the stacking of quantumdots can be organized to maximize the mobility and, as a consequence, the operational characteristics of such devices. However, it's important to notice it was not our aim to construct such photodetectors. 


\section{Sumário}

Resumo/Abstract iii

1. Introdução 1

1.1. Fotodetectores de infravermelho (QDIPs) $\ldots \ldots \ldots \ldots \ldots \ldots$

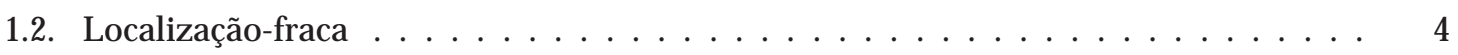

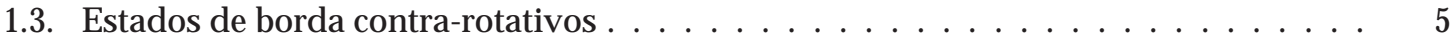

2. Conceitos e métodos $\quad 7$

2.1. O efeito Hall clássico ． . . . . . . . . . . . . . . . . . . . . . . . . . . . . 7

2.1.1. Efeito Hall em mais de uma sub-banda . . . . . . . . . . . . . . . . . . 10

2.2. O efeito Hall quântico . . . . . . . . . . . . . . . . . . . . . . . . . . . . 11

2.2.1. O problema quântico . . . . . . . . . . . . . . . . . . . . . . . 11

2.2.2. Estados de borda . . . . . . . . . . . . . . . . . . . . . . . . 15

2.2.3. Transição entre platôs . . . . . . . . . . . . . . . . . . . . . . . . 15

2.2.4. O efeito do $\operatorname{spin} \ldots \ldots \ldots \ldots \ldots \ldots \ldots$

2.2.5. IQHE em duas sub-bandas . . . . . . . . . . . . . . . . . . . . 17

2.3. O efeito Shubnikov-de Haas . . . . . . . . . . . . . . . . . . . . . . . . . . . . . . 19

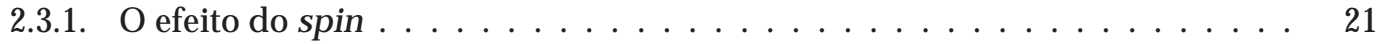

2.4. O formalismo de Landauer-Büttiker . . . . . . . . . . . . . . . . . . . . . . 21

2.4.1. O efeito Hall quântico revisitado . . . . . . . . . . . . . . . . . . . . . 24

2.5. Localização fraca . . . . . . . . . . . . . . . . . . . . . . . . . 26

3. Processos e equipamentos 29

3.1. Amostras . . . . . . . . . . . . . . . . . . . . . . . . . . . . . . . . . . 29

3.2. A formação dos pontos-quânticos . . . . . . . . . . . . . . . . . 33

3.2.1. Descrição das amostras . . . . . . . . . . . . . . . . . . . . 36

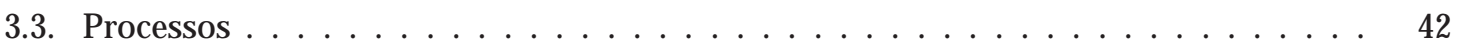

3.3.1. A barra-Hall . . . . . . . . . . . . . . . . . . . . . 43

3.3.2. Contato ôhmico . . . . . . . . . . . . . . . . . . . . . . . . 44

3.3.3. Contato de controle (gate ou porta) _ . . . . . . . . . . . . . . . 45

3.3.4. A rede de antipontos-quânticos . . . . . . . . . . . . . . . . . . . . . . . . 49 


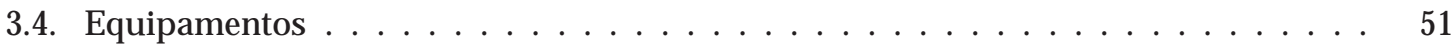

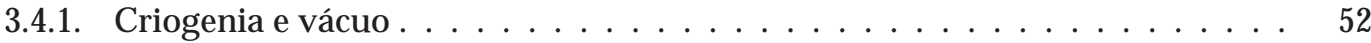

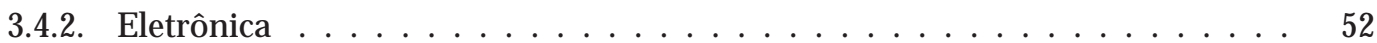

4. Resultados 55

4.1. Estados de borda contra-rotativos . . . . . . . . . . . . . . . . . 55

4.1.1. Resultados . . . . . . . . . . . . . . . . . . . . . . . . 55

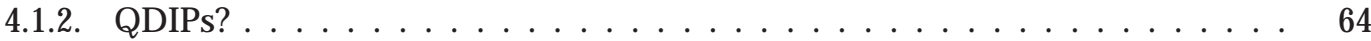

4.2. Localização fraca e interações elétron-elétron em 2DES com pontos-quânticos . . . . 66

4.2.1. Resultados . . . . . . . . . . . . . . . . . . . . . . 66

4.3. Fotodetectores de infravermelho . . . . . . . . . . . . . . . . . . . 72

4.3.1. Resultados do $1^{\circ}$ conjunto . . . . . . . . . . . . . . . . . . . . 72

4.3.2. Resultados do $2^{\circ}$ conjunto . . . . . . . . . . . . . . . . . . . . 80

5. Conclusões e perspectivas 83

A. Lista de símbolos $\quad 85$

B. Lista de siglas $\quad 89$

C. Súmula curricular $\quad 91$

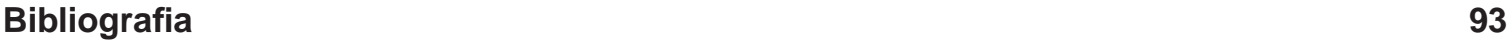




\section{1 \\ Introdução}

Segundo A. J. Severino [2, p. 150], "a tese de doutorado (...) trata da abordagem de um único tema," mas por diversas razões desenvolvemos não um, mas três tópicos neste trabalho, todos envolvendo pontos-quânticos [3]. Por esta razão este capítulo e o de resultados serão fracionados em três partes: "fotodetectores de infravermelho," "localização-fraca" e "estados de borda contra-rotativos."

\subsection{Fotodetectores de infravermelho (QDIPs)}

Na última década as fibras ópticas de sílica vêm substituindo os antigos fios de cobre e possibilitando uma nova gama de aplicações, desde procedimentos cirúrgicos até simples decorações domésticas. As fibras ópticas atuais apresentam um mínimo local de atenuação para radiações com comprimento de onda de 1,3 $\mu \mathrm{m}$ e um mínimo absoluto para de 1,5 $\mu \mathrm{m}$, isto é, sinais com estas freqüências podem percorrer distâncias muito maiores (dezenas a centenas de vezes) nas fibras ópticas antes de serem perdidos em meio aos ruídos. Para as telecomunicações, isto implica não só na redução da energia utilizada, mas também na redução significativa do número de repetidores numa longa linha de transmissão de dados e, conseqüentemente, na redução dos custos de instalação e manutenção. Isto afeta os preços praticados e, por conseguinte, a economia de um país e do mundo.

Todavia, foi só há alguns poucos anos que as primeiras emissões em 1,3 $\mu \mathrm{m}$ foram atingidas [4, 5], e apenas ainda mais recentemente (em meados de 2002), o LNMS conseguiu fabricar pontosquânticos (QD, quantum-dots) que emitem fótons de 1,5 $\mu \mathrm{m}$ [6], tornando-se um dos primeiros 
(a)

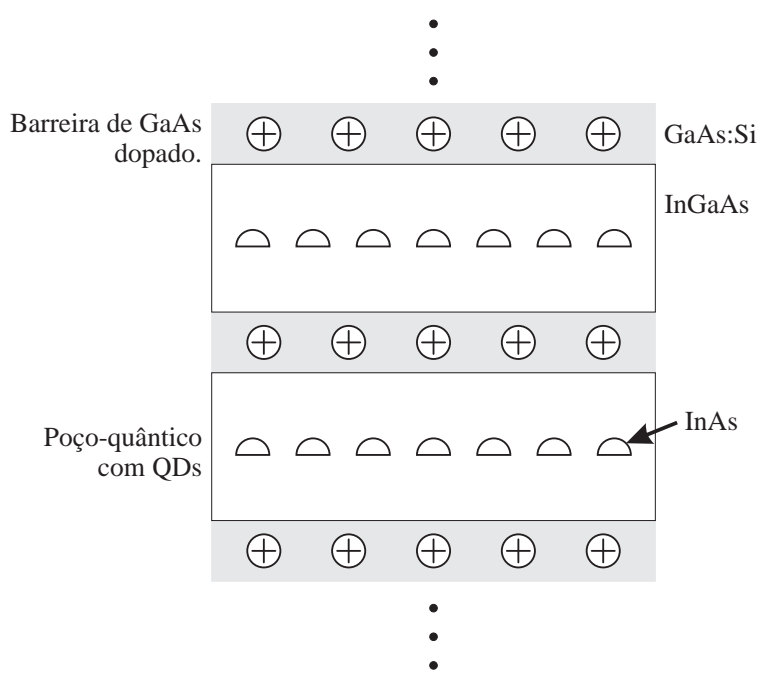

(b)

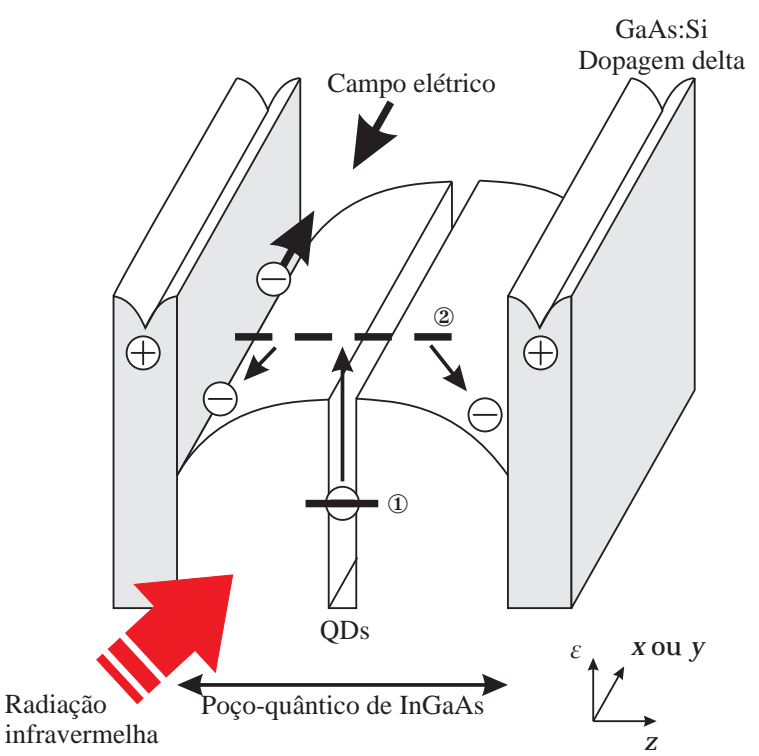

Figura 1.1.: (a) seqüência de crescimento das camadas semicondutoras de um QDIP; (b) representação esquemática do perfil de potencial da banda de condução da unidade básica. Esta não é a estrutura estudada neste trabalho.

laboratórios no mundo a obter tal resultado, e a despeito de alguns trabalhos que impossibilitavam a obtenção de pontos-quânticos com o tamanho necessário para isso [4].

Além disso, devido ao confinamento tridimensional dos elétrons nos QDs, os QDIPs (quantumdots infrared photodetector) oferecem uma série de vantagens, como baixa corrente de escuro e temperaturas de operação mais elevadas $[7,8,9]$. Por essas razões diversos grupos de pesquisa estão em busca de otimizações.

Embora atualmente vários grupos de pesquisa tenham um excelente domínio da tecnologia de crescimento de diferentes tipos de sistemas contendo pontos-quânticos (o nosso inclusive), suas aplicações têm sido previstas e experimentadas apenas recentemente, não apenas como detectores de radiação infravermelha [10, 11, 12, 13, 14], mas também como lasers [15, 16], memórias ópticas [17, 18], transistores monoeletrônicos [19], traçadores biológicos [20] e LEDs orgânicos [21].

A primeira demonstração de que os pontos-quânticos são eficientes detectores de radiação infravermelha foi reportada em 1998 por S. J. Xu et al [22]. A partir desta data, estruturas com diferentes arquiteturas têm sido propostas para a confecção destes fotodetectores e suas potencialidades estão sendo testadas (veja, eg, a ref. 23). Este também é o nosso intuito.

A função de um fotodetector é transformar excitações ópticas específicas em sinais elétricos. Isto é feito através dos três seguintes processos, nesta ordem: (i) geração de portadores pela luz incidente, (ii) transporte dos portadores e (iii) interação da corrente fotogerada com o circuito externo. A figura 1.1 ilustra o perfil de potencial da região-ativa de um QDIP transversal ${ }^{1}$ típico [17], que

${ }^{1}$ Os QDIPs podem ser de dois tipos: verticais [24], quando a corrente elétrica percorre as diversas camadas da heteroestru- 
consiste na repetição de uma unidade básica, composta de um poço-quântico (InGaAs na figura) contendo pontos-quânticos (InAs, por exemplo) no seu interior. As dopagens planares fornecem elétrons para o canal (poço-quântico), onde são armadilhados pelos pontos-quânticos até que fótons de energia específica os retirem de lá.

O material semicondutor de que são formados os pontos-quânticos tem um gap entre as bandas de valência e condução menor que o do material hospedeiro (InGaAs), de sorte que os níveis de energia dos pontos-quânticos estão abaixo daquele(s) do poço-quântico. Essa diferença de energia $(=h v)$ deve ser ajustada, através da largura do poço-quântico e do tamanho dos pontos-quânticos, de modo que $v$ seja a freqüência do sinal que queremos medir com o fotodetector. Assim, quando um fóton com energia $h v$ incidir sobre a heteroestrutura, ele promoverá a transição de um elétron no nível localizado (1) para o (2), estendido (figura). Ali o elétron será transportado na direção $x$ por um campo elétrico (aplicado externamente) até a extremidade da estrutura, estabelecendo uma corrente elétrica que pode ser medida externamente.

Para ter bom desempenho, os fotodetectores devem ter alta sensitividade, alta velocidade de resposta e ruído mínimo. Além disso, devem ser compactos, devem utilizar baixas voltagens e correntes e ser confiáveis sob as condições de operação. O ganho fotocondutivo de um fotodetector pode ser expresso como $\mu \tau E / L$, onde $E$ é o campo elétrico no canal condutor, $L$ é o espaçamento entre os eletrodos e $\mu$ e $\tau$ são a mobilidade de transporte e o tempo de vida dos portadores fotoexcitados, respectivamente [17]. Esta equação nos indica que para melhorar o desempenho de um fotocondutor devemos ter portadores com alta mobilidade e longo tempo de vida no canal condutor. Em particular, o bom desempenho de fotodetectores de pontos-quânticos depende das seguintes características ideais:

- a concentração de dopantes e a distância deles ao poço-quântico devem ser dimensionadas de tal modo que na ausência de fótons com energia $h v$ todos os elétrons estejam armadilhados pelos pontos-quânticos. A presença de um sistema bidimensional de elétrons (2DES) residual no poço-quântico dá origem à chamada corrente de escuro (dark current), que reduz a sensibilidade do dispositivo. Esta adequação, por sua vez, dependerá também da densidade dos pontos-quânticos e do tamanho deles;

- o tamanho dos pontos-quânticos deve ser tal que eles tenham apenas um estado ligado. Isto garante, primeiro, que depois de excitados pela radiação infravermelha eles não agem mais como centros espalhadores coulombianos, posto que agora estão neutros; e segundo, que não sejam sensíveis a outros fótons que não os $h v$ (esta condição deve ser satisfeita em conjunto com a seguinte). Para se obter pontos-quânticos de InAs, por exemplo, com dimensões adequadas deve-se adotar baixas temperaturas de crescimento e baixas taxas de deposição de InAs $(\sim 0,3 \AA / s)$;

- a largura e/ou a altura do poço-quântico devem ser tais que ele contenha apenas um estado, garantindo que não haja outra transição diferente da (1) $\rightarrow$ (2), ou seja, que o QDIP não seja sensível a outros comprimentos de onda;

tura; ao longo da direção do crescimento (z), ou transversais, quando a corrente elétrica percorre a amostra no plano $x y$. 
- o tempo de vida $(\tau)$ dos portadores no estado (2) e sua mobilidade $(\mu)$ devem ser longos para que possam gerar corrente elétrica antes de serem novamente capturados pelos pontosquânticos. Isto pode ser feito afastando-se o 2DES tanto da dopagem como dos pontosquânticos. Alternativamente, a dopagem pode ser feita nos próprios pontos-quânticos [25];

- a intensidade da corrente fotogerada deve ser maximizada, o que pode ser feito empilhandose várias unidades básicas (figura). No entanto, esta arquitetura pode gerar tensões internas que ocasionam degradação da morfologia dos pontos-quânticos. Este tipo de efeito foi recentemente observado em algumas estruturas utilizadas para o desenvolvimento de fotodetectores transversais [12] e a sua influência no desempenho deles começa a ser testada;

Outras complicações são a inomogeneidade de tamanho e da distribuição dos pontos-quânticos. O primeiro transforma o nível (1) numa banda de energia de largura proporcional à inomogeneidade de tamanho; o segundo reduz o tempo de vida do elétron no estado (2).

Portanto o dimensionamento e a otimização dos QDIPs depende de uma série de parâmetros e é nossa intenção investigar as propriedades dos portadores fotogerados para várias combinações deles, procurando otimizar estruturas já apresentadas e/ou mesmo propor outras. A construção de um fotodetector completo não é o nosso objetivo atual, haja vista que isto requer infra-estrutura da qual não dispomos.

\subsection{Localização-fraca}

Nos últimos quinze anos, trabalhos teóricos e experimentais sobre a condutividade de amostras desordenadas em baixíssimas temperaturas levaram a avanços na teoria quântica do transporte de cargas, proposta por Boltzmann [26, p. 319] 2. Além disso, na última década este trabalho tem sido extendido para amostras com alta mobilidade [27, 28, 29].

Para sistemas bidimensionais, a condutividade elétrica em campo magnético nulo em baixas temperaturas decresce logaritmicamente com o decréscimo na temperatura. Este aspecto não-clássico dos portadores têm sido interpretado através de dois mecanismos distintos, a saber: a localizaçãofraca (WL, weak-localization) e interações elétron-elétron (EEI, electron-electron interaction).

O primeiro deles tem origem na interferência construtiva das funções de onda de portadores percorrendo um mesmo percurso, mas em sentidos opostos. Na presença de campos magnéti$\cos (B)$ pouco intensos, as funções de onda adquirem uma fase adicional que destrói a coerência inicial ( $B=0)$, o que resulta na magnetorresistência negativa (i.e., magnetocondutância positiva). Partículas com spin comportam-se de modo diferente e a magnetorresistência anômala resulta de uma competição da localização-fraca com a assim chamada antilocalização-fraca: acoplamentos spin-órbita introduzem transições aleatórias entre os estados de spin dos elétrons que são espalhados através das trajetórias temporalmente inversas. Daí resulta a supressão da localização-fraca e,

\footnotetext{
${ }^{2}$ Esta teoria institui que a função de distribuição dos elétrons num estado de condução de corrente elétrica difere da função de Fermi por um valor proporcional à taxa de troca de momento do elétron. Assim, dado um mecanismo de espalhamento que leve um elétron de um estado $k$ para outro, é possível determinar a função de distribuição fora do equilíbrio e, daí, as propriedades estatísticas dos elétrons (corrente, tensão, mobilidade, etc).
} 
eventualmente, até mesmo a presença de um comportamento oposto, evidenciado pela presença do "pico de anti-localização" em $B=0$. A largura deste pico é determinada pelo tempo de coerência de fase do elétron e sua amplitude, pela razão entre este e o tempo de espalhamento spin-órbita.

Hoje, a teoria da localização-fraca está bem estabelecida como um método eficiente de obter os tempos de relaxação de fase e de spin do elétron.

Devido ao rápido desenvolvimento da spintrônica, que visa manipular o spin ao invés da carga do elétron em dispositivos "spintrônicos," o interesse nas propriedades de spin de poços-quânticos (QW, quantum-well) e de outras heteroestruturas semicondutoras vem crescendo entre os pesquisadores, particularmente no que tange a interação spin-órbita [30, 31]. Por outro lado, o tempo de coerência de fase do elétron é uma das propriedades mais importantes desses sistemas, posto que determina o limite quântico dessas amostras. Ademais, provê informações acerca das interações elétron-elétron e elétron-fônon.

Mas ainda faltam estudos sistemáticos sobre o tempo de coerência em sistemas bidimensionais de elétrons com alta mobilidade. Por exemplo, ainda não há qualquer estudo experimental sobre a relação entre o tempo de coerência e o caminho livre médio, particularmente através do método da localização-fraca. De qualquer forma, a dependência do tempo de relaxação de fase com a temperatura e com a condutividade (ou, se preferir, com o caminho livre médio) é de fundamental importância para uma compreensão dos processos de espalhamento inelásticos em tais sistemas.

Nós empregamos os efeitos de localização-fraca e interações entre elétrons para obter os tempos de coerência e espalhamento spin-órbita de um sistema bidimensional de elétrons próximos a uma camada com pontos-quânticos autoformados. Observamos que o tempo de coerência depende do estágio evolutivo dos pontos-quânticos. Mais que isso, a variação observada sugere que a tensão mecânica acumulada durante o crescimento da camada que dá origem aos pontos-quânticos "congela" os elétrons do 2DES.

Esta parte do trabalho foi desenvolvida em parceria com o professor visitante A. K. Meikap.

\subsection{Estados de borda contra-rotativos}

Embora ainda haja controvérsias [32], atualmente é bastante aceita a explicação do efeito Hall quântico inteiro com base nos chamados estados de borda, proposta inicialmente por Halpering [33], em 1982. Segundo ela, quando o fator de preenchimento $v$ é um número inteiro, existem $v$ estados estendidos ao longo da periferia da amostra que conduzem a corrente elétrica sem dissipação de energia. Esta concepção do fenômeno permite utilizar o formalismo de Landauer-Buttiker [34] para equacioná-lo e obter corretamente o resultado experimental

$$
R_{H}=\frac{h}{e^{2}} \frac{1}{v^{\prime}}
$$

onde $R_{H}$ é a resistência Hall.

Esta relação entre estados de borda e a resistência Hall ocorre devido à influência do campo 
magnético, que destrói a simetria temporal do transporte de cargas e impõe aos elétrons circularem pela amostra no sentido horário (campo magnético apontando para o leitor). Topologicamente, diz-se que um estado de borda é enantiomorfo (chiral), ou seja, ele e sua imagem refletida num espelho não se sobrepõem.

Contudo, alguns trabalhos teóricos prevêem a existência de estados que percorrem a amostra no sentido oposto ao usual. Por exemplo, Thouless et al [35] estudaram a influência de campos magnéticos intensos e potenciais periódicos bidimensionais fracos sobre o 2DES. Tal potencial introduz nos níveis de Landau uma estrutura fractal chamada de borboleta de Hofstadter (Hofstadter's butterfly) [36], que pode resultar em resistências Hall negativas. Este fenômeno foi atribuído a estados de borda que percorrem a amostra no sentido oposto ao usual [37]. Outro exemplo: para uma tira bidimensional a resistência Hall é dada por

$$
R_{H}=\frac{h}{e^{2}} \frac{1}{N-M^{\prime}}
$$

onde $N$ é a quantidade de estados de borda "normais" e $M$, o de estados "contra-rotativos" [37, 38]. Outra possibilidade é utilizar uma rede bidimensional de pontos-quânticos conectados sob a ação de campos magnéticos intensos: Johnson et al [1] utilizaram a equação de Landauer-Büttiker para mostrar que, na presença de estados de borda normais e contra-rotativos, este sistema apresenta platôs Hall dados por

$$
R_{H}=\frac{h}{e^{2}} \frac{N-M}{N^{2}+M^{2}}
$$

desde que os estados sejam independentes e só interajam nos contatos.

Se a probabilidade de transmissão do elétron entre os pontos-quânticos for igual a um, ele poderá percorrer livremente o interior da rede de pontos-quânticos no sentido anti-horário (considerando o campo magnético apontando para o leitor). Por outro lado, quando a probabilidade de transmissão é próxima de zero, o elétron fica confinado no ponto-quântico, percorrendo-o no sentido horário. Em situações intermediárias podemos ter tanto estados normais como contra-rotativos [39].

Contudo, a fabricação dessas redes bidimensionais de pontos-quânticos conectados é muito difícil, posto que qualquer variação na taxa de transmissão entre pontos-quânticos pode destruir os estados contra-rotativos. Além disso, a escala de campo magnético na qual os estados contra-rotativos podem ser observados depende da razão entre o fluxo magnético através de uma célula da rede e o quantum de fluxo magnético $\left(\Phi_{0}=h / e\right)$, o que implica em pontos-quânticos tão próximos quanto $100 \mathrm{~nm}$ para $1 \mathrm{~T}$. Apenas recentemente redes como essas foram fabricadas em heteroestruturas de GaAs/AlGaAs e comportamentos anômalos na condutância Hall foram observadas, associados com a complexidade da estrutura espectral dos níveis de Landau [40].

Ao procurar pela ocorrência do efeito Hall ferromagnético [41] em 2DES sujeitos a um potencial periódico, deparamo-nos com um comportamento anômalo do efeito Hall quântico inteiro, o qual atribuímos aos estados de borda contra-rotativos, conforme os trabalhos de Johnson et al $[1,39]$. Além deste trabalho e o do de Geisler et al [40], temos notícia de apenas mais um trabalho experimental que reporta comportamento anômalo nos platôs do efeito Hall quântico: ref. 42. 


\section{2 \\ Conceitos e métodos}

Apresentaremos neste capítulo conceitos e métodos importantes para o desenvolvimento deste trabalho: o efeito Hall clássico (ou ordinário), ferramenta importante para qualquer estudo de transporte de cargas; o efeito Hall quântico inteiro, essencial para a compreensão do primeiro resultado experimental, e o formalismo de Landauer-Büttiker, que completa a explicação. Em seguida, veremos brevemente o efeito Subnikov-de Haas (também uma ferramenta) e, por fim, o fenômeno da localização-fraca. Conceitos adjacentes serão introduzidos brevemente quando necessários.

\subsection{O efeito Hall clássico}

O fenômeno, descoberto em 1879 por Edwin Herbert Hall, refere-se ao aparecimento de um campo elétrico perpendicular ao fluxo de corrente em um condutor (ou semicondutor) submetido a um campo magnético $(\boldsymbol{B})$ de baixa intensidade. A diferença de potencial associada a este campo, conhecida como tensão Hall ( $V_{H} \approx E_{y} l_{y}$ na figura 2.1), é diretamente proporcional a $B$ e, a partir dela, podemos calcular a concentração de portadores de corrente e suas mobilidades de transporte. Daí sua importância.

A explicação mais simples, baseada no modelo clássico de Drude, é a seguinte (acompanhe pela figura 2.1): devido ao campo elétrico $E_{x}$ aplicado, os elétrons, impelidos pela força elétrica (-e $\left.E_{x}\right)$,

${ }^{1} \mathrm{~A}$ rigor, $B$ é de baixa intensidade se $\omega_{c} \tau \lesssim 1, \operatorname{com} \omega_{c}=e B / m^{*}$. 


\section{Conceitos e métodos}

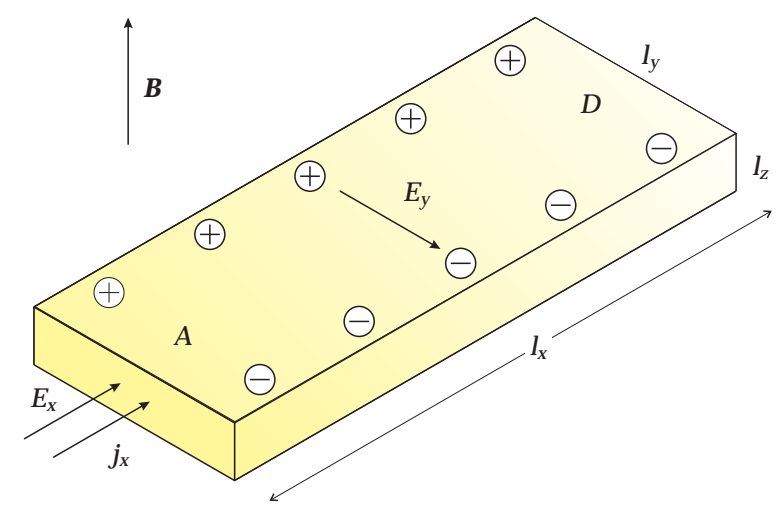

Figura 2.1: vista em perspectiva da região de interesse (fig. da p. 44) ilustrando o efeito Hall: a força magnética gera um desequilíbrio na distribuição de cargas transversal à corrente elétrica $\left(j_{x}\right)$, dando origem ao chamado campo Hall $\left(E_{H}\right)$ e, por conseguinte, à tensão Hall $\left(V_{H}\right)$. Para amostras tridimensionais, $j_{x} \doteq I /\left(l_{y} l_{z}\right)$, e para amostras bidimensionais, $j_{x} \doteq I / l_{y}$.

dão origem à densidade de corrente $j_{x}$. Ao aplicarmos um campo magnético perpendicularmente a esta corrente (na direção $z$, por exemplo), a força magnética (-e $v \times B$, onde $v$ é a velocidade de arrasto dos elétrons) passa a agir sobre esses elétrons, empurrando-os para o lado direito da amostra. Mas este movimento é limitado pela dimensão da amostra nesta direção e, por isso, os elétrons vão se acumulando ali. À medida que isso ocorre, o excesso de elétrons à direita e o conseqüente déficit à esquerda geram um campo elétrico $E_{y}$ no sentido de conter este movimento. O equilíbrio ocorre quando a força elétrica gerada pelo desequilíbrio de cargas dentro da amostra balanceia a força magnética:

$$
F=-\mathrm{e}(E+v \times B)=0,
$$

$\operatorname{com} \boldsymbol{E}=\left(E_{x}, E_{y}, 0\right)$. Lembrando que $j=n$ ev ( $n$ é a concentração de portadores), que $v \doteq \mu \boldsymbol{E}$ ( $\mu$ é a mobilidade de transporte dos portadores) e resolvendo a equação acima na direção $\hat{y}$, obtemos rapidamente um resultado bastante genérico (veja [43, p. 23] para um outro enfoque):

$$
n=\frac{I}{\mathrm{e}\left(V_{H} / B\right)} \quad \text { e } \quad \mu=\frac{1}{n \mathrm{e} \rho_{0}}
$$

onde $I$ é a corrente elétrica e $\rho_{0}$, a resistividade da amostra quando $B=0$.

Assim, uma vez que controlamos $I$ e $B$ conforme a configuração ilustrada na figura 2.1, basta medirmos $V_{H}$ (veja a fig. 3.11 na página 44) e $\rho_{0}$ (a seguir) para podermos calcular $n$ e $\mu$ : veja um exemplo na figura 2.2 .

A resistividade em campo nulo $\left(\rho_{0}\right)$ pode ser obtida da versão microscópica da primeira lei de Ohm: $E_{x}=\rho_{0} j_{x}$. No caso de sistemas tridimensionais (fig. 2.1), $E_{x} \approx V_{0} / l_{x}$ e $j_{x} \doteq I /\left(l_{y} l_{z}\right)$, donde concluímos que $\rho_{0}=R_{0}\left(l_{y} l_{z}\right) / l_{x}$ : a segunda lei de Ohm $\left(R_{0}=V_{0} / I\right)$; mas para sistemas bidimensionais, onde os portadores estão confinados num plano, $j_{x} \doteq I / l_{y}$, o que nos leva a $\rho_{0}=$ $R_{0} / \beth,{ }^{2}$ onde $\beth \doteq l_{x} / l_{y}$ é o fator de forma. Também podemos determinar $\rho_{0}$ através do método de Van-der Pauw [44]. Neste caso, $] \doteq \ln (2) / \pi{ }^{3}$

Vamos refinar um pouco. Na teoria semi-clássica de Sommerfeld (o passo seguinte em termos de

${ }^{2}$ Se preferir, faça $l_{z}=1$ na última expressão para $\rho_{0}$.

${ }^{3} \mathrm{O}$ método de Van-der Pauw também pode ser utilizado para sistemas tridimensionais. 


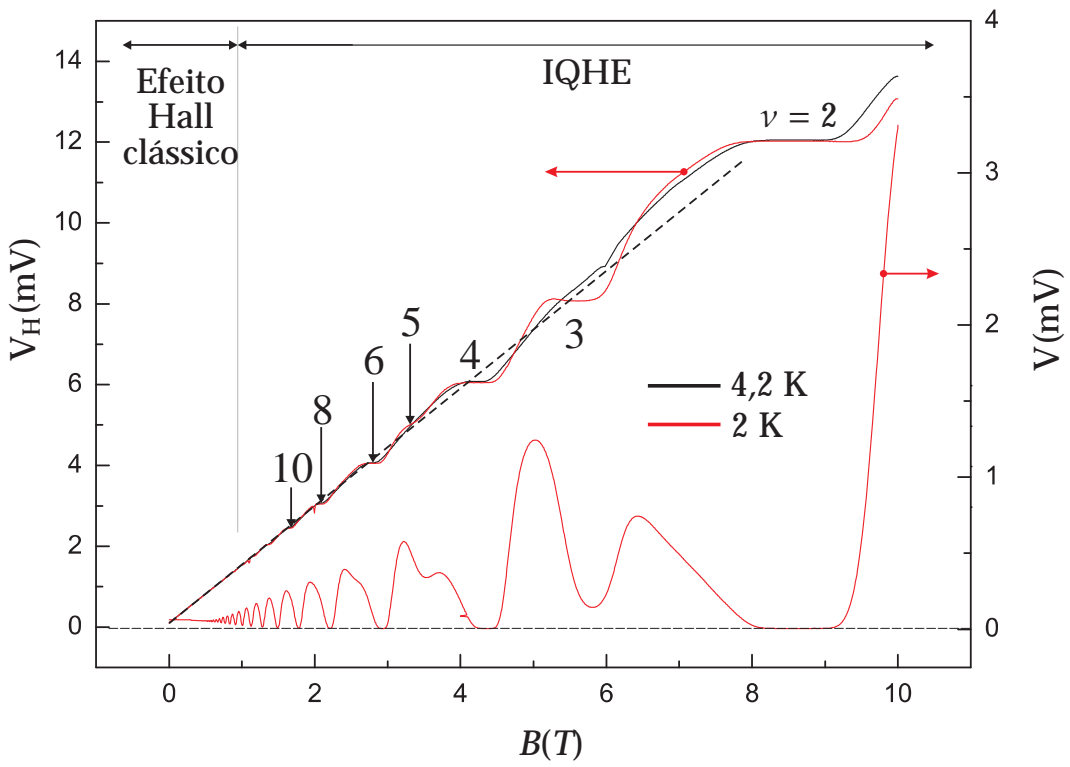

Figura 2.2.: exemplo de medida dos efeitos Hall clássico, quântico (sec. 2.2) e Shubnikov-de Haas (sec. 2.3) num HEMT (high electron-mobility transistor). A corrente é $1 \mu \mathrm{A}, \rho_{0}=25,6 \Omega$ e a inclinação da curva (reta tracejada) é $1,43 \mathrm{mV} / \mathrm{T}$, de modo que $n=4,3 \times 10^{15} \mathrm{~m}^{-2}$ e $\mu=54,3 \mathrm{~m}^{2} / \mathrm{Vs}$. Como das oscilações de magnetorresistência obtemos a mesma concentração (sec. 2.3) obtida do efeito Hall, concluímos que há apenas uma sub-banda ocupada (2.1.1). É recomendável que se faça um ajuste de reta no gráfico para obter o coeficiente angular correto ao invés de calculá-lo supondo que $V_{H}=0$ quando $B=0$. Isto é de fato verdade, mas experimentalmente podemos ter, como na figura acima, um $V_{H} \neq 0$ para $B=0$. Isto acontece porque a bobina supercondutora possui uma magnetização residual. Ou seja, embora nosso equipamento meça $B=0$, na verdade temos $B \approx 0$.

refinamento físico e matemático), os elétrons são representados por ondas planas ${ }^{4}$ que satisfazem as condições de contorno de Born-Von Karman. Agora a dinâmica do efeito Hall, ilustrada pela figura 2.1, é regida pelas equações

$$
\dot{r}=\frac{1}{\hbar} \nabla_{k} \varepsilon(k) \quad \text { e } \quad \hbar \dot{k}=-\mathrm{e}(E+\dot{r} \times B)=0 .
$$

A energia do estado $|k\rangle$ é $\varepsilon(\boldsymbol{k})=\hbar^{2} k^{2} /\left(2 m_{0}\right)$, o que nos leva de volta a (2.1), posto que $\boldsymbol{v}=\hbar k / m_{0}$ neste caso. Portanto, as equações 2.2 não sofrem alteração.

Podemos melhorar ainda mais. A teoria de Bloch procura descrever os efeitos do material no qual os elétrons se encontram inserindo na equação de Schrödinger um potencial $U(r)$ com a periodiciadade da rede cristalina, assim: $U(r+R)=U(r)$, onde $R$ é um vetor da rede de Bravais. Assim, um autoestado $|b, k\rangle$ é definido pelo índice da banda $b \in \mathbb{N}$ e pelo vetor de onda $k$, que pertence à primeira zona de Brillouin ${ }^{6}$ (ignoramos o spin). A relação de dispersão $\varepsilon_{b}(k)$ é nãotrivial, mas em geral $k_{F}$ (o vetor de onda de Fermi) é muito menor que os limites da zona de

\footnotetext{
${ }^{4}$ Ou seja, os elétrons são livres de interações.

${ }^{5}\left\langle\boldsymbol{r}+L_{\iota} \hat{\imath} \mid \boldsymbol{k}\right\rangle=\langle\boldsymbol{r} \mid \boldsymbol{k}\rangle$, sendo $L_{\iota}$ a dimensão da amostra na direção $\iota=\{x, y, z\}$.

${ }^{6}$ Esta é a chamada representação da zona (de Brillouin) reduzida. Alternativamente, podemos escrever $|k\rangle$ se não limitarmos $k$ (mas esta representação não é utilizada).
} 


\section{Conceitos e métodos}

Brillouin. Por este motivo, podemos expandir $\varepsilon_{b}(k)$ em torno de $k_{0}$ e utilizar a aproximação da massa efetiva, obtendo

$$
\varepsilon_{b}(k) \approx \varepsilon_{b}\left(k_{0}\right)+\frac{\hbar^{2}}{2 m_{b}^{*}}\left(k-k_{0}\right)^{2}
$$

onde $m_{b}^{*}$ é a massa efetiva da banda $b$. No nosso caso (GaAs, AlGaAs, etc), $\boldsymbol{k}_{0}=0$ (ponto $\Gamma$ da primeira zona de Brillouin) e fazemos $\varepsilon_{b}\left(k_{0}\right)=0$ para simplificar. E como antes, utilizando a equação acima em (2.3), obtemos o resultado (2.2).

Mas há um detalhe importante que deixamos de lado: ao deduzir (2.2), avaliamos somente a componente $\hat{y}$ das equações 2.1 e 2.3. Em $\hat{x}$ temos $-\mathrm{e} E_{x}=0$, o que implica em $I=0$. Se isso fosse verdade, $v=0$ e também a força magnética. Logo, não haveria efeito Hall. E de fato não há quando $I=0$, mas este não é o caso. O problema aqui é que não incluimos a influência dos espalhamentos (colisões) dos elétrons. Isso é feito incluindo em (2.1) [ou (2.3)] a força de espalhamento $-p / \tau$ :

$$
F=-\mathrm{e}(E+v \times H)-\frac{p}{\tau}=0 .
$$

$p=m v$ na teoria de Drude e igual a $\hbar \dot{k}$ nas semi-clássicas (Sommerfeld e Bloch). $\tau$ é chamado de o tempo de relaxação do momento e interpretado como o tempo médio no qual um elétron perde ou ganha o momento $p$ (conseqüentemente, $1 / \tau$ é a taxa de relaxação ${ }^{7}$ do momento). As teorias de Drude e Sommerfeld atribuem incorretamente aos íons da rede cristalina a responsabilidade por essa troca de momento (espalhamentos ou, se preferir, colisões). Por outro lado, na teoria de Bloch uma rede perfeita não promove espalhamento, de modo que $1 / \tau=0$. Isto tampouco é verdadeiro, já que $\tau$ é finito. Então, ocorre que os espalhamentos se devem às imperfeições na rede, como dopagens (que podemos controlar), impurezas, defeitos, fônons, etc.

A despeito dessas distinções teóricas importantes, o resultado (2.2) permanece inalterado.

\subsubsection{Efeito Hall em mais de uma sub-banda}

Quando mais de uma sub-banda participa da condução da corrente, $n$ e $\mu$ obtidos das equações 2.2 representam valores efetivos, assim relacionados com $n_{s}$ e $\mu_{s}$ de cada sub-banda [46]:

$$
n=\frac{\left(\sum_{s} n_{s} \mu_{s}\right)^{2}}{\sum_{s} n_{s} \mu_{s}^{2}} \quad \text { e } \quad \mu=\frac{\sum_{s} n_{s} \mu_{s}^{2}}{\sum_{s} n_{s} \mu_{s}}
$$

Isso dificulta bastante a análise (veja, e.g., [45, ap. C]). Mas quando a distância entre a dopagem e o sistema bidimensional de elétrons é maior que o comprimento de onda de de Broglie de qualquer das sub-bandas envolvidas (como é o caso em muitas de nossas amostras), a sobreposição (overlap) delas com a distribuição de cargas da dopagem é a mesma. Disto resulta que $\mu_{s}$ é igual para qualquer

\footnotetext{
7"Relaxação" significa justamente isso: "troca."

${ }^{8} \mathrm{E}$ de fato são. Por exemplo, a base e o coletor de um transístor bipolar são qualitativamente idênticas, distinguindo-se pelo tamanho e pela dopagem (um tipo de defeito controlável na estrutura cristalina), ou seja, por $\tau$. Se essa relação entre dopagem e $\tau$ não existisse, como sugere Drude, não poderíamos construir tais dispositivos.
} 
sub-banda [47]. Usando isto na equação anterior, concluimos que

$$
n=n_{1}+n_{2}+\cdots \quad \text { e } \quad \mu=\mu_{1}=\mu_{2}=\cdots,
$$

ou seja, a concentração obtida do efeito Hall é a concentração total de portadores e a mobilidade é a mesma para qualquer sub-banda. Os valores de $n_{s}$ individualmente podem ser obtidos a partir do efeito Shubnikov-de Haas, conforme veremos.

\subsection{O efeito Hall quântico}

O efeito Hall quântico inteiro (IQHE, integer quantum Hall effect), descoberto em 1980 por Klaus von Klitzing et al [48], refere-se à quantização da resistência (e da condutância) Hall que ocorre para certos intervalos de campo magnético intenso (platôs na fig. 2.2):

$$
R_{H}=\frac{R_{K}}{N}
$$

$R_{K} \doteq h / e^{2}=25812,807 \Omega$ é a constante de von Klitzing e $N \equiv N(B)$ é a quantidade de níveis de Landau (a seguir) abaixo do de Fermi. Nos anos seguintes à sua descoberta, à medida que o conhecimento acerca deste fenômeno crescia, outros fenômenos correlatos foram descobertos. Hoje o termo "efeito Hall quântico" refere-se a um "conjunto de fenômenos com profundas implicações teóricas" [49], dentre os quais os efeitos Hall quântico fracionário e ferromagnético.

Duas observações importantes: (a) a quantização ocorre na resistência $\mathrm{R}$ (condutância), não na resistividade $\rho$ (condutividade $\sigma$ ). Isto ocorre porque, conforme veremos, quando vale (2.5) o fluxo de corrente reside exclusivamente nas bordas da amostra, revogando de $\rho$ a característica de representar o material (a equação acima independe dele); (b) o IQHE não é um fenômeno de muitos corpos pois podemos explicá-lo resolvendo a equação de Schrödinger para um elétron (a seguir). Mais: é justamente devido a ausência de interações que explica o IQHE.

\subsubsection{O problema quântico}

Para compreendermos o efeito Hall quântico precisamos resolver a equação de Schrödinger independente do tempo de um elétron sujeito ao campo magnético $B=\nabla \times A$ perpendicular ao plano dos elétrons, conforme a configuração da figura 2.1, cuja hamiltoniana é

$$
\hat{H}=\frac{1}{2 m}(\hat{p}-\mathrm{e} \hat{A})^{2}+V(\hat{r}) .
$$

Utilizando o calibre de Landau, $A=(0, x B, 0)$, e assumindo $V(r)=V(x, y)+V(z)$, a equação de Schrödinger pode ser separada numa componente em $z$ e outra em $x$ e $y$, que representa o sistema bidimensional propriamente dito. Assim, independentemente de $V(z)=0$ (modelo de Landau, a seguir) ou ser dado por algum potencial de confinamento (poços-quânticos, como no nosso caso), a 


\section{Conceitos e métodos}

$$
B=0
$$

(a)

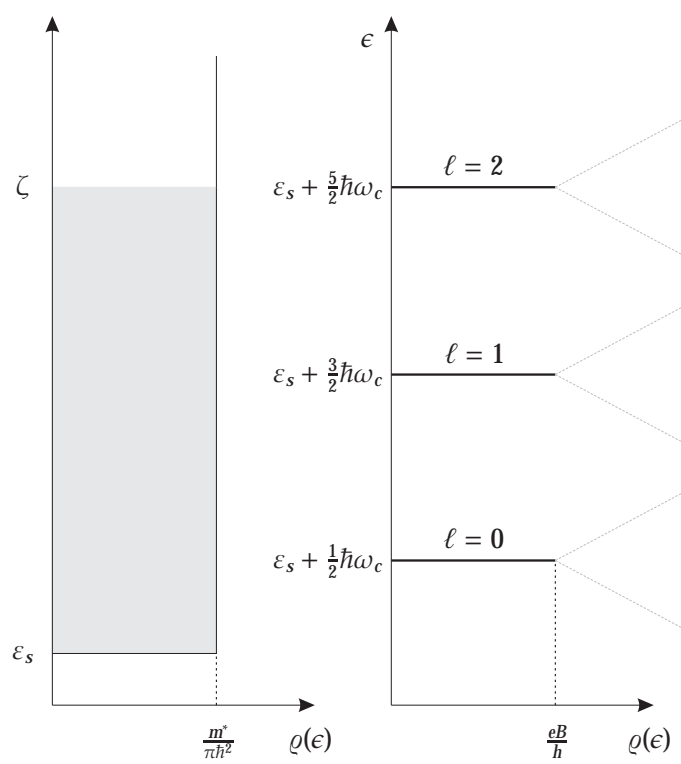

(b)

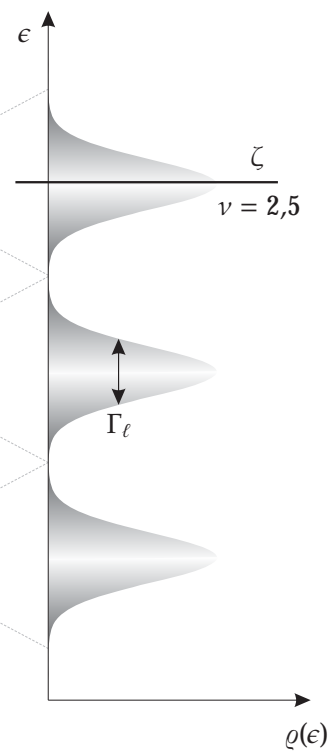

(c)

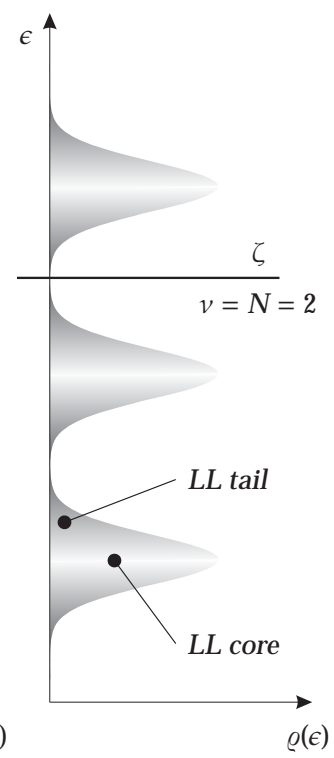

Figura 2.3.: (a) densidade de estados dos LL sem a influência da desordem. $\epsilon_{s}$ é a energia do fundo da sub-banda s. (b) A desordem quebra a degenerescência desses níveis [= eB/h em (a)], distribuindo os estados numa faixa de energia (representada por $\Gamma_{\ell}$ ) ao redor de $\epsilon_{\ell}$. Na situação ilustrada, há dois níveis de Landau completamente ocupados (abaixo do de Fermi, $\zeta$ ), enquanto o terceiro está apenas parcialmente ocupado: $v=2,5$. Em (c), o nível de Fermi encontra-se entre dois de Landau, de modo que os dois primeiros LL estão plenamente ocupados: $v=N=2$. No centro dos níveis de Landau ( $L L$ core), os estados são estendidos e, portanto, podem conduzir corrente elétrica, mas nas perifeiras ( $L L$ tail) eles são localizados. O degradê ilustra a transição de estados estendidos (branco) para localizados (cinza).

solução no plano $x y$ é a mesma.

O caso mais simples, proposto inicialmente por Landau, é considerar $V(x, y)=0$. Isto feito, a solução é uma função de onda localizada ao redor de $x_{0}=-l_{B}^{2} k$, sendo $l_{B}=\sqrt{\hbar /(e B)}$ o comprimento magnético e $k=2 \pi r / l_{y}$, com $r \in \mathbb{N}$; em $y$, é uma onda plana (delocalizada): veja, por exemplo, [32, p. 9]. Mas o importante aqui é que as autoenergias são $\epsilon_{\ell}=\left(\ell+\frac{1}{2}\right) \hbar \omega_{c}$ e são chamadas de níveis de Landau (LL, Landau level), com $\ell \in \mathbb{N}$. Eles têm degenerescência $e B / h[32$, p. 10] e distam entre si de $\hbar \omega_{c}$, de modo que a densidade de estados pode ser escrita como (fig. 2.3a)

$$
\varrho(\epsilon)=\frac{e B}{h} \sum_{\ell} \delta\left(\epsilon-\epsilon_{\ell}\right)
$$

Logo, se temos $n$ elétrons (por unidade de área) e em cada nível de Landau cabem $e B / h$, precisamos de $N$ níveis de Landau (abaixo do nível de Fermi, $\zeta$ ) para acomodá-los. Formalmente,

$$
n=\int_{0}^{\zeta} \frac{e B}{h} \sum_{\ell} \delta\left(\epsilon-\epsilon_{\ell}\right) d \epsilon=\frac{e B}{h} N
$$

Observe que se utilizarmos $n$ obtido do efeito Hall clássico (eq. 2.2) na equação acima, lembrando 
que $\omega_{c}=e B / m$ e $R_{H} \doteq V_{H} / I$, obtemos (2.5). Podemos ver isto na figura 2.2: o prolongamento para altos campos magnéticos (reta tracejada) do efeito Hall clássico $(B<1 \mathrm{~T})$ cruza o centro dos platôs do efeito Hall quântico. Mas isto nem sempre é verdadeiro [50] e esclarece pouco.

Ademais, a equação anterior permite-nos concluir, erroneamente, que $n$ tem de ser um múltiplo inteiro de $e B / h$, a degenerescência dos níveis de Landau. Isto ocorre porque $\varrho$ acima não leva em consideração a presença da desordem nas amostras, i.e., de potenciais espalhadores aleatórios como impurezas, defeitos na rede cristalina, etc. Fazer isso não é uma tarefa fácil [e perceba que isto equivale a fazer $V(x, y) \neq 0]$. Primeiro porque a forma desse potencial não é conhecido e, segundo, porque mesmo no caso mais simples (arranjo aleatório de potenciais puntuais) o trabalho matemático é enorme. Mas a despeito dessas dificuldades, é fenomelogicamente evidente que $V(x, y)$ destrói a degenerescência dos níveis de Landau, distribuindo os $e B / h$ estados numa banda de energia ao redor de $\epsilon_{\ell}$ que pode ser satisfatoriamente representada por uma gaussiana [51]:

$$
\varrho(\epsilon)=\frac{e B}{h} \sum_{\ell} \frac{\sqrt{2 / \pi}}{\Gamma_{\ell}} \exp \left[-\frac{2\left(\epsilon-\epsilon_{\ell}\right)^{2}}{\Gamma_{\ell}^{2}}\right],
$$

onde $\Gamma_{\ell}$ é a largura natural dos níveis de Landau, da ordem de meV [52]: veja a fig. 2.3b.

É possível também representar a densidade de estados dos LLs por elipsóides, conforme a aproximação autoconsistente de Born (veja, por exemplo, a equação 3.9 da referência 53), que só considera espalhamentos de primeira ordem ${ }^{9}[54$, p. 12]. Talvez por isso essa representação não seja muito adequada, conforme verificaram Gobsch et al [55] (no caso, para descrever as oscilações do nível de Fermi em função de B). A mesma inadequação foi verificada para $\varrho$ representada por funções delta de Dirac.

De qualquer forma, quando o nível de Fermi estiver como na figura 2.3b, o LL estará parcialmente ocupado (considere, por simplicidade, que $T=0$ ). Representamos esta situação dizendo que temos $v=2,5$ níveis de Landau ocupados e chamamos $v$ de o fator de preenchimento. Ele substitui $N$ na eq. 2.7, de modo que $v \doteq n /(e B / h)$. Além disso, $v=N$ sempre que o nível de Fermi está entre dois de Landau (fig. 2.3c), situação na qual vale (2.5). Mas note que em geral não é correto substituir $N$ por $v$ na equação 2.5 , embora isto seja muito utilizado.

$V(x, y)$ perturba $\epsilon_{\ell}$, aumentando-o se o centro de espalhamento for repulsivo, ou reduzindo-o, em caso contrário. Por esta forma, $\epsilon_{\ell} \rightarrow \epsilon_{\ell}(x, y)=\epsilon_{\ell}+\delta \epsilon(x, y)$ em todo o plano $x y$, conforme ilustramos na figura 2.4. E como os elétrons percorrem trajetórias equipotenciais $\epsilon_{\ell}(x, y)=\epsilon$ nesse plano [54, p. 13], segue que se o nível de Fermi estiver na borda de um nível de Landau ( LL tail) a trajetória será fechada: fig. 2.4a. Um elétron neste estado não pode ir da fonte para o dreno (cap. 3) e, portanto, não conduz corrente; ele está num estado localizado. Por outro lado, se o nível de Fermi cruzar o centro de um nível de Landau ( $L L$ core), a trajetória é aberta; um elétron neste estado conduz corrente e está num estado dito estendido: fig. 2.4b.

Aproveitando o ensejo, é conceitualmente importante notar que os elétrons no centro dos níveis de

\footnotetext{
${ }^{9}$ Isto significa que ela considera todos os estados inicias e finais possíveis ligados por apenas um espalhamento, qualquer que seja ele.
} 


\section{Conceitos e métodos}

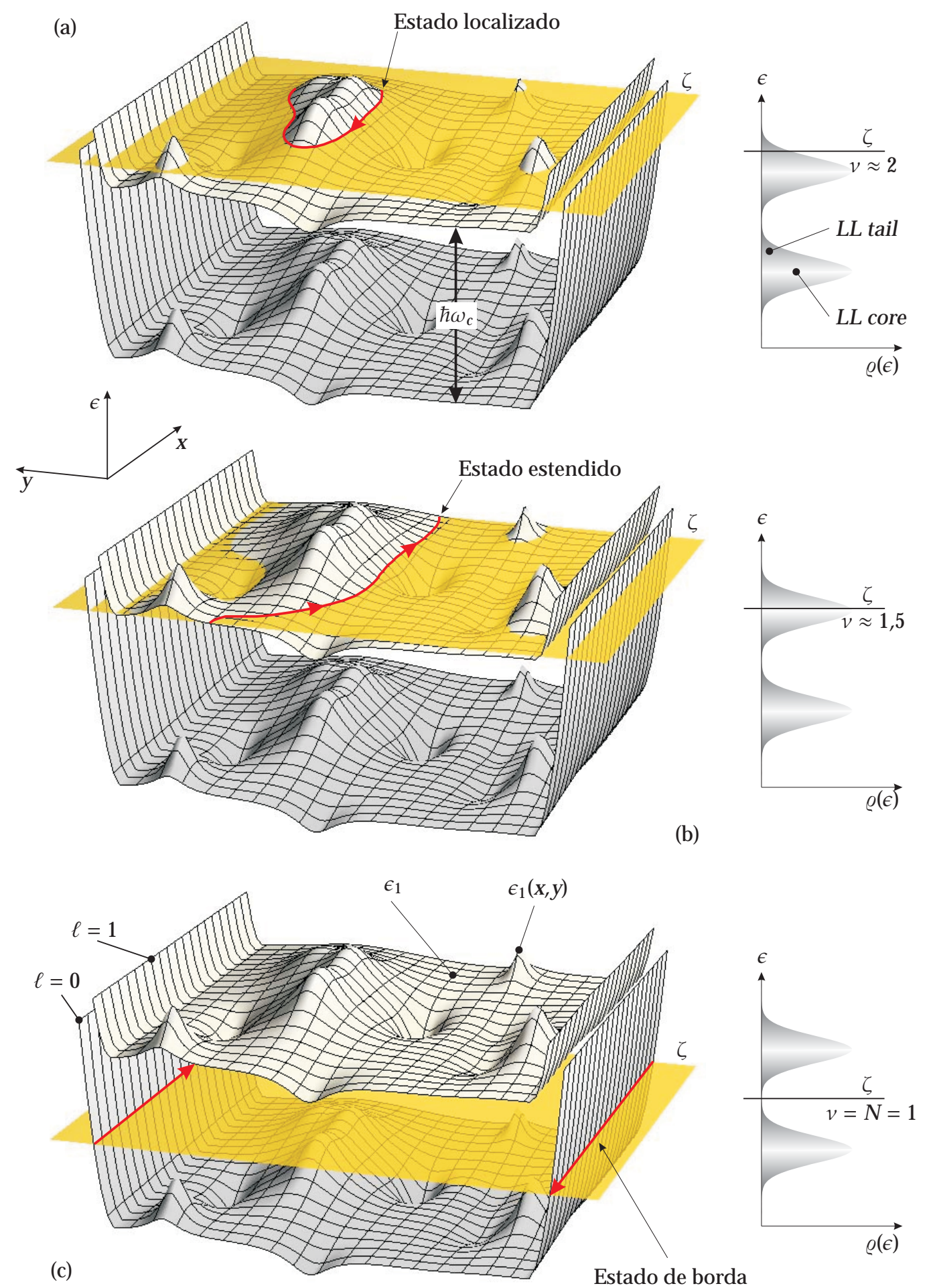

Figura 2.4.: a relação entre os níveis de Landau e de Fermi no plano $x y$ da figura 2.1. (a) Quando o nível de Fermi encontra-se na periferia de um LL, todos os estados com energia $\zeta$ no interior da amostra são localizados. Neste caso a condução da corrente elétrica ocorre sem dissipação de energia através dos estados de borda. (b) Por outro lado, quando o nível de Fermi está no centro de um de Landau, há estados estendidos tanto no interior da amostra como nas bordas. Neste caso a condução é dissipativa. (c) Mesmo quando não há estados com energia $\zeta$ (nos gaps entre LLs) os estados de borda transportam cargas de um extremo ao outro da amostra. 
Landau (em estados estendidos, portanto) abaixo do de Fermi também conduzem corrente elétrica. Mas a sua influência na corrente total é nula, já que há tantos elétrons percorrendo a amostra da fonte para o dreno como no sentido oposto. Mais: é incorreta a afirmação de que "elétrons que não estão no nível de Fermi não conduzem corrente," embora seja correto dizer que "elétrons que não estão no nível de Fermi não contribuem para a corrente total" [43].

\subsubsection{Estados de borda}

Agora, observe a figura 2.4: nas bordas da amostra (na direção $y) \epsilon_{\ell}(x, y) \rightarrow \infty^{10}$ por conta do potencial de confinamento dos elétrons na amostra. Conseqüentemente, sempre haverá $N$ estados estendidos $\epsilon_{\ell}(x, y)=\zeta$ nas bordas da amostra; os chamados de estados de borda (edge-states), inicialmente sugeridos por Halperin em 1982 [33]. Mesmo quando o nível de Fermi está entre dois de Landau (fig. 2.4c) e nem mesmo estados localizados têm energia igual à de Fermi, os estados de borda conectam a fonte e o dreno, garantindo a condução de corrente elétrica.

A condução de corrente elétrica pelos estados de borda tem uma característica especial: ela é nãodissipativa. Por conseguinte, não há queda de tensão, razão pela qual sempre que $R_{H}$ apresenta um platô, $R=0$ (fig. 2.2). Veja a figura 2.9 (p. 25): isto acontece porque os elétrons que deixam o contato 1 (com energia $\mu_{1}$, o potencial eletroquímico deste contato), em direção ao 4 (dreno), percorrem a amostra pela borda superior, enquanto que os elétrons que partem do contato 4 (energia $\mu_{4}$ ) percorrem a amostra pela borda inferior. Esta separação espacial (igual à largura da amostra) torna nulo o espalhamento entre esses estados, e mesmo os espalhamentos produzidos por impurezas próximas não mudam o estado inicial simplesmente por inexistência de outros estados.

\subsubsection{Transição entre platôs}

Por outro lado, quando o nível de Fermi está no centro de um LL, há estados estendidos por todo o plano $x y$ (inclusive nas bordas). Neste caso, a corrente percorre toda a amostra através de estados estendidos com energia $\epsilon \approx \zeta$. E por se sobreporem, o espalhamento é finito e, com ele, a resistência (e a resistividade).

Teoricamente, a transição entre platôs é descrita como uma transição de fase contínua com parâmetro de ordem $\xi$ [56], o comprimento de localização, que corresponde ao diâmetro médio de uma trajetória fechada do elétron: à medida que o nível de Fermi aproxima-se do centro de um nível de Landau, $\xi$ aumenta e as diversas trajetórias fechadas se aproximam uma da outra até o ponto em que um elétron pode pular de uma trajetória para a outra, via tunelamento. Neste ponto crítico, a teoria prevê que $\xi$ divirge conforme $\left|\epsilon-\epsilon_{c}\right|^{\lambda}, \operatorname{com} \lambda=7 / 3$ [57]. $\epsilon_{c}$ é a energia do ponto de cela.

\footnotetext{
${ }^{10} \mathrm{Na}$ verdade, $V(x, y) \rightarrow-e \phi$, onde $\phi$ é a função-trabalho, a energia necessária para retirar um elétron da amostra.
} 


\section{Conceitos e métodos}

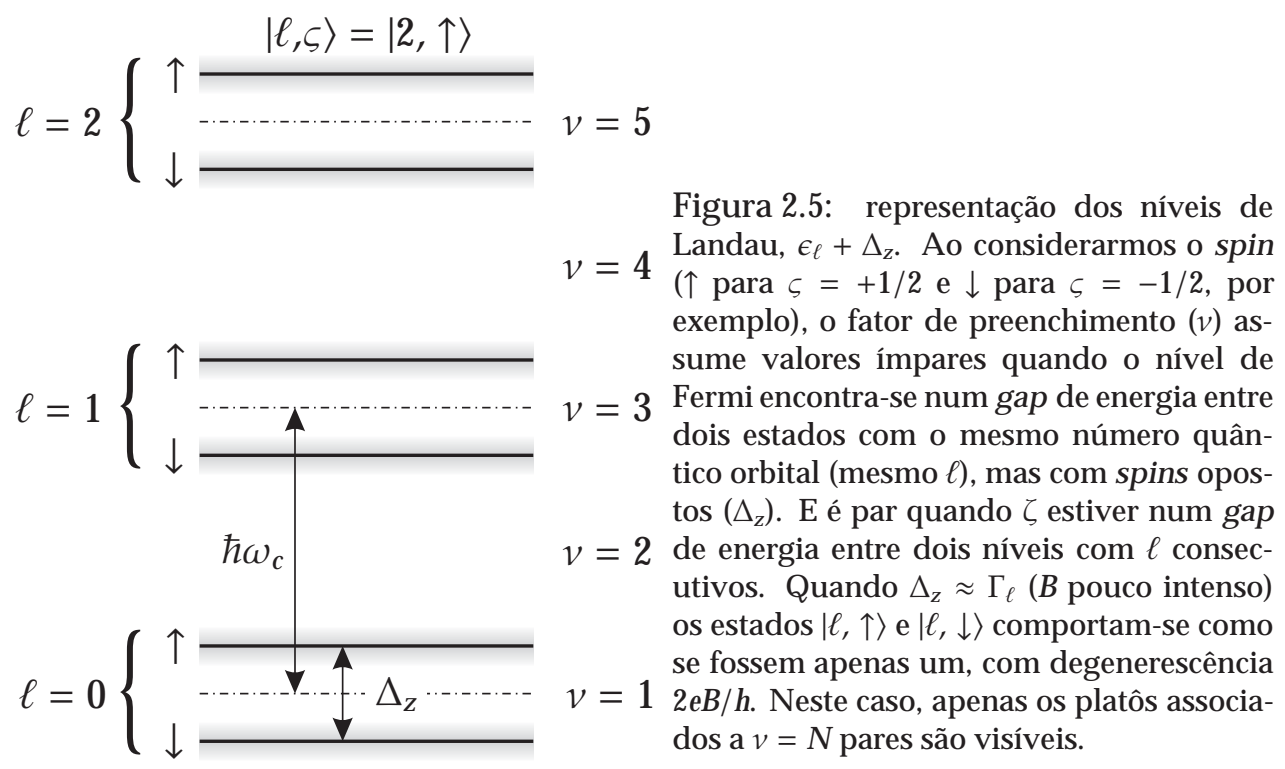

\subsubsection{O efeito do spin}

Sob a ação do campo magnético $B$, elétrons com spins opostos ocupam estados que diferem de $\Delta_{z}=g \mu_{B} B$ em energia (single-electron Zeeman splitting), onde $g$ é o fator de Landè $(=-0,44$ para elétrons no GaAs) e $\mu_{B} \approx 0,06 \mathrm{meV} / \mathrm{T}$, o magneton de Bohr. Matematicamente,

$$
\epsilon_{\ell, \varsigma}(x, y)=\epsilon_{\ell}+\delta \epsilon(x, y)+\varsigma \Delta_{z}
$$

$\operatorname{com} \varsigma= \pm 1 / 2$ representado o número quântico de spin. Desta forma, observe que $v$ é ímpar quando o nível de Fermi está num gap $\Delta_{z}$ (qualquer que seja $\ell$ ), e é par quando $\zeta$ está num gap $\hbar \omega_{c}$ (qualquer que seja ५): fig. 2.5 (isto é verdadeiro se houver apenas uma sub-banda ocupada).

A densidade de estados ainda é dada por (2.8) e como $\Delta_{z} \ll \hbar \omega_{c}$, quando $B$ é suficientemente pouco intenso, $\Delta_{z} \approx \Gamma_{\ell}$ e os estados $|\ell, \uparrow\rangle$ e $|\ell, \downarrow\rangle$ se sobrepõem (em energia), formando uma banda de estados estendidos que nos impede de distinguí-los experimentalmente: não haverá em $R_{H}(R)$ um platô (zero) associado a $\Delta_{z}$. Além disso, $\varrho=0$ apenas nos gaps $\hbar \omega_{c}$, de sorte que ao variarmos $B$ entre dois platôs sucessivos dois níveis de Landau (um com spin para cima e outro, para baixo) serão preechidos (ou desocupados). Assim, apenas os platôs associados a $v=N$ pares aparecem $(B<3$ T na figura 2.2). Por outro lado, à medida que intensificamos $B$, a densidade de estados nos gaps $\Delta_{z}$ aproxima-se de zero (pois $\Delta_{z}$ torna-se maior que $\left.\Gamma_{\ell}\right)^{11}$ e em $R \times B$ aparecem mínimos locais que se aproximam de $R=0$. Paralelamente, em $R_{H} \times B$ os platôs com $v$ impares começam a aparecer $(B>3$ T na figura 2.2).

\footnotetext{
${ }^{11} \mathrm{~A}$ rigor, $\Gamma_{\ell} \propto B^{1 / 2}$ [52], de modo que $\Delta_{z}$ cresce mais rapidamente que $\Gamma_{\ell}$ à medida que $B$ torna-se mais intenso.
} 
Alguns autores representam este fenômeno reescrevendo (2.5) assim:

$$
R_{H}= \begin{cases}R_{K} /\left(2 N^{\prime}\right)=12906,403 \Omega / N^{\prime} & (\text { sem resolução de spin); } \\ R_{K} / N=25812,807 \Omega / N & \text { (com resolução de spin); }\end{cases}
$$

outros preferem escrever $R_{H}=R_{K} /(b N)$, onde $b$ é degenerescência de spin. Embora corretas, essas expressões podem confundir, pois dão a impressão de que $R_{H}$ obedece relações de quantização diferentes para baixos (com $N^{\prime}$ ) e altos (com $N$ ) campos magnéticos.

Agora que a fenomenologia básica está compreendida, faz-se necessário refiná-la. Isto pode ser feito matematicamente trocando $g$ por $g^{*}(B)$ na expressão de $\Delta_{z}$, o fator $g$ amplificado pelas interações de troca [58]. Ocorre que $g \mu_{B} B$ é a energia de interação de um elétron com o campo magnético (a autoenergia da hamiltoniana de Heisenberg de um elétron), ou seja, ela não leva em consideração a presença de outros elétrons; particularmente, a interação de troca. Quando o 2DES não está polarizado, i.e., quando há tantos elétrons com spin para cima quanto para baixo, essa influência é pequena, mas quando $v$ é ímpar $g^{*}$ chega a ser vinte vezes superior a $g$ [59].

Observe que $g^{*}$ depende do campo magnético e é diferente de zero mesmo que $g=0$, ao menos para $B$ suficientemente intenso. Em verdade, conforme o modelo proposto por Fogler e Shklovskii [60] em 1995, à medida que o campo magnético torna-se menos intenso, a desordem no sistema destrói continuamente as interações de troca até que $g^{*}=0$ (transição de fase de segunda ordem), de forma análoga à destruição do ferromagnetismo pela temperatura [26]. Alternativamente, Piot et al [59] descrevem o mesmo fenômeno no sentido oposto, como uma transição do estado paramagnético do 2DES [61] para o ferromagnético (transição de Stoner), conforme B é intensificado e comparando os custos energéticos de cada fase.

Outros fenômenos decorrentes das interações entre os elétrons (many-body) têm sido previstos e observados, especialmente para $v=1$, onde o 2DES é dito estar num estado ferromagnético itinerante [62], já que todos os elétrons têm a mesma orientação de spin e ainda assim mantém sua mobilidade no plano xy. Talvez o mais famoso desses fenômenos seja o Skyrmion [63, 64], um estado excitado do 2DES cuja energia é mais baixa que a do estado $v=2$ e que consiste numa perturbação localizada na orientação dos spins (veja a fig. 3 da ref. 49).

\subsubsection{IQHE em duas sub-bandas}

Conforme vimos há pouco, quando o 2DES é composto por apenas uma sub-banda, $v$ ímpares estão associados aos gaps $\Delta_{z}$ (amplificado por $g^{*}$ ou não), enquanto $v=$ par, aos $\hbar \omega_{c}$. É simples assim. Mas quando duas (ou mais) sub-bandas estão presentes, isto deixa de ser verdadeiro. Particularmente, a presença da segunda sub-banda torna a associação platô/gap dependente da amostra (veja, e.g., a ref. 52). Observe a figura 2.6, conhecida como Landau-level fan, por exemplo. Ela esquematiza a energia de um elétron (single-particle) sujeito ao campo magnético,

$$
\epsilon_{s \ell}(B)=\epsilon_{s}+\epsilon_{\ell}(B)+\varsigma \Delta_{z}(B)
$$




\section{Conceitos e métodos}

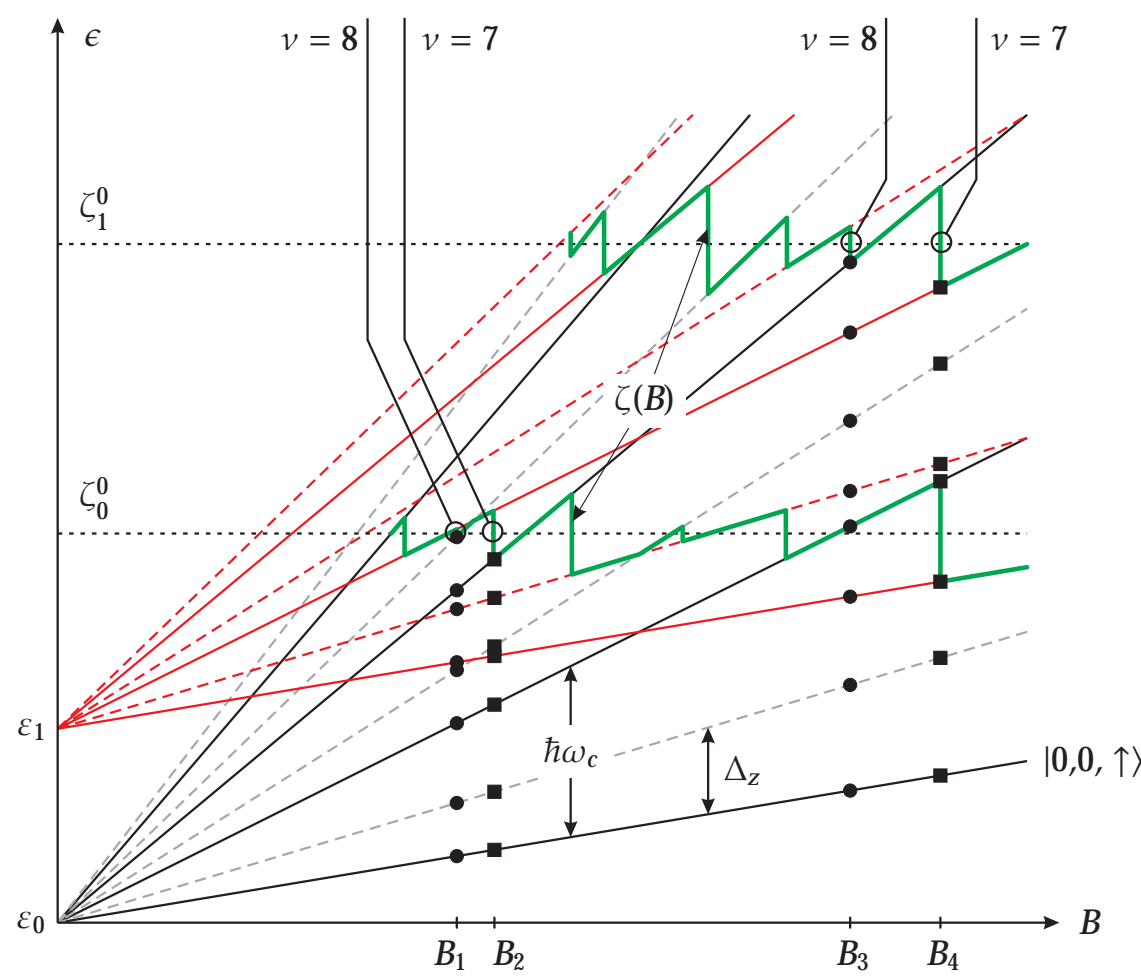

Figura 2.6.: LL fan para o 2DES com duas sub-bandas. As retas contínuas (tracejadas) representam os níveis de Landau com spin para cima (baixo), ao passo que a cor representa a sub-banda: preto para a primeira e vermelho para a segunda. Esta figura representa dois 2 DES, um com nível de Fermi em campo nulo igual a $\zeta_{0}^{0}$ e o outro, $\zeta_{1}^{0}$ (neste exemplo, portanto, eles diferem pela concentração de portadores). Para o primeiro, $v=7$ (os círculos e quadrados em preto auxiliam a contagem dos níveis de Landau abaixo do de Fermi) quando o nível de Fermi estiver entre os estados $|s, \ell, \varsigma\rangle=|1,1, \uparrow\rangle$ e $|0,2, \uparrow\rangle$, mas no segundo, o nível de Fermi encontra-se entre os estados $|0,2, \uparrow\rangle$ e $|0,2, \downarrow\rangle$ (num gap de spin). Situação análoga acontece para $v=8$. Concluímos daí que a associação entre gap e o fator de preenchimento num 2DES com duas (ou mais) sub-bandas torna-se dependente da amostra. As linhas verdes ilustram pictoricamente as oscilações dos níveis de Fermi em função do campo magnético $\left[\zeta_{s}(B)\right]$. $\varepsilon_{s}$ é a energia de fundo da sub-banda $s$.

para um 2DES com duas sub-bandas. $\epsilon_{s}$ é a energia do fundo da s-ésima sub-banda.

Na figura esquematizamos dois 2DES, um com nível de Fermi $\zeta_{0}^{0}$ e outro, com $\zeta_{1}^{0}>\zeta_{0}^{0}$. Ou seja, temos dois 2DES com concentrações diferentes. Observe, por exemplo, a situação em que $v=8$. Para o sistema bidimensional $\zeta_{0}^{0}$, isto ocorre quando $B=B_{1}$; para o 2DES com $\zeta_{1}^{0}$, ocorre em $B_{4}$. A diferença no campo magnético não é o que importa, pois a concentração é diferente e, por conseguinte, a quantidade de níveis de Landau para acondicionar os elétrons. A questão é que no primeiro caso o nível de Fermi encontra-se no gap entre os estados $|s, \ell, \varsigma\rangle=|0,2, \downarrow\rangle$ e $|1,1, \uparrow\rangle$, mas no segundo, está entre os estados $|0,2, \uparrow\rangle$ e $|1,1, \downarrow\rangle$. Se se tratasse de um 2DES com apenas uma sub-banda, não importaria qual fosse a concentração, fatores de preenchimento ímpares estariam relacionados aos gaps de spin, enquanto fatores de preenchimento pares, aos gaps $\hbar \omega_{c}$.

Ainda na figura 2.6, as linhas sinuosas em verde representam as oscilações do nível de Fermi em função do campo magnético, sem levar em conta a largura natural dos níveis de Landau [55]. 
Observe que no limite em que $B$ tende a zero, $\zeta_{s}(B) \approx \zeta_{s}^{0}$. Nesta situação a depopulação dos níveis de Landau ocorre independentemente [65] e a posição dos platôs (em $B$ ) depende do fator de preenchimento de cada sub-banda: $v_{s} \doteq n_{s} /($ degenerescência dos LLs). Contudo, como isto ocorre perto de $B=0$ (lembre-se, a escala de $B$ depende de $\omega_{c}$ ), os platôs não são visíveis. Mas este fenômeno pode ser verificado através das oscilações da magnetorresistência (efeito Shubnikovde Haas, a seguir): as oscilações recebem contribuições independentes das sub-bandas e isto nos permite determinar $n_{s}$ para cada uma das sub-bandas.

Por outro lado, quando $B$ é intenso, na região em que os platôs se manifestam, a depopulação dos níveis de Landau não ocorre independentemente em cada sub-banda. Visando sempre reduzir sua energia, o 2DES redistribui cargas entre os níveis de Landau de cada sub-banda, e disto resulta que os platôs relacionam-se não com $v_{s}$, mas com o fator de preenchimento total: $v=v_{1}+v_{2}$.

\subsection{O efeito Shubnikov-de Haas}

O efeito Shubnikov-de Haas (SdH), descoberto em 1920 por Lev Vasiljevich Shubnikov e Wander Johannes de Haas, refere-se ao comportamento oscilatório da magnetorresistividade (fig. 2.7), conforme modela a equação de Lifshitz-Kosevich [66]:

$$
\rho(B)=\rho_{0}+A \frac{\Lambda}{\operatorname{senh} \Lambda} \exp \left(-\frac{\pi}{\omega_{c} \tau_{s}}\right) \cos \left(\frac{2 \pi \zeta}{\hbar \omega_{c}}+\phi\right),
$$

onde $\rho_{0}$ é a resistividade em campo nulo (veja o parágrafo após a equação 2.2$), \Lambda=2 \pi^{2} k_{B} T /\left(\hbar \omega_{c}\right)$ e $\tau_{s}$ é o tempo de vida do quasi-elétron no 2DES (tempo quântico). ${ }^{12} A$ e $\phi$ são constantes. O fator $\Lambda / \operatorname{senh}(\Lambda)$ representa a influência da temperatura, enquanto a exponencial representa o alargamento dos níveis de Landau devido às colisões [66].

Mas o efeito propriamente dito, representado pelo cosseno na equação anterior, pode ser facilmente compreendido através do que expusemos na seção 2.2: quando $\hbar \omega_{c} \approx \Gamma_{\ell}$ (e, portanto, $\Delta_{z} \rightarrow 0$ ), a oferta de estados estendidos oscila conforme o nível de Fermi percorre os de Landau, atingindo máximos quando está no centro de um LL, o que corresponde a um máximo em $\rho(B)$, e mínimos quando entre eles.

O período dessas oscilações pode ser determinado se definirmos $B_{\ell}$ como o campo magnético no qual $\zeta=\epsilon_{\ell}$ [máximo em $\left.\rho(B)\right]$ : podemos reescrever esta igualdade como $B_{\ell}^{-1}=(\ell+1 / 2) \hbar e /\left(m^{*} \zeta\right)$, de modo que o período das oscilações, a distância em $\mathrm{T}^{-1}$ entre dois máximos consecutivos, ${ }^{13}$ é

$$
\Delta\left(\frac{1}{B}\right) \doteq \frac{1}{B_{\ell}}-\frac{1}{B_{\ell+1}}=\frac{\hbar e}{m^{*} \zeta}
$$

precisamente o período do argumento do cosseno na expressão de $\rho(B)$. Realmente, este cosseno

\footnotetext{
${ }^{12}$ Em geral não nos preocupamos com isto, mas todas as propriedades estudadas num 2DES referem-se não ao elétron propriamente dito, mas ao quasi-elétron.

${ }^{13}$ Poderiamos ter utilizado os mínimos de $\rho(B)$, associados a $\zeta=\epsilon_{\ell}+\hbar \omega_{c} / 2$, de forma análoga à que faremos na seção seguinde, quando considerarmos o spin.
} 


\section{Conceitos e métodos}

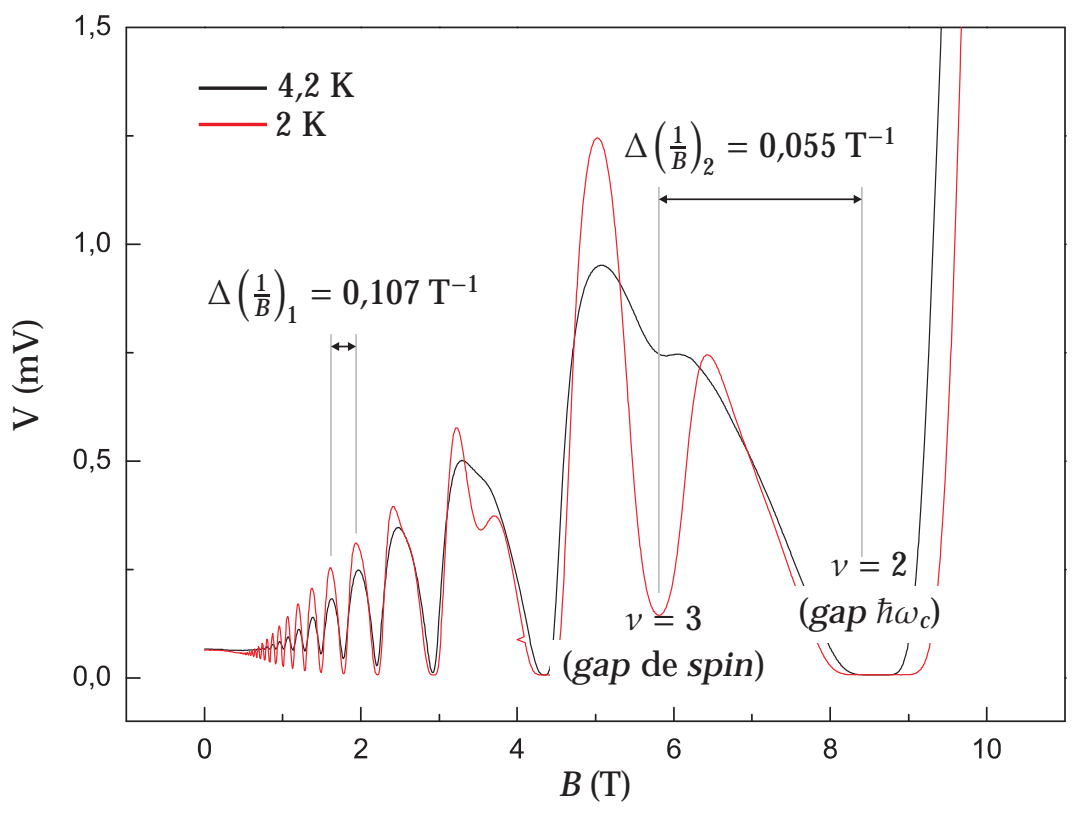

Figura 2.7.: exemplo de medida do efeito Shubnikov-de Haas num HEMT (o mesmo da fig. 2.2). Para $B$ pouco intenso ( $\leqslant 0,5 \mathrm{~T}$ na figura) o 2DES pode ser descrito pelo modelo de Drude, que prevê nenhuma magnetorresistência. Para valores intermediários $(0,5 \lesssim B \lesssim 2 \mathrm{~T})$ vale a equação de Lifshitz-Kosevich e podemos facilmente obter a concentração a partir de $\Delta\left(\frac{1}{B}\right)_{1}$ : conforme a equação 2.11 , obtemos $n=4,5 \times 10^{15} \mathrm{~m}^{-2}$. Compare com aquele obtido do efeito Hall clássico, na figura 2.2. Já para $B \gtrsim 2 \mathrm{~T}, V$ chega a zero, como resultado de não haver estados estendidos sobre o nível de Fermi. Nesta situação a equação de Lifshitz-Kozevich deixa de valer, mas ainda é possível obter a concentração a partir da equação 2.12: de $\Delta\left(\frac{1}{B}\right)_{2}, n=4,4 \times 10^{15} \mathrm{~m}^{-2}$.

decorre de uma aproximação válida quando $\zeta \gg \hbar \omega_{c}$ [66], que geralmente ocorre para campos magnéticos de intensidade "intermediária" $(0,5 \lesssim B \lesssim 2$ T na figura 2.7), onde a oferta de estados estendidos oscila, mas nunca se anula.

Quando B é pouco intenso, os LLs estão muito próximos ( $\left.\hbar \omega_{c} \ll \Gamma_{\ell}\right)$ e se sobrepõem; $\varrho(\epsilon)$ aproximase da densidade de estados em campo nulo (constante) e o 2DES pode ser descrito pelo modelo de Drude, donde $\rho(B)=$ constante, conforme ilustra a região $B \lesssim 0,5 \mathrm{~T}$ da figura 2.7.

No outro extremo, quando $B$ é muito intenso ( $\gtrsim 4 \mathrm{~T}$ na figura 2.7 ), os níveis de Landau estão muito distantes uns dos outros $\left(\hbar \omega_{c}>\Gamma_{\ell}\right)$. Então, quando $\zeta$ estiver entre os LLs $(v=N)$, apenas os estados de borda conduzirão corrente, sem perda de energia, cf. sec. 2.2. Logo a resistência é nula. E perceba que agora falamos da resistência ao invés de resistividade. Isto porque como a correntetotal - é nula dentro da amostra, $\rho(B)$ não representa uma propriedade do material; ela não é uma quantidade escalonável.$^{14}$ Mas quando o nível de Fermi está sobre o centro de um LL, a condução ocorre normalmente por toda a amostra e $\rho$ (podemos utilizá-lo agora) é finito, como ilustram os picos na fig. 2.7.

\footnotetext{
${ }^{14}$ Isto significa que $R$ e $\rho$ não podem ser relacionados por uma regra de escala (dimensões da amostra), como na segunda lei de Ohm, por exemplo: $R \propto \rho$.
} 
Retornando à expressão (2.10), como $\zeta=\pi \hbar^{2} n / m^{*}$ no 2DES,

$$
n=\frac{2 e / h}{\Delta\left(\frac{1}{B}\right)} \approx \frac{4,8 \times 10^{14} \mathrm{~m}^{-2}}{\Delta\left(\frac{1}{B}\right)} .
$$

Assim, quando o 2DES possui apenas uma sub-banda, podemos determinar a concentração de portadores (igual àquela obtida do efeito Hall clássico) através das oscilações $\mathrm{SdH}$ : basta tomarmos os valores de $B$ de dois máximos (ou mínimos) consecutivos e aplicarmos na expressão acima (veja um exemplo na figura 2.7). Esta expressão é válida mesmo quando (2.9) não vale.

Outra forma de se calcular a concentração de portadores é executar uma transformada de Fourier sobre $\rho\left(\frac{1}{B}\right)$, cujo resultado é uma lorentziana na posição $B_{i}$ tal que $n=2 e B_{i} / h$ (compare com a equação 2.11) [45, ap. A]. Este método é especialmente útil quando o 2DES é composto por mais de uma sub-banda, onde a segunda parcela em (2.9) é substituída por uma somatória de termos análogos, um para cada sub-banda ocupada [66]. Este método só pode ser utilizado no intervalo de validade de (2.9).

\subsubsection{O efeito do spin}

Quando $\Delta_{z} \gtrsim \Gamma_{\ell}$ (B intenso), zeros consecutivos em $R$ estão associados a diferentes gaps sobre os quais $\zeta$ se localiza. Na figura 2.5, por exemplo, quando $v=1$ o nível de Fermi está no gap $\Delta_{z}$; quando $v=2$, $\zeta$ está no gap $\hbar \omega_{c} ; v=3$ ocorre quando o nível de Fermi no gap $\Delta_{z}$ seguinte. E assim sucessivamente. Assim, para $v=1$ na figura $2.5, \zeta=\epsilon_{0}$, donde $B_{v=1}^{-1}=e \hbar /\left(2 m^{*} \zeta\right)$, e observe que agora o índice de $B$ indica o fator de preenchimento ao invés de $\ell$. Para $v=2, \zeta=\epsilon_{0}+\hbar \omega_{c} / 2$, resultando em $B_{2}^{-1}=e \hbar /\left(m^{*} \zeta\right)$. Então, $\Delta(1 / B) \doteq B_{2}^{-1}-B_{1}^{-1}=e / h n$ e

$$
n=\frac{e / h}{\Delta\left(\frac{1}{B}\right)} \approx \frac{2,4 \times 10^{14} \mathrm{~m}^{-2}}{\Delta\left(\frac{1}{B}\right)} .
$$

O raciocínio vale para todos os $v$ e, por conseguinte, a expressão acima vale sempre que se puder distinguir experimentalmente os estados $|\ell, \uparrow\rangle$ e $|\ell, \downarrow\rangle$ (diz-se que há resolução de spin).

\subsection{O formalismo de Landauer-Büttiker}

O formalismo de Landauer-Büttiker (LB) é uma descrição do transporte de cargas que expressa a corrente elétrica entre dois (ou mais) pontos em termos da probabilidade de o elétron ir de um para o outro. Trata-se de uma alternativa às descrições de Kubo, Boltzmann e Drude, especialmente útil quando essa probabilidade aproxima-se da unidade. Isto ocorre geralmente em amostras mesoscópicas, ${ }_{1}^{15}$ mas no nosso caso a fórmula de LB permite-nos compreender a condução num estado Hall quântico (num platô).

\footnotetext{
${ }^{15}$ Segundo S. Datta [43, p. 1] uma amostra mesoscópica é aquela cujas dimensões estão entre as microscópicas e macroscópi-
} cas 


\section{Conceitos e métodos}

A segunda lei de Ohm para sistemas bidimensionais estabelece que a condutância $(G)$ de uma amostra condutora retangular é dada pela lei de escalonamento $\sigma W / L$, onde $\sigma$ é uma propriedade do material que independe de suas dimensões (a condutividade) e $L$ e $W$ são o comprimento e a largura da amostra, respectivamente. ${ }^{16}$ Todavia, isto é verdade desde que $L$ e $W$ sejam muito maiores que (i) o comprimento de onda de de Broglie, (ii) o caminho livre médio e (iii) o comprimento de relaxação de fase dos portadores [43]. Quando um dos critérios acima não é atendido, a segunda lei de Ohm não vale e a amostra é dita mesoscópica.

Particularmente, quando $L$ torna-se demasiadamente pequeno, a condutância aproxima-se de um limite (a resistência dos contatos); quando $W$ é muito pequeno, $G$ varia discretamente [43]. Para uma amostra qualquer com dois contatos, ambos os fenômenos podem ser compreendidos através da fórmula de Landauer,

$$
G=\frac{b}{R_{K}} M T,
$$

onde $G$ é a condutância entre esses dois contatos, b é a degenerescência de spin, $T$ é a probabilidade de transmissão de um contato ao outro (a probabilidade de um elétron partir de um contato e chegar ao outro) e $M$ é a quantidade de modos transversais (a seguir) que participam do transporte de cargas (um número inteiro).

O confinamento dos elétrons na direção do crescimento através de poços-quânticos, por exemplo, dá origem a estados de energia discretos chamados de sub-bandas (ou, se preferir, os níveis de energia do QW), que distam de alguns meV. No plano perpendicular à direção de crescimento (plano $x y$ ) também há o confinamento dos elétrons, mas devido aos limites da amostra (e.g., dimensão $l_{y}$ na fig. 2.1), que também dá origem a níveis discretos de energia, desta vez alcunhados de modos transversais.

Note que $M \equiv M(W)$ : à medida que $W$ é reduzido, a distância em energia entre dois modos transversais aumenta (como os níveis de energia de um QW afastam-se conforme o poço-quântico torna-se mais e mais estreito). Com isso, a quantidade de modos transversais ocupados no nível de Fermi reduz mantendo $\Delta M=1$ ( $M$ é um número inteiro). Por conseguinte, $G$ também varia discretamente a passos de $b T / R_{K}$. Este resultado foi observado experimentalmente por B. J. van Wees et al [67] e D. Wharam et al [68]. A largura da amostra foi controlada através de um split-gate (conforme a configuração ilustrada pela figura da página 58).

Ademais, $T \equiv T(L)$ e é possível demonstrar que $R \doteq G^{-1}=\rho L / W+R_{0}$ [43, p. 62], onde a primeira parcela é a $2^{a}$ lei de Ohm e $R_{0}$ é a resistência do contato. Enquanto a amostra tem alguns poucos $M$ modos transversais, os contatos - macroscópicos - a ela conectados têm $M \gg 1$. Então, um elétron que cruza a junção amostra-contato, deixando a amostra em direção ao contato, tem uma infinidade de estados disponíveis para assumir ali. $\mathrm{O}$ mesmo não se pode dizer quando este elétron é injetado na amostra: como há pouca disponibilidade de estados (de modos transversais), a probabilidade de o elétron ser refletido na junção é grande e inevitável. Resulta daí a resistência do contato.

Mas em amostras "grandes" como as nossas (da ordem de $100 \mu \mathrm{m}$ ) os modos transversais distam

\footnotetext{
${ }^{16}$ Rigorosamente, $L$ e $W$ são as dimensões da amostra nas direções paralela e perpendicular ao fluxo de portadores.
} 
Figura 2.8: os elementos da equação (2.13): $N_{i}$ é a quantidade de modos de condução injetados pelo contato $i$ na amostra (corrente injetada); $R_{i}$ é a quantidade de modos refletidos dentro da amostra e de volta para o contato $i$ (corrente de reflexão); $T_{i j}$ é a quantidade de modos que atingem o contato $i$, vindo de todos os outros $j \neq i$ contatos (corrente transmitida).

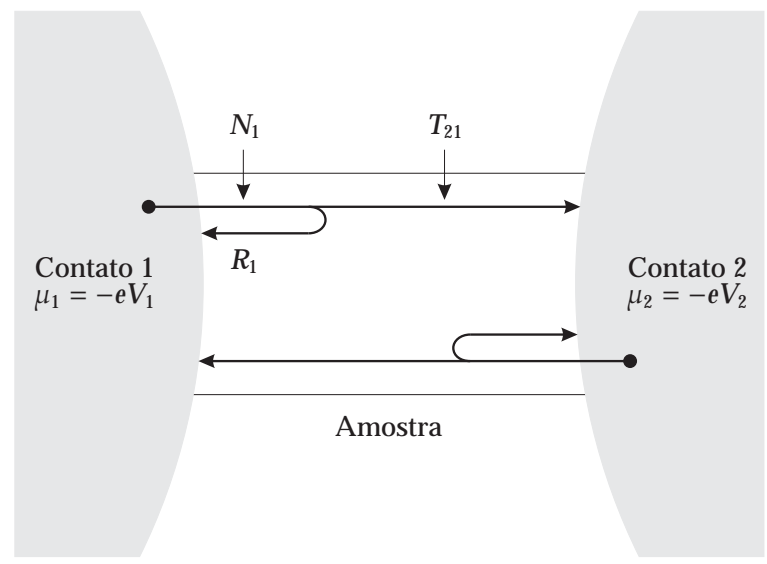

entre si de alguns $\mu \mathrm{eV}$ e em geral podemos ignorá-los, como o fizemos até agora. O conceito de modo transversal é importante porque no nosso caso são os estados de borda que fazem as vezes deles, quando $v=N \in \mathbb{N}$ : nossas amostras não são mesoscópicas, mas quando a condução ocorre através dos estados de borda sem dissipação de energia, podemos descrevê-la facilmente através do formalismo de Landauer-Büttiker. Mas antes de vermos isso, convém apresentar a generalização da fórmula de Landauer, introduzida por M. Büttiker [69]:

$$
I_{i}=-\frac{e}{h}\left(N_{i}-R_{i}\right) \mu_{i}+\frac{e}{h} \sum_{j \neq i} T_{i j} \mu_{j} .
$$

Para um dado contato $i, I_{i}$ é a corrente através dele, $N_{i}$ é a quantidade de modos de condução (modos transversais, níveis de Landau) que são injetados na amostra (corrente injetada), $R_{i}$ é a quantidade de modos de condução refletidos pela amostra de volta para o contato $i$ (corrente refletida) e $T_{i j}$ é a quantidade de modos transmitidos (corrente transmitida) de todos os outros contatos $j$ para o $i$ (note a ordem dos índices). $\mu_{i}$ é o potencial eletroquímico desse contato.

Vejamos um exemplo: considere a figura 2.8. Ela ilustra uma amostra com dois contatos (índice i), cada qual mantido externamente a um potencial eletroquímico $\mu_{i}$. Suponha que o contato 1 injete $M\left(=N_{1}\right)$ modos de condução com energia $\mu_{1}$ na amostra. Se a probabilidade de um elétron atingir o contato 2 for $T$, então $T M\left(=T_{21}\right)$ modos chegarão lá e $R_{1}=(1-T) M$ retornarão para 1 (não há acúmulo de cargas na amostra). Neste cenário, a equação 2.13 aplicada ao contato 1 fica

$$
I_{1}=\frac{1}{R_{K}}[M-(1-T) M] V_{1}-\frac{1}{R_{K}} T M V_{2},
$$

onde $V_{i}$ é o potencial eletrostático do contato $i$, que atende a relação $\mu_{i}=-e V_{i}$. Analogamente para o contato $2\left(N_{2}=M\right.$ e $\left.T_{12}=T\right), R_{K} I_{2}=[M-(1-T) M] V_{2}-T M V_{1}$.

A corrente que percorre a amostra é $I$, de tal forma que $I_{1}=I$ e $I_{2}=-I$ (o sinal é escolhido arbitrariamente). Disto resulta duas equações linearmente dependentes, e de qualquer uma delas obtemos

$$
I=\frac{M T}{R_{K}}\left(V_{1}-V_{2}\right) \Rightarrow G \doteq \frac{I}{V_{1}-V_{2}}=\frac{1}{R_{K}} M T .
$$




\section{Conceitos e métodos}

Esta é a equação de Landauer apresentada a pouco, com $b=1$. Se o spin não estiver resolvido no problema, podemos simplesmente integrar $b$ a $M$, fazendo a transformação $M \rightarrow b M^{\prime}$ na equação anterior.

Cuidado para não confundir $T \operatorname{com} T_{i j}$. O primeiro é a probabilidade de transmissão e o segundo, a quantidade de modos transmitidos; $T_{i j}=M T$ na expressão de $G$ acima e $T \in[0,1]$.

\subsubsection{O efeito Hall quântico revisitado}

No regime clássico do efeito Hall, a densidade de corrente na amostra é bastante complexa [70], o que torna sua descrição sob a perspectiva do formalismo de LB numericamente trabalhosa [34, p. 127]. Mas quando o nível de Fermi encontra-se entre quaisquer dois de Landau, o transporte de cargas ocorre (quase) balisticamente pelas bordas da amostra (fig. 2.9), através de $N$ estados de borda e podemos usar facilmente a fórmula de Landauer-Büttiker para descrever esta situação.

Acompanhe pela figura 2.9, que representa a geometria da barra-Hall de nossas amostras: o transporte entre dois contatos é balístico quando a probabilidade de transmissão é máxima. Então, o contato 1 injeta $N$ estados de borda com energia $\mu_{1}$ na amostra (corrente injetada) e todos eles atingem o contato 2 exclusivamente (ou seja, $T=1$ ). O contato 1 também recebe $N$ estados de borda com energia $\mu_{6}$ do contato 6 (corrente transmitida), de modo que $T_{21}=T_{16}=N$ (probabilidade de transmissão é igual a um). E como não há "comunicação" entre 1 e qualquer outro contato, todos os outros $T_{i j}=0$. Analogamente, o contato 2 recebe os $N$ estados de borda com $\mu_{1}$ do contato $1 \mathrm{e}$ transmite outros $N$ com $\mu_{2}$ para o 3: $T_{21}=T_{32}=N$ e, nas outras combinações de $i$ e $j, T_{i j}=0 . R_{i}=0$ para todos os contatos. Fazendo o mesmo para os outros contatos, obtemos a seguinte matriz de transmissão (as colunas indexam os contatos de origem e as linhas, os de destino):

$$
T=\left(\begin{array}{cccccc}
0 & 0 & 0 & 0 & 0 & N \\
N & 0 & 0 & 0 & 0 & 0 \\
0 & N & 0 & 0 & 0 & 0 \\
0 & 0 & N & 0 & 0 & 0 \\
0 & 0 & 0 & N & 0 & 0 \\
0 & 0 & 0 & 0 & N & 0
\end{array}\right) .
$$

Agora, suponha (como no nosso caso) que apliquemos a corrente I através dos contatos 1 (drain ou dreno) e 4 (source ou fonte). Esta corrente é conhecida, de modo que podemos escrever $I_{1}=-I_{4}=I$. Os outros contatos ou não são utilizados (diz-se que estão "em aberto") ou estão conectados a circuitos de alta impedância, como multímetros e lock-ins. Qualquer que seja o caso, a corrente 


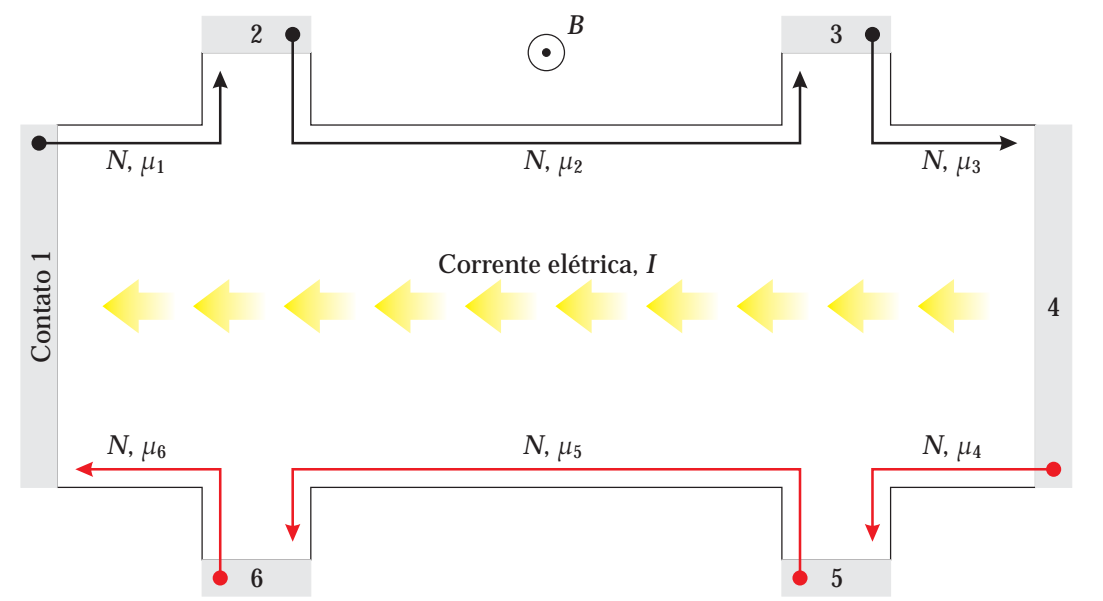

Figura 2.9.: quando $v$ é um inteiro $N$, o transporte de cargas ocorre pelas bordas da amostra sem dissipação de energia: são os chamados estados de borda. Esta configuração pode ser facilmente descrita através do formalismo de Landauer-Büttiker e prevê corretamente que a resistência Hall é $R_{K} / N$.

através deles é nula: $I_{2}=I_{3}=I_{5}=I_{6}=0$. Isto tudo posto em (2.13) resulta em

$$
\left(\begin{array}{c}
I \\
0 \\
0 \\
-I \\
0 \\
0
\end{array}\right)=\frac{N}{R_{K}}\left(\begin{array}{l}
V_{1} \\
V_{2} \\
V_{3} \\
V_{4} \\
V_{5} \\
V_{6}
\end{array}\right)-\frac{N}{R_{K}}\left(\begin{array}{llllll}
0 & 0 & 0 & 0 & 0 & 1 \\
1 & 0 & 0 & 0 & 0 & 0 \\
0 & 1 & 0 & 0 & 0 & 0 \\
0 & 0 & 1 & 0 & 0 & 0 \\
0 & 0 & 0 & 1 & 0 & 0 \\
0 & 0 & 0 & 0 & 1 & 0
\end{array}\right) \cdot\left(\begin{array}{c}
V_{1} \\
V_{2} \\
V_{3} \\
V_{4} \\
V_{5} \\
V_{6}
\end{array}\right)
$$

onde $V_{i}=-\mu_{i} /$ e é o potencial eletrostático do $i$-ésimo contato. E para simplificar as contas, podemos aterrar o contato 1 , impondo $V_{1}=0$. Com isso obtemos o seguinte resultado:

$$
V_{1}=V_{2}=V_{3}=0 \quad \text { e } \quad V_{4}=V_{5}=V_{6}=\frac{R_{K}}{N} I .
$$

Assim, quando medimos a resistência Hall (entre os contatos 2 e 6, por exemplo) obtemos $\left(V_{6}-V_{2}\right) / I=R_{K} / N$ : o efeito Hall quântico inteiro. Adicionalmente, quando medimos a tensão longitudinal (e.g., contatos 2 e 3), obtemos zero.

Portanto, o formalismo de Landauer-Büttiker fornece uma descrição simples e elegante do transporte de cargas quando $v=N$ : a resistência Hall é simplesmente a resistência do contato 4 (na fig. 2.9), que depende exclusivamente da quantidade de modos transversais (estados de borda; níveis de Landau) que conduzem a corrente elétrica; e a resistência longitudinal é nula porque não há espalhamento entre os contatos 2 e 3. 
(a)

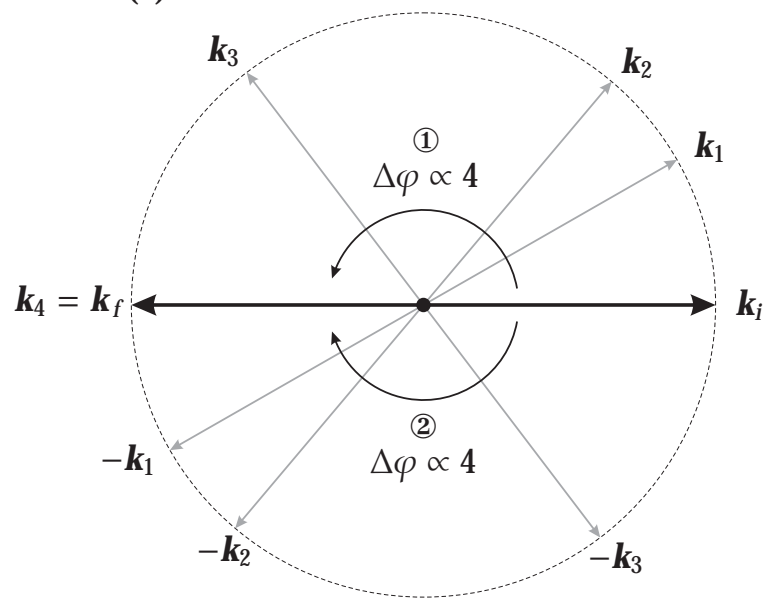

(b)

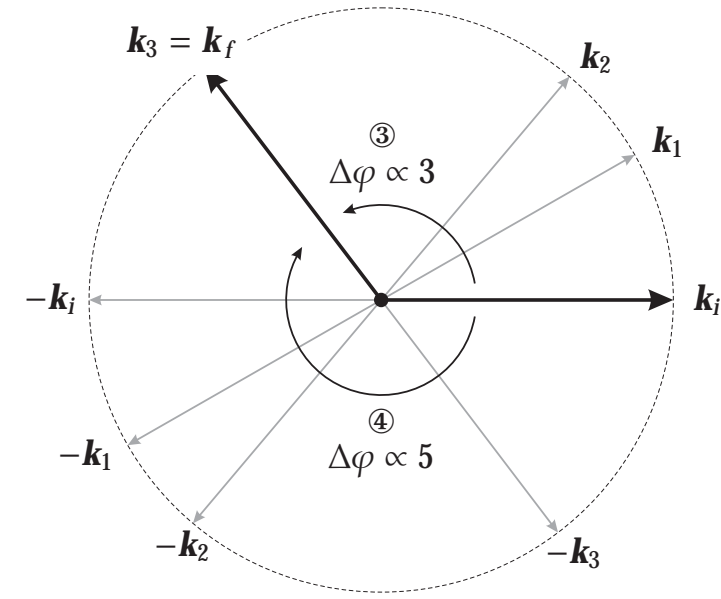

Figura 2.10.: comparação entre as sequências de espalhamento elástico quando o estado (vetor de onda) final é (a) oposto ao inicial e (b) qualquer outro. O primeiro é duas vezes mais provável que o segundo, donde origina-se a localização-fraca. A defasagem $\Delta \varphi$ é proporcional ao número de espalhamentos elásticos desde o estado inicial $\left(k_{i}\right)$ até o final $\left(k_{f}\right)$.

\subsection{Localização fraca}

Em todos os fenômenos explicados até agora a fase da função de onda do elétron era um parâmetro ignorável. Isto porque todos eles têm como parâmetro físico básico o tempo de espalhamento elástico ou tempo de relaxação do momento $(\tau)$, que é o tempo de vida do elétron num autoestado do momento. A teoria do transporte de cargas de Boltzmann ignora interferências entre as ondas parciais espalhadas e assume que seu momento anula-se após $\tau$. Sob essas condições não há qualquer correlação estatística entre a fase do elétron antes e após o espalhamento, o que de fato é válido para metais ou semicondutores a altas temperaturas. Mas acontece que em baixas temperaturas o tempo de espalhamento inelástico (ou tempo de relaxação da fase: $\tau_{\varphi}$ ), o tempo de vida do elétron num autoestado de energia, pode ser muito maior que $\tau$ e, com isso, ele pode sofrer inúmeros espalhamentos elásticos antes de perder sua fase [71].

A localização-fraca, inicialmente explicada por P. W. Anderson [72] através da teoria de Kubo, é justamente uma conseqüência dessas interferências: durante um processo de $n$ espalhamentos elásticos, desde $\left|\boldsymbol{k}_{i}\right\rangle$ até $\left|\boldsymbol{k}_{f}\right\rangle$, o elétron troca momento com os agentes espalhadores, passando por vários autoestados do momento:

$$
k_{i} \rightarrow k_{1} \rightarrow k_{2} \rightarrow \cdots k_{n}=k_{f}
$$

A probabilidade desse elétron terminar num estado $\left|\boldsymbol{k}_{f}\right\rangle$ qualquer é a mesma, qualquer que seja $\boldsymbol{k}_{f}$, exceto se ele for igual a $-\boldsymbol{k}_{i}$. Neste caso, existe outra seqüencia igualmente provável:

$$
k_{i}=-k_{n} \rightarrow-k_{n-1} \rightarrow \cdots-k_{1} \rightarrow-k_{i}
$$


que é oposta à primeira. Como as trocas de momento são simétricas, as mudança de fase nestes dois processos é idêntica: $\varepsilon t / \hbar$, sendo $\varepsilon$ a energia (que se conserva) e $t$ o tempo decorrido desde $\left|\boldsymbol{k}_{i}\right\rangle$ até $\left|\boldsymbol{k}_{f}\right\rangle$. Além disso, a amplitude de probabilidade do primeiro processo é igual à do segundo [71, p. 6]. Isso não acontece com nenhum outro estado final diferente de $-\boldsymbol{k}_{i} \mathrm{e}$, por conta disso, a probabilidade desses dois processos acontecerem aos pares é precisamente o dobro de qualquer outro.

Como o estado final é $-\boldsymbol{k}_{i}$ (ou seja, o elétron que inicialmente se deslocava numa direção, agora desloca-se na direção oposta), esta seqüência de espalhamento tem um nome especial: retroespalhamento ou backscattering. Essa tendência de sempre retornar mantém o elétron parcialmente localizado, daí o nome localização-fraca. Como conseqüência, a resistência para $B=0$ é maior que aquela prevista pela teoria de Drude.

A figura 2.10 compara duas seqüência de espalhamento, começando em $k_{i}$ : em (a) o estado final é o oposto do inicial; em (b), um qualquer. No primeiro, tanto o processo (1) como o (2) é composto por 4 espalhamentos elásticos. Assim, a diferença de fase por um ou por outro é precisamente a mesma: $\Delta \varphi=4 \tau \varepsilon / \hbar$. Por conseguinte, os elétrons estão em fase. Em (b), há 3 espalhamentos elásticos no processo (3) $(\Delta \varphi \propto 3)$ e 5 no (4) $(\Delta \varphi \propto 5)$. Há, portanto, uma diferença de fase de $2 \tau \varepsilon / \hbar$ entre as duas funções de onda em $\boldsymbol{k}_{f}$.

Para temperaturas maiores, os espalhamentos se tornam parcialmente inelásticos e $\Delta \varphi$ sofre influência das variações em $\varepsilon$. Conseqüentemente, mesmo o retroespalhamento se torna incoerente e o a localização-fraca é destruída após $\tau_{\varphi}$. Logo, a dependência da resistividade com a temperatura permite-nos determinar o tempo de coerência da função de onda dos elétrons (outro nome para $\left.\tau_{\varphi}\right)$.

Campos magnéticos também destroem a localização-fraca. Para uma seqüência de espalhamento que engloba uma área qualquer cujo fluxo magnético é $\Phi$, a função de onda do elétron receberá uma fase adicional igual a $2 e \Phi / \hbar$. Como resultado, o retroespalhamento deixa de ser o mais favorável, em detrimento de algum outro estado $\boldsymbol{k}_{f}$. Assim, a tendência de retornar desaparece e a resistência elétrica diminui. 
2. Conceitos e métodos 


\section{5 \\ Processos e equipamentos}

Neste capítulo apresentaremos os processos e equipamentos utilizados neste trabalho, desde o crescimento das amostras até a sua caracterização.

\subsection{Amostras}

As heteroestruturas utilizadas neste trabalho foram fabricadas no Laboratório de Novos Materiais Semicondutores (LNMS) do Instituto de Física da Universidade de São Paulo (IFUSP) através de epitaxia por feixe molecular (MBE, molecular beam epitaxy) [73, 74].

A epitaxia por feixe molecular é apenas uma das chamadas técnicas de crescimento epitaxial ${ }^{1} \mathrm{e}$ caracteriza-se principalmente pela capacidade de produzir filmes monocristalinos ultrafinos com precisão atômica. A palavra "epitaxia" é um hibridismo do prefixo grego "epi" (acima) com o radical latino "axis" (eixo) e procura representar a idéia de que a camada cristalina em crescimento (epicamada) tende a seguir a orientação cristalográfica da camada imediatamente abaixo (substrato); já o termo "feixe molecular" refere-se ao regime molecular dos elementos químicos que incidem na superfície do substrato. Assim, a técnica MBE consiste em incidir um feixe molecular de átomos ou moléculas sobre um substrato cristalino (previamente produzido por alguma outra técnica) e, com isso, produzir mais uma camada atômica estruturalmente idêntica à anterior, e assim sucessivamente para as camadas seguintes (veja a figura 3.1).

\footnotetext{
${ }^{1}$ Técnicas correlatas são a MOCVD (metalorganic chemical vapour deposition) e a CBE (chemical beam epitaxy).
} 


\section{Processos e equipamentos}

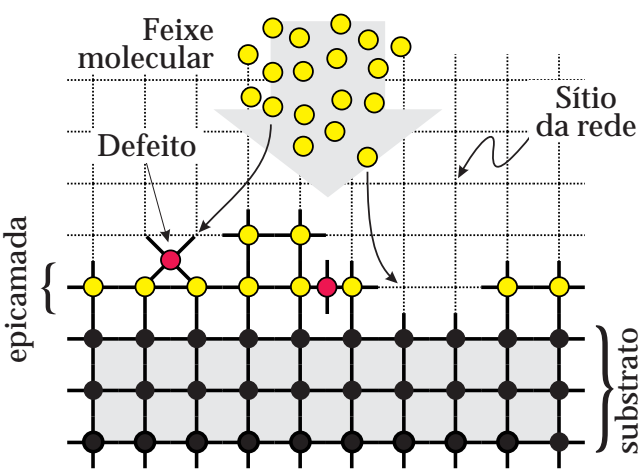

Figura 3.1: ao incidir sobre o substrato, os átomos ou moléculas do feixe molecular tendem a se posicionar nos sítios da rede. Deste modo, o crescimento segue a estrutura cristalina do substrato, pois é assim que a energia total é minimizada. Os átomos da epicamada podem ou não ser diferentes daqueles do substrato, dependendo do que se quer obter.

A figura 3.2(a) é uma representação das partes principais de um equipamento de MBE genérico e a figura 3.2(b) é uma fotografia do equipamento utilizado para crescer as amostras deste trabalho. ${ }^{2}$ O equipamento é constituído de duas câmaras de vácuo independentes (sistemas de vácuo independentes) e conectadas por uma válvula gaveta, específica para ambientes de ultra-alto-vácuo. A primeira delas (câmara de entrada) não está representada na figura 3.2(a) por que tem pouco interesse para a compreensão do método propriamente dito: Ela é utilizada para manusear as amostras e, por isso, freqüentemente exposta à atmosfera-ambiente (daí a necessidade de essas duas câmaras possuirem sistemas de vácuo independentes). É na segunda câmara (de crescimento), acima da válvula gaveta (fig. 3.2(a)), que o crescimento ocorre: O substrato é fixado no centro (portaamostras) e para ele estão apontadas as células de Knudsen, cada qual contendo um bloco de elemento químico sólido puro, e somente ele. No nosso caso, as células contém As (arsênio), Al (alumínio), In (índio), Ga (gálio) e Si (silício, usado nas dopagens). O feixe molecular é obtido pela sublimação desses elementos e seu fluxo é controlado pela temperatura de cada célula. Entre o substrato e cada célula existe um obturador pneumático que interrompe ou não a incidência desse fluxo sobre o substrato, conforme o interesse. Então, e.g., se quisermos jogar apenas alumínio no substrato, abrimos o obturador da célula de $\mathrm{Al}$ e fechamos os das outras. A quantidade de átomos que incide sobre o substrato é diretamente proporcional ao tempo de abertura do obturador. Deste modo, manipulando as temperaturas das células de Knudsen e os tempos de exposição (do substrato às células) podemos atingir taxas de crescimento tão baixas quanto $1 \mu \mathrm{m} / \mathrm{h}$ (ou alguns angströns por segundo).

O canhão de elétrons e a tela fluorescente na figura 3.2(a) são necessários para monitorar o crescimento através de uma técnica chamada RHEED (reflection high-energy electron diffraction): Basicamente, o canhão de elétrons incide sobre a superfície da amostra em crescimento um feixe rasante ( $\sim 1^{\circ}$ com a superfície) de elétrons altamente energéticos ( $8 \mathrm{keV}$ no nosso caso), projetando na tela fluorescente o padrão de difração produzido pelo feixe na superfície da amostra. Então suponha que temos uma superfície perfeitamente lisa. Como a incidência é rasante, o feixe é totalmente refletido e difratado pelas camadas mais superficiais (1 a 5 MC). ${ }^{3}$ Assim, o padrão de

\footnotetext{
${ }^{2}$ No Laboratório de Novos Materiais Semicondutores (LNMS) do Departamento de Física dos Materiais e Mecânica (DFMT) do Instituto de Física (IF) da Universidade de São Paulo (USP).

${ }^{3}$ Chamamos de monocamada (MC) a distância entre dois planos sucessivos de átomos da mesma espécie numa estrutua
} 

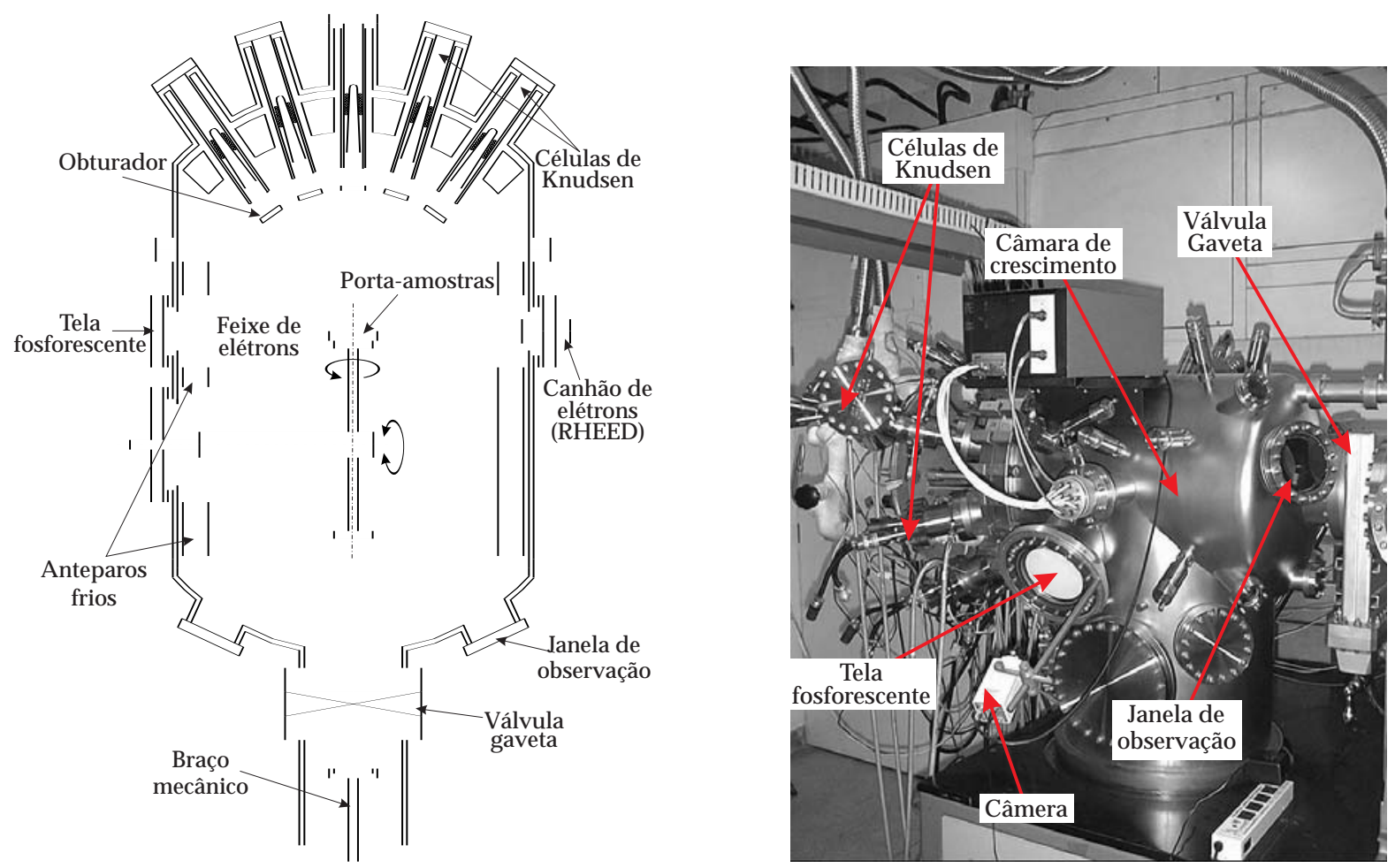

Figura 3.2.: (a) Esquema genérico de um sistema MBE (visto de cima). (b) Fotografia do equipamento MBE do laboratório LNMS no Instituto de Física da Universidade de São Paulo (campus SP). A câmera (na parte inferior) capta os padrões de difração que aparecem na tela fosforescente e envia-os para um monitor. O leitor pode ter uma noção do tamanho do equipamento observando o filtro-de-linha na parte inferior direita da figura.

difração observado é um conjunto de listras, característico de uma estrutura bidimensional (a área de incidência). Inversamente, suponha agora que temos uma superfície rugosa. Neste caso o feixe será fortemente bloqueado pela rugosidade. Agora, o feixe de elétrons tem de atravessar as rugosidades e quando isto acontece as condições de difração são associadas a um arranjo tridimensional de átomos. Isto implica que o padrão de difração, nesta situação, é um conjunto de pontos, característico de uma estrutura tridimensional (rugosidade da superfície). A figura 3.3 ilustra essas duas situações.

Embora o crescimento por MBE seja praticamente isento de defeitos, ele não ocorre camada por camada atômica exatamente. A figura 3.1 ilustra isso: Cada linha horizontal de átomos (círculos) é uma monocamada. A primeira monocamada acima do substrato (círculos amarelos) ainda não está completa, embora a segunda (imediatamente acima) já tenha começado a se formar. Essa figura mostra uma situação em que a rugosidade é alta, mas dentro em breve a primeira camada acima do substrato estará completa e a segunda (acima) ainda estará em formação. Quando isto ocorrer a rugosidade terá reduzido. O crescimento ocorre desta maneira: A rugosidade da superfície oscila, e é isso que a técnica RHEED mede. Quando uma monocamada está completa, a rugosidade é mínima e a difração do feixe eletrônico é característico de uma estrutura bidimensional (conjunto

cristalina. Especificamente no nosso caso, onde a estrutura é do tipo zinc-blend [26] e a orientação cristalográfica é (001), $1 \mathrm{MC}=a / 2$, onde $a$ é o parâmetro de rede. 

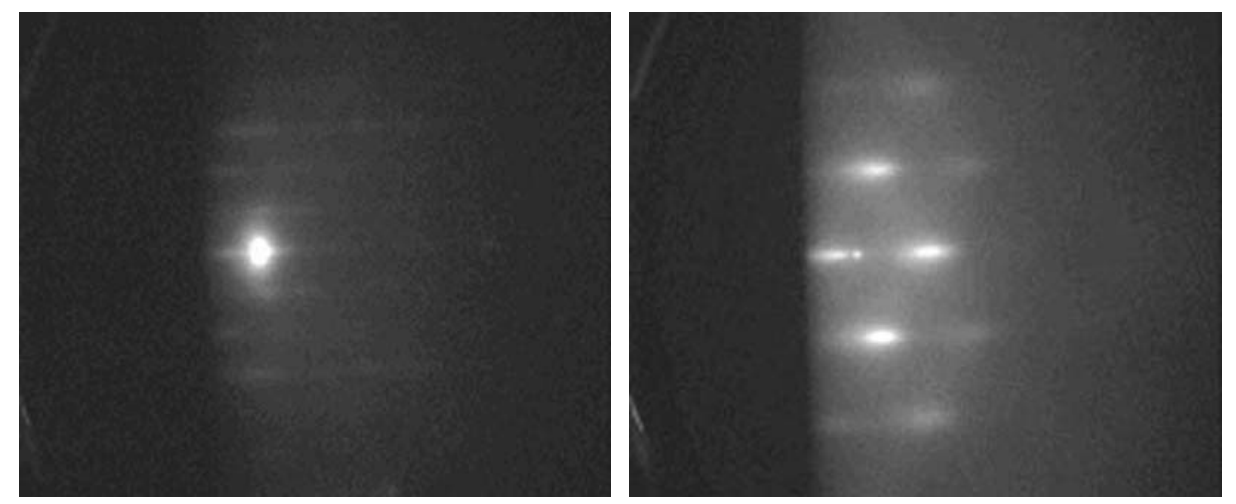

Figura 3.3.: À esquerda vemos o padrão de difração característico de uma estrutura bidimensional (veja o texto); À direita, o padrão é devido à rugosidade da superfície (aglomerados tridimensionais de átomos), indicando que a monocamada mais superficial ainda não está completa. O ponto intenso no centro é a parte do feixe que não sofreu difração.

de listras). Mas quando só metade de uma monocamada está completa, a rugosidade é máxima e o padrão de difração é o de uma estrutura tridimensional (conjunto de pontos). A figura 3.3 mostra uma foto dessas duas situações e as referências [73] e [74] explicam pormenorizadamente a técnica.

A técnica RHEED também é utilizada para verificar a formação dos pontos-quânticos: Conforme veremos na próxima seção, os QDs são pequenos aglomerados tridimensionais de átomos e, por isso, produzem um padrão de difração característico de uma estrutura tridimensional.

O feixe molecular obtido da sublimação dos elementos químicos nas células de Knudsen incide sobre o substrato a uma taxa que varia de $10^{18}$ até $10^{20}$ átomos por metro quadrado e por segundo. Ao atingir a superfície, esses átomos sofrem uma enorme variedade de trocas energéticas antes de entrarem em equilíbrio termodinâmico com o substrato e, só então, serem efetivamente incorporados na amostra ${ }^{4}$ (isto ocorre por que as temperaturas do substrato e a das células de Knudsen não são a mesma). Essas trocas energéticas ocorrem através de cinco maneiras, ou fenômenos, distintos (basicamente): Adsorção, difusão e incorporação; desadsorção e dissociação. Um átomo ou molécula adsorvido está simplesmente em contato com a superfície do substrato, mantido ali por intermédio de interações de Van der Waals (sem troca de elétrons). Esse é, geralmente, o primeiro estado pelo qual os átomos ou moléculas do feixe incidente passam. A partir daí, eles podem "passear" (difundir) pela supefície trocando energia até se ligarem quimicamente (com troca de elétrons) a algum átomo da superfície, o que corresponde à incorporação no cristal propriamente dita. A desadsorção e a dissociação são os antônimos da adsorção e da incorporação, respectivamente.

A incorporação de um átomo ou molécula no cristal é o estado final desejado e geralmente ocorre junto de defeitos, impurezas ou ligações químicas incompletas (ou insaturadas: dangling bonds) na superfície pois eles propiciam uma menor variação da energia livre do substrato [74]. Mas isto não significa que a incorporação gere os defeitos, contrariando o que dissemos no início deste capítulo: Observe, por exemplo, a figura 3.1. Numa situação como esta, a incorporação ocorrerá mais provavelmente no degrau (que é um defeito) formado pelo substrato e pela epicamada, mas

\footnotetext{
${ }^{4}$ Para uma taxa de crescimento típica, de $1 \mathrm{MC} / \mathrm{s}$, um átomo de gálio sobre um substrato de GaAs a $600{ }^{\circ} \mathrm{C}$ pode realizar aproximadamente $10^{6}$ interações antes de ser efetivamente incorporado pelo cristal [74].
} 
ainda assim seguindo a orientação cristalográfica da região.

Para que a incorporação ocorra eficientemente (o que dá origem a amostras de melhor qualidade), os átomos ou moléculas adsorvidos precisam ter liberdade para difundirem-se pela superfície do substrato até encontrarem o sítio da rede mais apropriado para a incorporação. Se a superfície do substrato for muito rugosa (de má qualidade), os átomos ou moléculas adsorvidos não terão energia para transpor os aglomerados tridimensionais de átomos (já incorporados à superfície) e trocarão energia nas imediações da região onde incidiram. Assim, eles não poderão se difundir e acabarão sendo incorporados ali mesmo, prejudicando a qualidade da amostra. Por outro lado, se a superfície da amostra for lisa, haverá poucos obstáculos e os átomos ou moléculas poderão se difundir apreciavelmente, melhorando a qualidade da amostra. Portanto, a rugosidade inicial do substrato é um parâmetro que influencia fortemente a qualidade da amostra crescida; A temperatura é outro: Em baixas temperaturas, a adsorção é promovida (em detrimento da desadsorção) mas a difusão não; Em altas, a difusão melhora mas a adsorção não (a desadsorção melhora). Com efeito, os processos pelos quais os átomos ou moléculas do feixe incidente e os do substrato interagem são, por si só, extremamente complexos e um sem número de trabalhos procura abordá-los.

A condição de vácuo ultra-alto tem importância fundamental pois não só garante o regime molecular do feixe de átomos oriundos das células de Knudsen como também minimiza a contaminação da amostra em crescimento: Para se ter uma idéia, a câmara de crescimento é mantida em $10^{-10}$ torr (ultra-alto-vácuo) e, nesta pressão, o tempo necessário para que uma monocamada de impureza se forme numa superfície qualquer é da ordem de 28 horas; Em $10^{-6}$ torricelli (alto-vácuo), no entanto, esse tempo cai para cinco minutos! Com efeito, o crescimento epitaxial por feixe molecular não seria possível sem a atual tecnologia de vácuo.

\subsection{A formação dos pontos-quânticos}

Quando o filme epitaxial (epicamada) e o substrato sobre o qual ele é crescido possuem a mesma estrutura cristalina e um parâmetro de rede muito parecido (o caso do AlGaAs sobre GaAs) ou idêntico (GaAs sobre GaAs), o crescimento é coerente, i.e., o material depositado adota naturalmente o mesmo parâmetro de rede que o do substrato e o filme cresce camada por camada (fig. 3.1). Este regime de crescimento é conhecido como Frank-van der Merwe (FM) [73] e é o principal modo de crescimento em sistemas isentos de tensões (a seguir). No entanto, quando o material sublimado (na célula de Knudsen) tem um parâmetro de rede consideravelmente diferente daquele do substrato (InAs sobre GaAs, como no nosso caso, por exemplo), a camada em crescimento (epicamada) é forçada a assumir o parâmetro de rede do substrato. Isto significa que a energia potencial contida nas ligações químicas da epicamada não é mínima por que o parâmetro de rede do filme não é o seu natural. Neste caso, surge uma tensão mecânica que aumenta conforme aumentamos a quantidade (ou camadas) de material depositado. Mesmo assim o crescimento ainda é coerente e a epicamada é cristalograficamente perfeita; idêntica ao substrato. Mas esta situação não prossegue indefinidamente: Existe uma espessura crítica a partir da qual a tensão não pode mais ser contida 
(a)

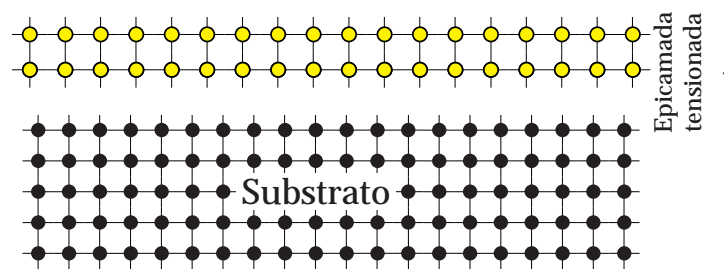

(c)

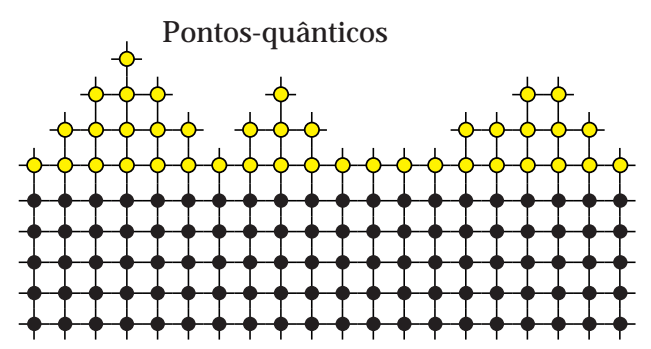

(b)

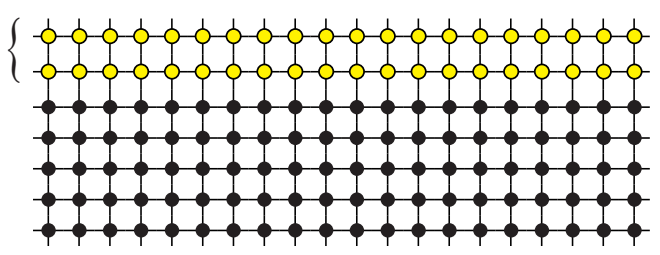

(d)

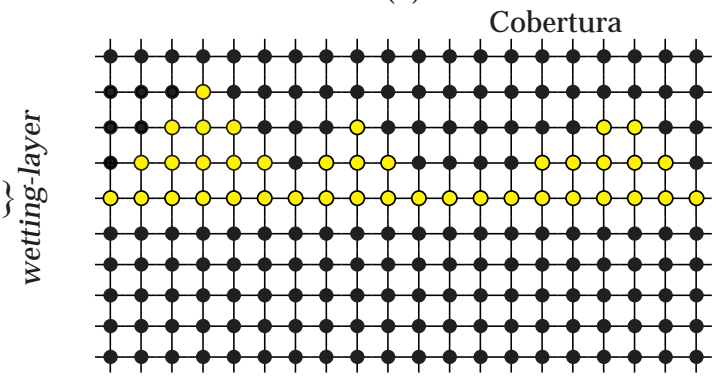

Figura 3.4.: Em (a) apresentamos separadamente uma representação das ligas do substrato (círculos pretos) e do filme epitaxial (círculos amarelos) que queremos crescer sobre ele, ilustrando a diferença entre seus respectivos parâmetros de rede (distâncias entre círculos vizinhos). (b) Ao crescermos um filme epitaxial cujo parâmetro de rede difere daquele do substrato, o filme fica mecanicamente tensionado. Mesmo assim, a estrutura cristalina do filme ainda é igual à do substrato. Este é o regime de crescimento Frank-van der Merwe (FM). (c) Quando o filme atinge uma espessura crítica, a tensão se torna tão grande que não pode mais ser contida por ele. Quando isto acontece, os átomos da epicamada tensionada se rearranjam e formam pequenas ilhas tensionadas (ou seja, com o parâmetro de rede do substrato). Essas ilhas são chamadas de pontos-quânticos e o regime de crescimento é agora conhecido como Stranski-Krastanov (SK). Abaixo dos QDs é comum restar um filme ultra-fino (de $1 \mathrm{MC}$ aproximadamente) conhecido por wetting-layer. (d) Depois de formados os QDs, é comum retomarmos o crescimento da liga do substrato, cobrindo os pontos-quânticos, daí o nome "cobertura."

pelas camadas epitaxiais. Quando isso acontece, os átomos das camadas recém-depositadas se deslocam e se aglutinam para formarem pequenas ilhas tridimensionais tensionadas (ditas coerentes). Essas ilhas são chamadas de pontos-quânticos e são literalmente pequenos "montes" (aglomerados) de átomos arranjados numa estrutura cristalina cujo parâmetro de rede ainda é o do substrato (por isso dita coerente), mas com um leve relaxamento em suas bordas (ou seja, à medida que nos afastamos do centro de um QD e nos aproximamos de sua superfície, o parâmetro de rede tende ao seu valor natural). Veja a figura 3.4.

O restante das camadas epitaxiais recém-depositadas que não é utilizado para formar os pontosquânticos fica sob a forma de um filme ultra-fino de aproximadamente $1 \mathrm{MC}$ de espessura chamado wetting-layer (camada molhada) logo abaixo dos QDs.

À medida que o crescimento prossegue, novos pontos-quânticos são formados e os já existentes crescem [3], elevando drasticamente a rugosidade da superfície. Por isso, o crescimento deixa de ser bidimensional (camada por camada) e passa a ocorrer tridimensionalmente: É o chamado regime Stranski-Krastanov (SK) [73].

O gráfico da figura 3.5(a) ilustra a concentração de QDs de arseneto de índio (nosso caso) em função da quantidade nominal (em monocamadas) de InAs depositada, obtida por Ramachandran et al em 1997 [75]. Como podemos ver, a densidade de pontos-quânticos cresce abruptamente logo 


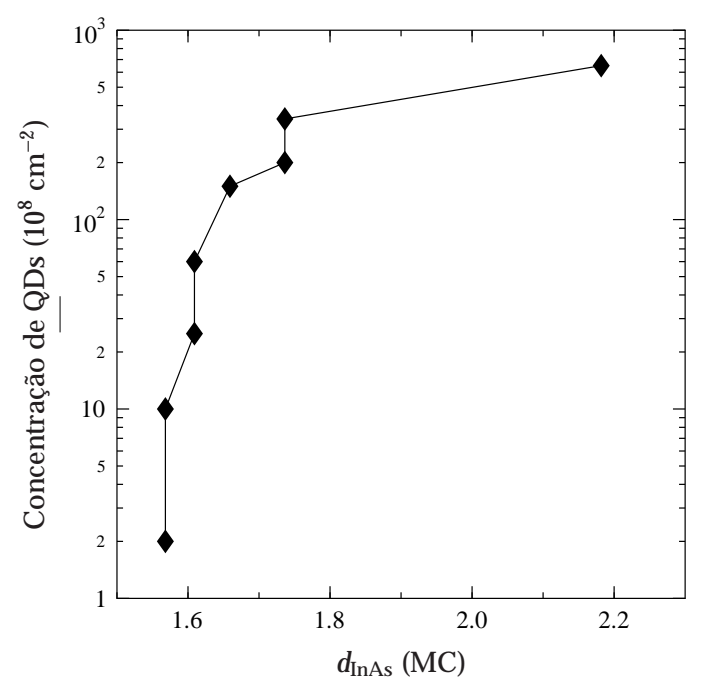

(a) A concentração de SQDs cresce drasticamente a partir de aproximadamente 1,6 MC de InAs depositadas, ilustrando a transição $2 \mathrm{D} \rightarrow 3 \mathrm{D}$ (ou $\mathrm{FM} \rightarrow \mathrm{SK}$, Frank-van der Merwe para Stranski-Krastanov): É neste momento que a tensão acumulada na epicamada não pode mais ser contida e formam-se os QDs, a forma encontrada pela estrutura para reduzir esta tensão.

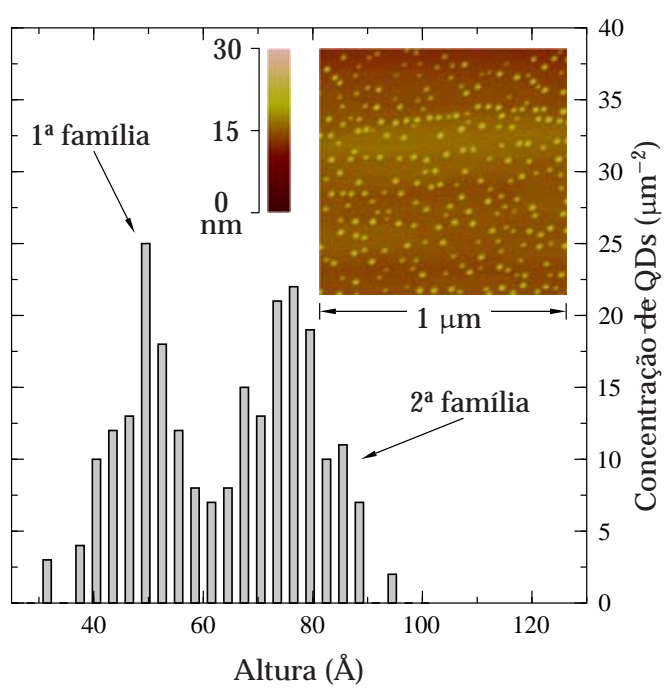

(b) A evolução dos SQDs ocorre através de "famílias" de pontos-quânticos, caracterizadas pelas suas dimensões. Aqui podemos ver claramente a existência de duas dessas famílias, uma com altura média de $45 \AA$ A, e outra com $75 \AA$. A figura inserida no gráfico é uma imagem obtida através de Microscopia de Força Atômica, e é a partir desta figura que contamos os QDs e medimos suas dimensões.

Figura 3.5.: Em (a) apresentamos a concentração de pontos-quânticos auto-organizados em função da espessura nominal de InAs depositado. Este resultado foi obtido por Ramachandran et al em 1997 [75]. Já em (b), ilustramos a existência de "famílias" de SQDs, caracterizadas pelas suas dimensões. Este resultado foi obtido por Duarte et al em 2002 [3].

após a espessura crítica (transição $\mathrm{FM} \rightarrow \mathrm{SK}$ ou $2 \mathrm{D} \rightarrow 3 \mathrm{D}$ ), mas tem um valor máximo próximo de $10^{11} \mathrm{~cm}^{-2}$. Além disso, o crescimento não é homogêneo e na superfície da amostra coexistem QDs com dimensões distintas. Em verdade, geralmente os pontos-quânticos se agrupam em famílias, cada qual com uma distribuição gaussiana de tamanhos (altura, raio ou volume) em torno de um valor médio (figura 3.5(b)) que caracteriza essa família.

A despeito de a concentração de pontos-quânticos crescer abruptamente após a espessura crítica (aproximadamente 1,6 MC), o processo de remanejamento dos átomos da epicamada tensionada parece iniciar-se um pouco antes e um pouco menos drasticamente com a formação de imensos platôs com dimensões de $\sim 400 \AA$ paralelamente ao plano do crescimento e de $2-3 \mathrm{MC}(\sim 7 \AA)$ perpendicularmente. Aparentemente este é o primeiro passo na formação dos pontos-quânticos e o fato de esses platôs ainda não serem ilhas tridimensionais renderam-lhes o nome de Q3Ds (quasi-three dimensional). Ainda existe muita controvérsia a respeito desse fenômeno, especialmente por que - até onde sabemos - somente dois trabalhos no mundo conseguiram observá-los experimentalmente: [3] e [76], o primeiro deles realizado neste laboratório.

Embora a formação dos pontos-quânticos represente uma redução na tensão mecânica acumulada durante o crescimento, ainda assim esta configuração não está completamente relaxada, haja vista que as ilhas tridimensionais possuem o parâmetro de rede do substrato, e não o seu natural. 


\section{Processos e equipamentos}

Destarte, à medida que o crescimento prossegue e os QDs crescem em quantidade e tamanho, a tensão também aumenta. Novamente, existe um tamanho máximo dos pontos-quânticos acima do qual a tensão não pode mais ser contida por eles. Neste momento as ilhas tensionadas relaxam, assumindo seu parâmetro de rede natural, e o crescimento deixa o modo SK, dando origem a inúmeros defeitos estruturais indesejáveis. De fato, qualquer aplicação atual de pontos-quânticos utilizando esta técnica de crescimento sempre permanece no regime SK, até por que as dimensões e a concentração dos QDs neste regime são controláveis através da quantidade de material depositado (dentre outros parâmetros), embora este controle não seja tão preciso quanto se gostaria.

Resumindo, o fenômeno de auto-formação e organização dos pontos-quânticos consiste na reoganização espontânea de parte da camada epitaxial tensionada durante o crescimento para diminuir sua energia total, e os QDs crescidos desta maneira são comumente conhecidos como pontosquânticos auto-organizados (SQDs, self-organized quantum-dots).

É interessante, importante e instrutivo observar que, grosso modo, não há diferenças morfológicas entre uma superfície repleta de pontos-quânticos e outra simplesmente rugosa: Ambas são formadas por “ondulações." Dito de outra forma, tanto os QDs como as ondulações numa superfície rugosa são aglomerados de átomos. Em verdade, a diferença essencial reside no fato de que os pontosquânticos são formados por uma liga diferente da do substrato, enquanto as ondulações numa superfície rugosa não. Isto significa que o gap de energia na região do ponto-quântico é diferente daquele no substrato. Então, e.g., no caso de QDs de arseneto de índio crescido sobre um substrato de GaAs, o gap do InAs é menor e a região do QD se torna um QW tridimensional. Todavia, o conceito de banda proibida (gap) tem origem na teoria de Bloch e não pode ser aplicado aqui indiscriminadamente pois a estrutura cristalina dos pontos-quânticos não é infinita, como requer esta teoria. De fato, uma das discussões a respeito dos QDs é justamente que tipo de centro espalhador ele é: atrativo [77] ou repulsivo [78].

A técnica de crescimento MBE fornece pontos-quânticos praticamente isentos de defeitos, além de oferecer um confinamento muito mais efetivo do que aquele obtido por litografia, por exemplo. Contudo, devido à espontaneidade da formação dos QDs, o controle de suas características é limitado. Particularmente, a aleatoriedade de tamanho e da distribuição espacial dos pontosquânticos sobre a superfície da amostra são desvantagens com relação a outras técnicas. Com efeito, atualmente a principal dificuldade em se aplicar os QDs em dispositivos eletrônicos e optoeletrônicos reside aí.

\subsubsection{Descrição das amostras}

As quatro seções a seguir apresentam as heteroestruturas utilizadas neste trabalho. Na primeira, as amostras utilizadas no estudo de estados de borda contra-rotativos; na segunda, aquelas analisadas através do fenômeno da localização-fraca; finalmente, nas duas seguintes apresentamos as estruturas utilizadas para averiguar fenômenos de transporte que possam ser utilizados no melhor dimensionamento de fotodetectores de infravermelho baseados em pontos-quânticos autoformados (QDIPs). 


\begin{tabular}{c|c|c|c|c|c|c|c} 
Amostra & $d(\mathrm{~nm})$ & $s_{1}(\mathrm{~nm})$ & $s_{2}(\mathrm{~nm})$ & $s_{3}(\mathrm{~nm})$ & $\delta_{1}\left(10^{15} \mathrm{~m}^{-2}\right)$ & $\delta_{2}\left(10^{15} \mathrm{~m}^{-2}\right)$ & $\delta_{3}\left(10^{15} \mathrm{~m}^{-2}\right)$ \\
\hline$A$ & 5 & 20 & 90 & - & 10 & 3 & - \\
$B$ & 1,4 & 50 & 130 & 30 & 4 & 4 & 1 \\
\hline
\end{tabular}

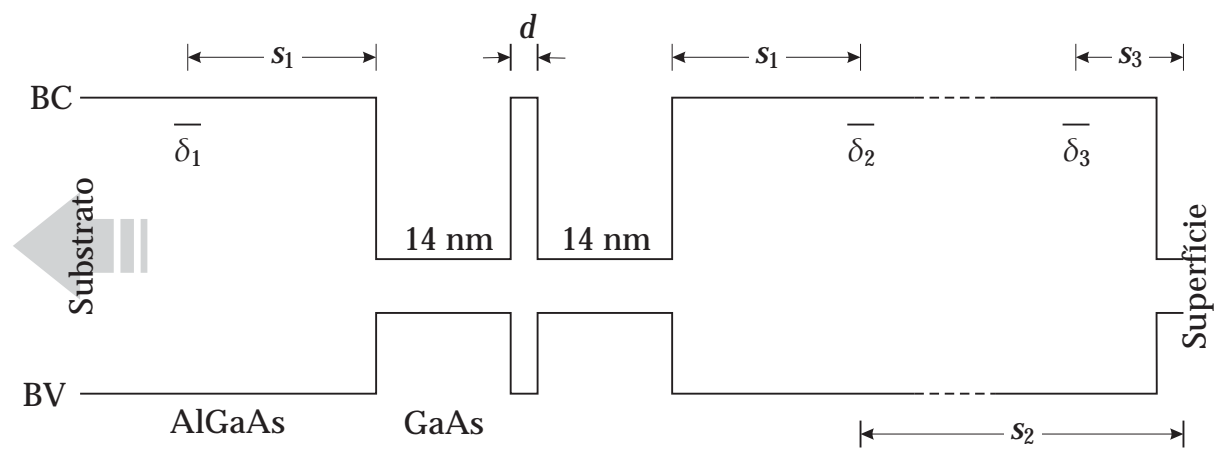

Figura 3.6.: parâmetros e esquema da heteroestrutura e do perfil de potencial da região-ativa das amostras de poços-quânticos duplos. A amostra $A$ não possui a dopagem $\delta_{3}$ (por conseguinte, nem $s_{3}$ ). BC é a banda de condução e BV, a de valência.

\section{Amostras para o estudo dos estados de borda contra-rotativos}

Apesar de muitas outras amostras terem sido crescidas (com diferentes parâmetros), apenas nas amostras $A$ e $B$ (fig. 3.6) observamos os estados de borda contra-rotativos. Concentraremo-nos nos resultados da amostra $A$, bem mais claros que os da $B$. A heteroestrutura delas é a seguinte, em ordem de crescimento:

- Substrato comercial semi-isolante de GaAs com orientação cristalográfica (001). No caso da amostra $B$ a superfície do substrato possui inclinação de dois graus, numa tentativa de reduzir a incorporação de impurezas durante o crescimento e, por conseguinte, melhorar a mobilidade dos elétrons no 2DES;

- camada de preenchimento (buffer) de $200 \mathrm{~nm}$ de GaAs, para reduzir a rugosidade do substrato, de algumas dezenas de nanometros para duas monocamadas de GaAs, aproximadamente;

- super-rede composta por 20 períodos de AlAs/GaAs, cada qual com 5 monocamadas de AlAs e 10 de GaAs, cuja finalidade é evitar a migração de contaminantes do substrato para a região-ativa (a seguir) da estrutura. Esta camada tem aproximadamente $170 \mathrm{~nm}$ de espessura;

- outro buffer de GaAs com 500 nm de espessura;

- a partir daqui o material hospedeiro passa a ser o AlGaAs, começando com um buffer de $80 \mathrm{~nm}$;

- a região-ativa (fig. 3.6) inicia-se com uma monocamada de AlGaAs dopada com silício, com concentração nominal de átomos dopantes igual a $\delta_{1}$ (veja a figura). Sua função é prover

\footnotetext{
${ }^{5}$ Monocamada é a distância entre dois planos sucessivos de átomos da mesma espécie numa rede cristalina. No nosso caso, onde a estrutura é do tipo zinc-blend e a orientação cristalográfica é (001), ela corresponde a meio parâmetro de rede. Então, para o GaAs $1 \mathrm{MC} \approx 2,8 \AA$ e para o InAs, $\approx 3 \AA$.
} 


\section{Processos e equipamentos}

elétrons para a formação do 2DES nos poços-quânticos;

- em seguida, a primeira camada de espaçamento (spacer-layer) de AlGaAs, com espessura $s_{1}$, encarrega-se de separar a região da dopagem dos QWs. Quanto mais espessa, maior a mobilidade e menor a concentração de elétrons no 2DES, de modo que $s_{1}$ é dimensionada de modo fornecer a maior mobilidade possível, com a restrição de garantir uma concentração mínima detectável pelos equipamentos utilizados;

- os dois poços-quânticos de GaAs, cada qual com espessura de $14 \mathrm{~nm}$ e separados por uma barreira de espessura $d(\mathrm{AlGaAs})$, constituem a região na qual se forma o 2DES. Trata-se de uma bicamada (bilayer), ou seja, um sistema bidimensional de elétrons com duas sub-bandas separadas espacialmente e cuja origem é o tunelamento entre os dois QWs [79], ao invés do potencial de confinamento dos poços-quânticos. É o principal canal de condução da amostra;

- segunda camada de espaçamento de AlGaAs (espessura $s_{1}$ ), separando o segundo QW da dopagem $\delta_{2}$, a seguir;

- a região-ativa propriamente dita acaba com a inserção de uma segunda camada de dopagem ( $s_{2}$ na figura 3.6), de igual ofício que a primeira e com concentração $\delta_{2}$. Na amostra $B, \delta_{1}=\delta_{2}$ para tornar (quase) simétrica a distribuição de cargas nos poços-quânticos. Já na amostra $A$ fizemos $\delta_{1} \neq \delta_{2}$ para induzir uma assimetria nessa distribuição de cargas;

- daqui para frente as camadas têm por função isolar a região-ativa da superfície. E para evitar a depleção de portadores das dopagens para a superfície, acrescenta-se uma terceira camada de dopagem $\left(\delta_{3}\right)$ que fornece os elétrons necessários para completar as ligações químicas insaturadas na superfície. Quando esta camada não está presente, como no caso da amostra $A$, este papel cabe à $\delta_{2}$ (por isso $\delta_{2}>\delta_{1}$ nessa amostra).

\section{Amostras para o estudo de localização-fraca}

As várias amostras deste conjunto diferem entre si pelo estágio evolutivo em que os pontosquânticos (QD, quantum-dots) se encontram e referir-nos-emos a esse estágio em termos da espessura nominal da camada de InAs ( $d_{\text {InAs, }}$ dada em monocamadas) depositada durante o crescimento das amostras (a seguir). Desta forma, pudemos abranger todos os estágios evolutivos dos QDs autoorganizados [45, cap. 2], desde as primeiras estruturas precursoras até a sua completa formação, quando já apresentam grande regularidade de tamanho e forma [3]. Utilizaremos seis amostras com espessuras nominais de 0 (amostra-referência) a 2,5 MC, todas com a seguinte estrutura básica:

- Substrato comercial semi-isolante de GaAs com orientação cristalográfica (001);

- buffer de $50 \mathrm{~nm}$ de GaAs;

- super-rede composta por 10 períodos de AlAs/GaAs, cada qual com 5 monocamadas de AlAs e 10 de GaAs. Esta camada tem aproximadamente $84 \mathrm{~nm}$ de espessura;

- outro buffer com $200 \mathrm{~nm}$ de GaAs afasta a região-ativa (a seguir) do substrato;

- a região-ativa inicia-se com uma monocamada de GaAs (camada $\delta$-Si) dopada com $4 \times 10^{16} \mathrm{~m}^{-2}$ $( \pm 10 \%)$ átomos de silício;

- spacer-layer com $7 \mathrm{~nm}$ de GaAs, separando a camada $\delta$-Si do poço-quântico de InGaAs; 


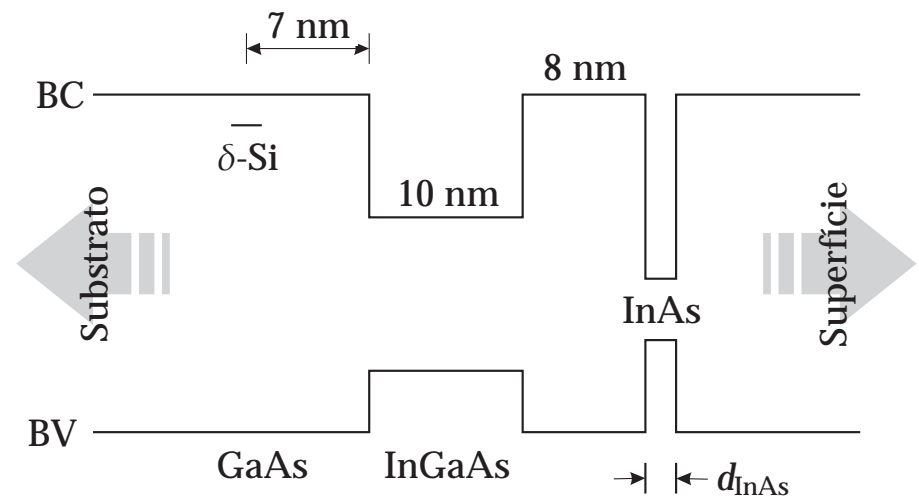

Figura 3.7.: representação do perfil de potencial da heteroestrutura das amostras contendo pontos-quânticos. O parâmetro que distingue as amostras é a espessura da camada de InAs: $d_{\text {InAs }}=0$ (amostra-referência), 1 MC, 1,5 MC (os QDs se formam a partir daqui), 1,75 MC, 2 MC e 2,5 MC.

- o poço-quântico de $\operatorname{In}_{x} \mathrm{Ga}_{1-\mathrm{x}} \mathrm{As}$ ( $\mathrm{x}=16 \%$, proporção atômica), com espessura de $10 \mathrm{~nm}$, constitui o principal canal de condução da heteroestrutura. $\mathrm{O}$ índice de proporção atômica (x) será omitido daqui para frente pois é constante em todas as amostras utilizadas. Assim, quando escrevermos InGaAs estaremos, na verdade, querendo dizer $\operatorname{In}_{\mathrm{x}} \mathrm{Ga}_{1-\mathrm{x}} \mathrm{As}$;

- segunda camada de espaçamento, de $8 \mathrm{~nm}$ de GaAs, separando o QW dos pontos-quânticos;

- a camada de InAs tem espessura nominal $d_{\text {InAs }}$ própria para cada amostra (fig. 3.7) e é nela que se formam os pontos-quânticos, quando $d_{\text {InAs }} \gtrsim 1,5 \mathrm{MC}$. Antes disso é apenas um poço-quântico muito delgado;

- outro buffer (50 nm de GaAs) separa a camada de InAs da cobertura (a seguir) e da superfície da amostra;

- finalmente, a cobertura consiste numa camada de $10 \mathrm{~nm}$ de GaAs uniformemente dopada com aproximadamente $10^{17}$ átomos de silício por $\mathrm{cm}^{3}$. Sua função é a mesma da camada $\delta_{3}$ da seção anterior (e, portanto, uma forma alternativa de evitar a depleção de portadores).

O perfil de potencial das bandas de condução e de valência (ponto $\Gamma$ ) da região-ativa está representada na figura 3.7.

Daqui para frente, referir-nos-emos a cada uma dessas amostras pela respectiva espessura nominal

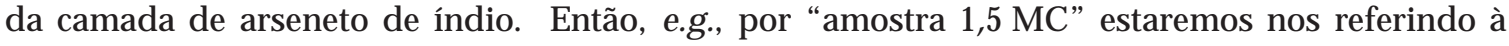
amostra deste conjunto cuja espessura nominal da camada de InAs é 1,5 MC. No caso da amostra $d_{\text {InAs }}=0$, poderemos nos referir a ela alternativamente por "amostra-referência."

\section{Amostras para o estudo relacionado aos QDIPs (1ํㅜ conjunto)}

A otimização da corrente fotogerada é feita empilhando-se unidades básicas (a seguir) da regiãoativa, formando diversos canais de condução (poços-quânticos, principalmente) paralelos até os contatos ôhmicos, conforme ilustra a figura 1.1 (p. 2). Quanto mais unidades básicas tivermos, maior será a corrente fotogerada. Mas ocorre que a sobreposição de heteroestruturas tensionadas (os pontos-quânticos) pode prejudicar a mobilidade [80], de modo que é preciso averiguar esta 


\section{Processos e equipamentos}

Tabela 3.1.: resumo das características da heteroestrutura estudada. As cinco amostras deste primeiro conjunto distinguem-se pelo número de períodos da heteroestrutura $2 \mathrm{MC}_{\mathrm{InAs}}+200 \AA_{\mathrm{GaAs}}$ inserido no buffer de $170 \mathrm{~nm}$ abaixo destacado: veja a figura 3.8.

\begin{tabular}{c|c|c} 
Camadas & Espessuras $(\mathrm{nm})$ & Observações \\
\hline \hline $\mathrm{GaAs}$ & \multicolumn{2}{|c}{ Substrato semi-isolante $(001)$} \\
\hline $\mathrm{GaAs}$ & 50 & Buffer \\
\hline$\left[(\mathrm{AlAs})_{5}(\mathrm{GaAs})_{10}\right] \times 10$ & 84 & Super-rede $(\mathrm{SR})$ \\
\hline $\mathrm{GaAs}$ & 20 & Buffer \\
\hline $\mathrm{GaAs}: \mathrm{Si}$ & $\sim 1 \mathrm{MC}$ & $n_{\mathrm{Si}}=4 \times 10^{12} \mathrm{~cm}^{-2}$ \\
\hline $\mathrm{GaAs}$ & 30 & Barreira anterior \\
\hline $\mathrm{In}_{\mathrm{y}} \mathrm{Ga}_{1-\mathrm{y}} \mathrm{As}$ & 10 & QW $(\mathrm{y}=16,534 \%)$ \\
\hline $\mathrm{GaAs}$ & 7 & Barreira posterior \\
\hline $\mathrm{GaAs}$ & 170 & Buffer \\
\hline $\mathrm{GaAs}: \mathrm{Si}$ & 10 & $3,0 \times 10^{17} \mathrm{~cm}^{-3}$ \\
\hline
\end{tabular}

influência no 2DES. Este foi o objetivo do primeiro conjunto de amostras desta parte do trabalho.

Nossa análise baseia-se em obter a mobilidade de transporte dos elétrons no canal das medidas de magnetorresistência e efeito Hall. Assim, para simplificar a análise dos dados, optamos por construir apenas um canal (um poço-quântico) e por colocar os pontos-quânticos fora dele. Fizemos isto por dois motivos: primeiro porque em medidas anteriores (não apresentadas aqui) em que os pontos-quânticos estavam dentro do poço-quântico, o 2DES tinha uma mobilidade tão baixa que não conseguimos definí-la. Segundo, porque a presença de vários 2DES parelelos poderiam levar a dificuldades que ocultariam a influência da tensão mecânica.

A figura 3.8 e a tabela 3.1 resumem a heterorestrutura das amostras deste conjunto. Todas elas possuem um plano de dopagem anteriormente ao poço-quântico de InGaAs e, em seguida, uma repetição de unidades básicas, cada qual composta por $2 \mathrm{MC}$ de InAs (pontos-quânticos) e $20 \mathrm{~nm}$ de GaAs. A quantidade de unidades básicas define as cinco amostras deste conjunto: 0 (amostrareferência), 1, 3, 5 e 7. Assim, a amostra 1 possui apenas um plano de pontos-quânticos (de $2 \mathrm{MC}$ de InAs), enquanto a amostra 5 MC possui 5: veja a figura 3.8. A amostra-referência não tem nenhuma camada de InAs e o perfil de potencial da amostra 1 é igual àquele apresentado na figura 3.7.

É importante notar que, em todas as amostras, a distância entre a borda posterior do poçoquântico e a superfície é fixa, independentemente da quantidade de camadas de pontos-quânticos que empilhamos. Isto é necessário para que a influência da superfície [81] seja a mesma em todas as amostras.

\section{Amostras para o estudo relacionado aos QDIPs (2ำ conjunto)}

O segundo e último conjunto de amostras foi projetado para que averiguássemos a melhor posição dos pontos-quânticos dentro do poço-quântico, de modo que a mobilidade de transporte do 2DES seja máxima. Isto equivale a dizer que o tempo de relaxação, o tempo de resposta e o tempo de vida 


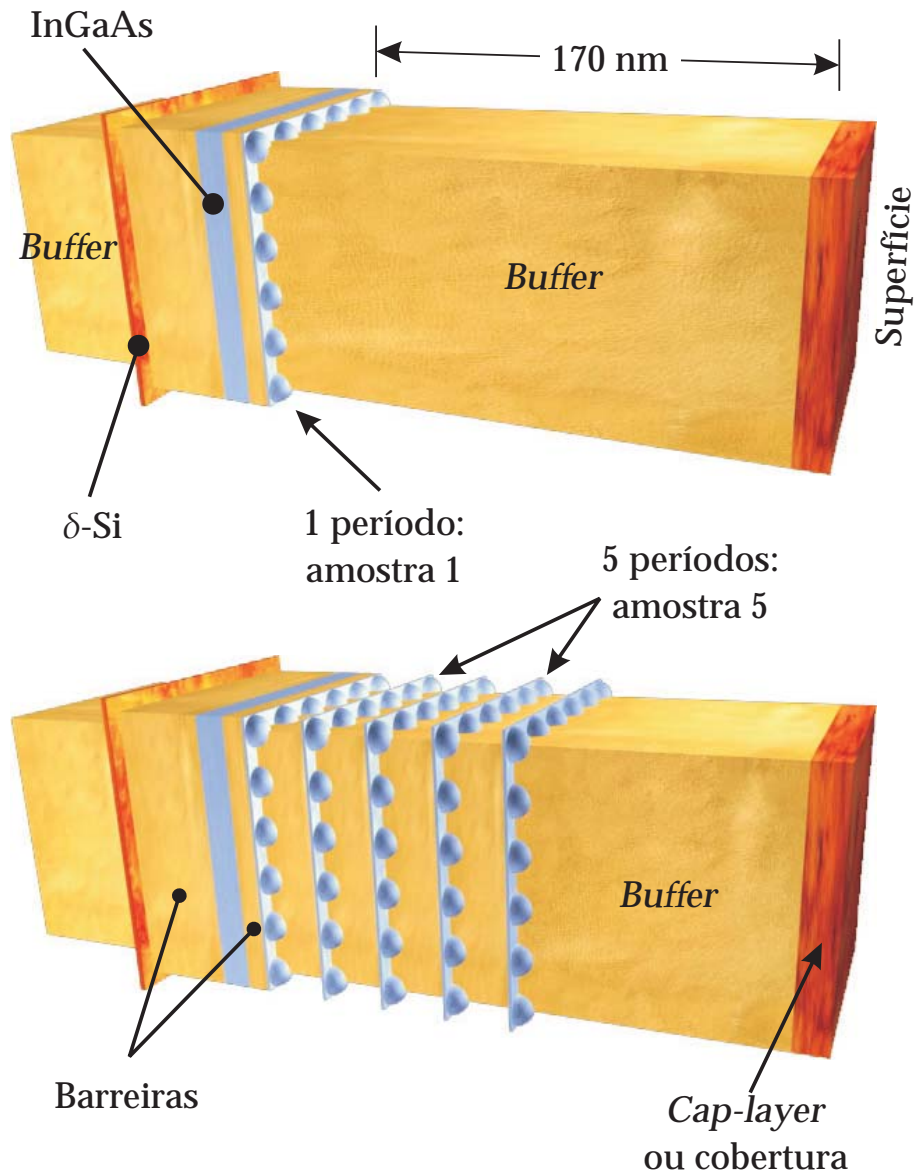

Figura 3.8.: ilustração das heteroestruturas das amostras 1 e 5, desde o início da região-ativa até a superfície. $\mathrm{O}$ crescimento ocorre da esquerda para a direita e neste sentido todas as camadas estão em escala. No plano perpendicular, as diferentes camadas são apresentadas com diferentes dimensões apenas para facilitar a visualização. As camadas em vermelho são regiões de GaAs dopado com silício ( $\delta$-Si e cobertura) e o poço-e os pontos-quânticos são apresentados em azul (regiões que contém In). Note que o buffer no qual são empilhados os pontos-quânticos possui sempre $170 \mathrm{~nm}$, independentemente da amostra, ou seja, da quantidade de planos com QDs empilhados. Isto é necessário para que as influências da superfície sobre o 2DES sejam não difiram de amostra para amostra.

do elétron fotogerado no estado excitado (do poço-quântico) são máximos.

A mobilidade é proporcional à sobreposição da função de onda dos elétrons no poço-quântico com a dos centros espalhadores [47], como dopagens, pontos-quânticos, interfaces, etc. Num poço-quântico quadrado os elétrons tendem a posicionarem-se junto da interface mais próxima da dopagem (veja os cálculos autoconsistentes de Cavalheiro [81], por exemplo). Neste caso, se os pontos-quânticos estiverem na interface oposta, a sobreposição será minimizada e, por conseguinte, a mobilidade será maximizada.

Já no caso de poços-quânticos parabólicos, os elétrons tendem a posicionarem-se no centro [82]. Mas como não é possível construir um bom poço-quântico parabólico de 20 nm (precisamos também

\footnotetext{
${ }^{6} \mathrm{Na}$ verdade, o tempo de vida é diferente do de relaxação [45], mas ambos decorrem da sobreposição da função de onda dos elétrons do 2DES com a dos centros espalhadores [47], de sorte que podemos dizer que são proporcionais.
} 


\section{Processos e equipamentos}

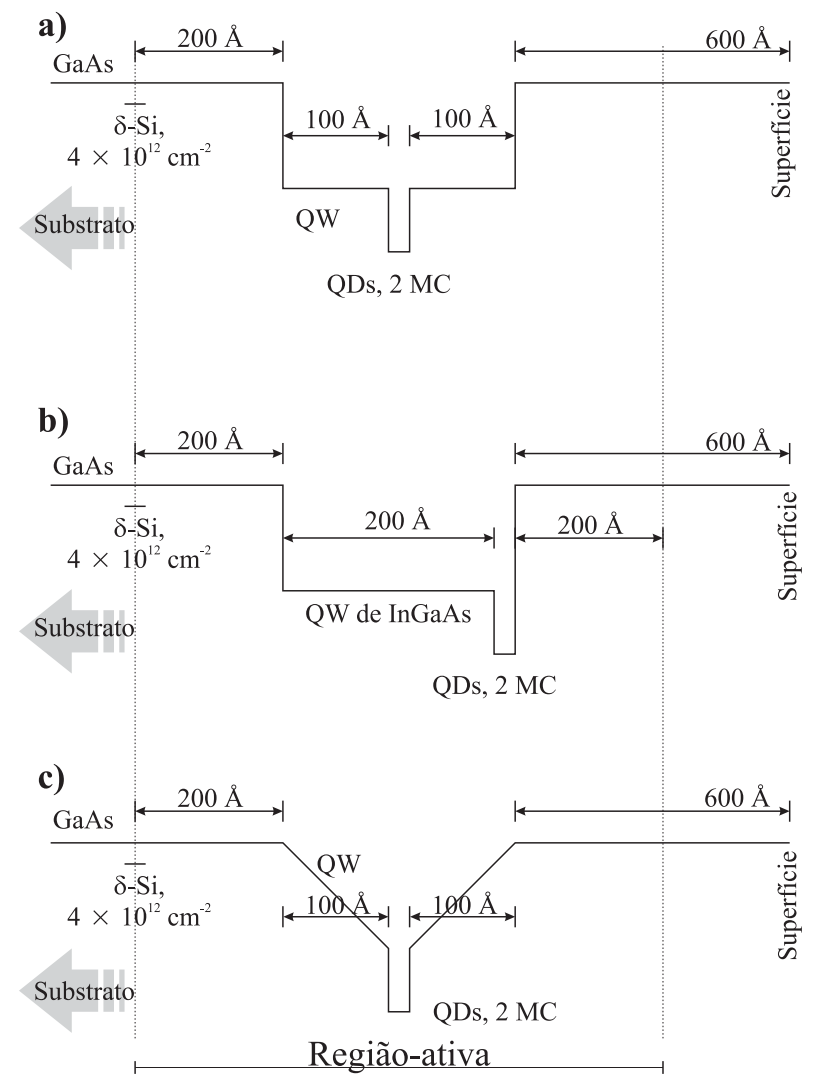

Figura 3.9.: perfil de potencial das amostras para pesquisa aplicada (somente a banda de condução está representada). Cada uma das figuras (a), (b) e (c) acima representa duas amostras: a primeira é simplesmente o que está desenhado, mas para a segunda a região-ativa demarcada representa um período dos dez existentes, ou seja, temos dez repetições consecutivas da região-ativa. Os pontos-quânticos de InAs estão representados como um poço-quântico estreito.

minimizar o tamanho do dispositivo, o que não seria muito efetivo se utilizássemos poços-quânticos parabólicos de $200 \mathrm{~nm}$, por exemplo), optamos por uma aproximação grosseira: uma variação linear do perfil de potencial (poço-quântico triangular).

A figura 3.9 ilustra o perfil de potencial da região-ativa das três amostras deste conjunto.

\subsection{Processos}

As medidas de transporte de cargas (capítulo 2) exigem alguma preparação prévia das amostras, a saber: (i) impressão da barra-Hall na amostra, (ii) corte, (iii) difusão dos contatos de índio (contato ôhmico), (iv) confecção da rede de antipontos-quânticos (opcional), (v) deposição do contato de controle ou gate (opcional) e (vi) a instalação dos terminais aos quais os equipamentos eletrônicos utilizados se conectam. A figura 3.10 ilustra uma amostra pronta para as medidas de transporte (consulte-a no decorrer das próximas seções). 


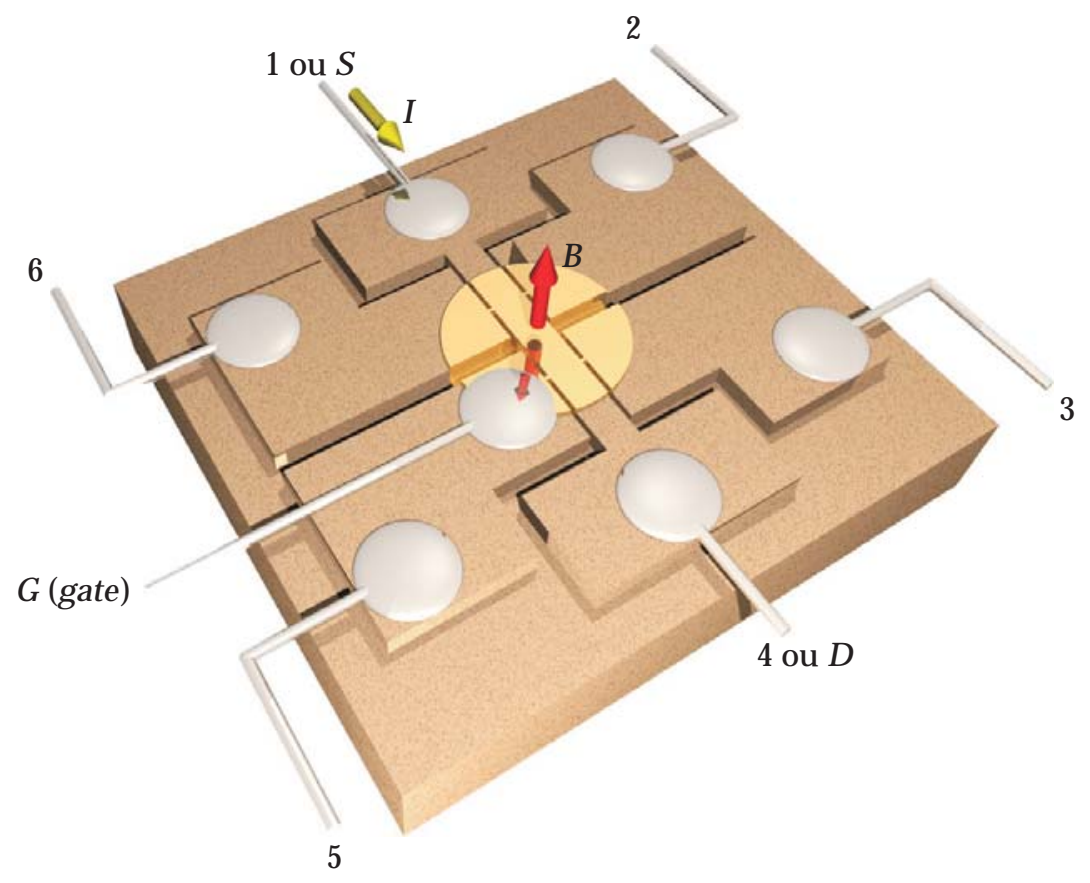

Figura 3.10.: amostra pronta para as medidas de transporte. A corrente elétrica é aplicada entre os contatos $S$ (fonte ou source) e $D$ (dreno ou drain), enquanto o contato $G$ (de controle ou gate) permite-nos modificar a concentração e a mobilidade dos elétrons nos canais (nos QWs). As medidas de magnetorresistência são feitas entre os contatos 2 e 3 (ou 5 e 6) e as do efeito Hall, entre os contatos 2 e 6 (ou 3 e 5).

\subsubsection{A barra-Hall}

Neste tipo de experimento é crucial que conheçamos a geometria da amostra. No nosso caso, por exemplo, trabalhamos com uma pequena região onde possamos assumir que a densidade de corrente seja uniforme. Uma geometria já bastante difundida neste sentido é a barra-Hall, ilustrada nas figuras 3.10 e 3.11. Somente na região em forma de "I" é permitido o fluxo de corrente elétrica e, apesar disso, a região de interesse consiste apenas na pequena área central, medindo $200 \mu \mathrm{m} \times 500 \mu \mathrm{m}$ (esta é a região ilustrada na figura 2.1). A corrente, fornecida por uma fonte de tensão, percorre a amostra no sentido $D \rightarrow S$ (dreno $\rightarrow$ fonte) e as medidas de tensões são feitas entre os contatos 2 e 3 (ou 5 e 6) para as medidas de magnetorresistência (efeitos Shubnikov-de Haas, localização-fraca e interações entre elétrons) e entre 2 e 6 (ou 3 e 5) para o efeito Hall (clássico e quântico). Uma geometria alternativa é a de Van-der Pauw [44], extensamente utilizada por nós em medidas de teste para avaliar rapidamente a concentração total de portadores e a mobilidade de transporte.

A implantação da barra-Hall nas amostras foi feita através de um processo litográfico no Laboratório de Microeletrônica (LME) da Escola Politécnica da Universidade de São Paulo: primeiramente devemos limpar a amostra com acetona e secá-la com nitrogênio gasoso; depois, fixamo-la (a vácuo)

\footnotetext{
${ }^{7}$ A figura 3.11 ilustra uma fonte de corrente apenas para simplificar o desenho. Um esquema mais correto das conexões eletrônicas é apresentado na figura 3.18, na página 53.
} 


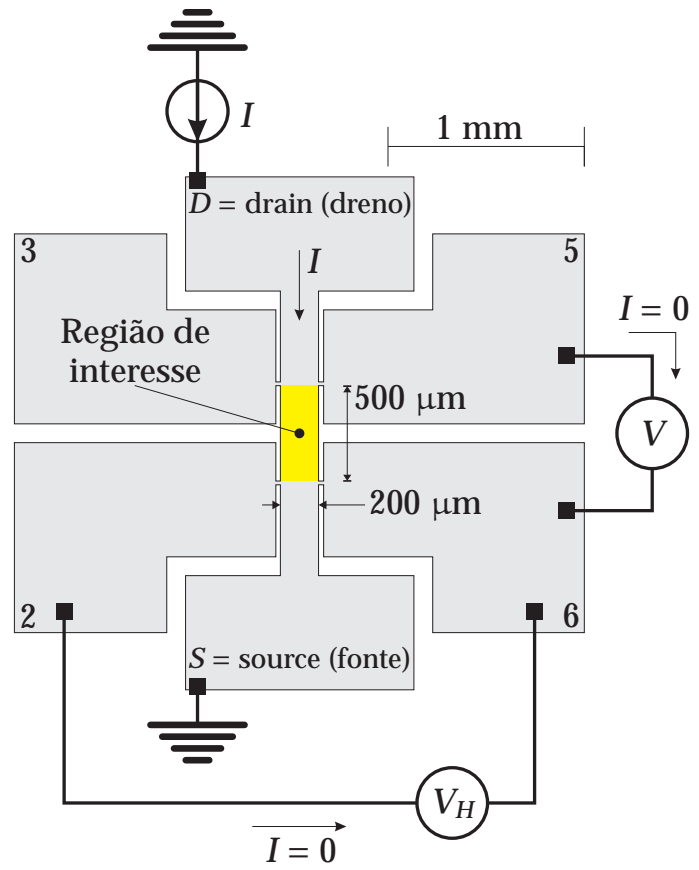

Figura 3.11: vista em planta da barra-Hall (compare com a figura anterior). A corrente elétrica é aplicada através dos contatos 1 (fonte ou source) e 4 (dreno ou drain) e mantém-se apenas na região central (em forma de "I"). A região de interesse é acessada por contatos instalados nas periferias, através dos quais efetuamos as medidas de magnetorresistência e efeito Hall.

pela base (substrato) em uma aparelho chamado spinner (que pode ser grosseiramente comparado a uma centrifugadora), pingamos algumas gotas de revelador fotosensível (fotorresiste) e fazemola girar durante algum tempo. Este passo deve ser feito sob luz amarela para que o fotorresiste não seja sensibilizado incorretamente. Com isso o fotorresiste fica espalhado uniformemente pela superfície da amostra. Em seguida, colocamos a amostra em forno a $80{ }^{\circ} \mathrm{C}$ por vinte minutos; depois posicionamos a máscara da barra-Hall sobre a amostra e incidimo-lhe luz ultra-violeta por 10 s. Deste modo, a parte do fotorresiste que não estava protegida pela máscara é sensibilizada. Agora, mergulhamos a amostra no revelador por aproximadamente trinta segundos, imergimo-la em água e a secamos novamente com $\mathrm{N}_{2}$. A revelação extrai o fotorresiste não-sensibilizado e, assim, o ataque químico a seguir não agride a região protegida pelo fotorresiste sensibilizado. $\mathrm{O}$ tempo do ataque químico depende da amostra e dos objetivos que queremos atingir. No caso de heteroestruturas como a nossa, entretanto, uma regra prática é usar um minuto de ataque para cada 1000 Å. Finalmente, retiramos o fotorresiste: a barra-Hall está instalada e a amostra está pronta para receber os contatos: fig. 3.11.

\subsubsection{Contato ôhmico}

Exceto pelo contato de controle (gate na fig. 3.10), todos os outros contatos são de índio, do tipo ôhmico. Um contato ôhmico é uma junção metal-semicondutor com comportamento ôhmico, isto é, no qual a relação entre a corrente elétrica e a tensão através da amostra é linear (neste tipo de junção, a função de trabalho do metal é menor que a do semicondutor, cf. ref. 83). Esses contatos são utilizados tanto para aplicar a corrente elétrica como para medir as diferenças de potencial oportunas. 
Para confeccioná-los, utilizamos o método de difusão, que consiste simplesmente em repousar um pouco de índio nas bordas da barra-Hall (nas regiões numeradas da figura 3.11) e, em seguida, aquecê-lo a $300{ }^{\circ} \mathrm{C}$ por alguns minutos (quatro, especificamente) numa atmosfera saturada de nitrogênio. Nessas circunstâncias o índio difunde verticalmente e forma um canal metálico ao longo de toda a heteroestrutura, que nos dá acesso à região-ativa, a porção da heteroestrutura que possui a estrutura de interesse (veja o capítulo 4). Por fim, é útil soldar terminais de ouro ou alumínio ${ }^{8}$ a esses contatos de modo a facilitar as conexões com os equipamentos eletrônicos.

Vimos no capítulo anterior que quando as medidas envolvem o transporte não dissipativo de cargas, como no caso do efeito Hall quântico, os estados estendidos localizam-se nas bordas da amostra. Por conta disso os contatos ôhmicos devem ser difundidos nas bordas da barra-Hall. Caso contrário um voltímetro ali conectado mediria a diferença de potencial entre estados localizados, que não conduzem a corrente elétrica. Exceto por este caso, não importa a posição dos contatos.

Outro detalhe experimental importante é que aos terminais de medida (2, 3, 5 e 6 nas figuras 3.10 e 3.11) são conectados instrumentos de alta impedância, o que torna nula a corrente entre o "I" central da barra-Hall e esses contatos. Com isso, a diferença de potencial entre os pontos 2 e 3 da figura 3.11, por exemplo, é precisamente a mesma entre as extremidades inferior e superior da região de interesse. Mais que isso, como a corrente é nula, a resistência dos contatos 2 e 3 (considerável quando há poucos modos de condução, como no caso do transporte não dissipativo associado ao efeito Hall quântico) não influencia a medida.

\subsubsection{Contato de controle (gate ou porta)}

O gate ou contato de controle, muito utilizado em transístores de efeito de campo (FET, field effect transistor), é um contato não-ôhmico cuja função é modificar a concentração de portadores e, com isso, controlar a corrente elétrica entre o dreno e a fonte (fig. 3.11). Há três tipos: o primeiro é aquele utilizado nos JFETs (junction FET), constituído de uma junção pn polarizada reversamente (fig. 3.12a); o segundo tipo utiliza uma junção metal-semicondutor do tipo Schottky (o outro tipo de junção metal-semicondutor é o ôhmico), utilizado nos MESFETs (metal-semicondutor FET, fig. 3.12b); e no terceiro existe uma delgada camada isolante (geralmente dióxido de silício) entre o contato metálico e a superfície do dispositivo, como nos MOSFETs (metal oxide semiconductor FET, fig. 3.12c).

Em qualquer um deles a concentração de portadores é controlada através da diferença de potencial entre o gate e a fonte $\left(V_{G S}\right)$, que cria uma região de depleção nos arredores do gate. Trata-se basicamente de um capacitor, onde uma das placas é o contato metálico e a outra, o gás de elétrons (veja a ref. 84, por exemplo). E diferentemente dos contatos ôhmicos, não há (idealmente) fluxo de cargas entre o gate e o 2DES, a chamada corrente de fuga (ou leakage).

Em todas as nossas amostras utilizamos os tipos dois e três acima, e ouro como contato metálico.

\footnotetext{
${ }^{8}$ Fios de cobre não são recomendados porque em baixas temperaturas eles se tornam rígidos, introduzindo tensões mecânicas que podem quebrar os contatos ou, mais sutilmente, torná-los não-ôhmicos. Alumínio, por outro lado, não tem boa aderência ao índio.
} 


\section{Processos e equipamentos}

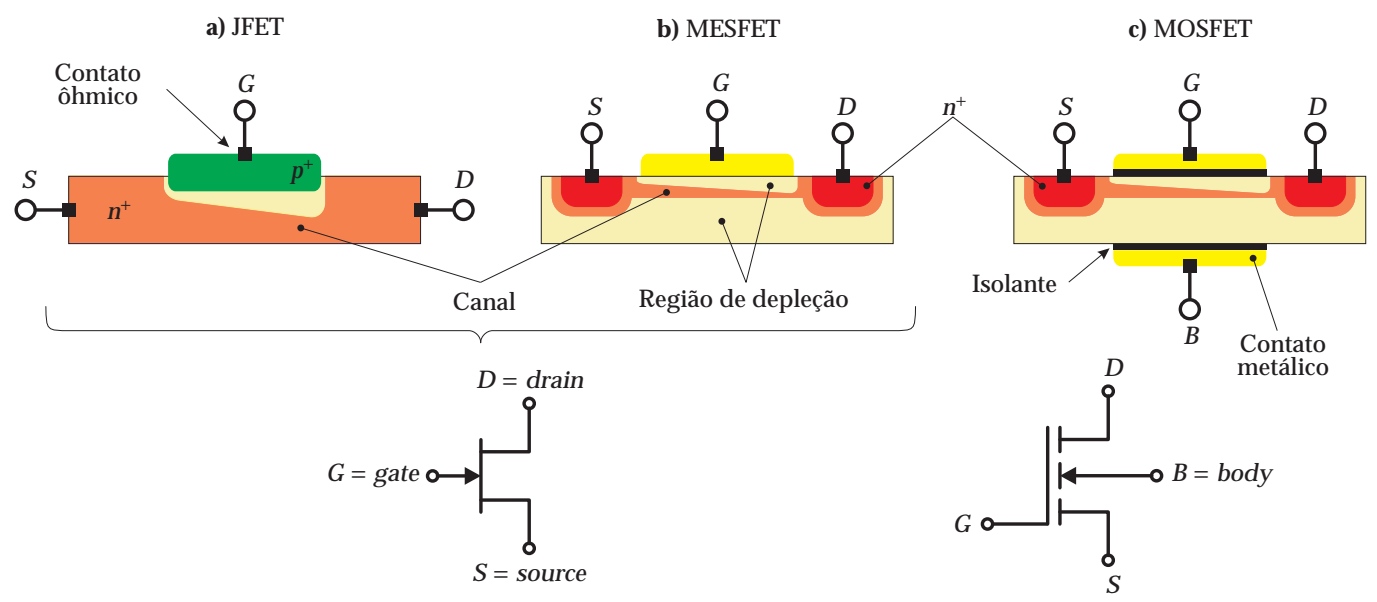

Figura 3.12.: os três tipos de gate utilizados em transístores de efeito de campo e seus os símbolos eletrônicos: (a) de junção, (b) Schottky e (c) MOS. Nas nossas amostras, utilizamos os dois últimos.

Nas amostras com super-rede de antipontos-quânticos (p. 49) o gate é basicamente do tipo MOS, exceto que o PMMA sobre o qual efetuamos a litografia dos antipontos exerce o papel de isolante (ao invés do óxido). Entretanto, nessas amostras pode ocorrer de na região dos furos não haver PMMA após a revelação. Neste caso, o gate é do tipo Schottky. Nas outras amostras o contato de controle é exclusivamente Schottky: um filme de ouro de $500 \mathrm{~nm}$ ou, alternativamente, um de titânio $(80 \mathrm{~nm})$ seguido por outro de ouro (20 nm).

\section{Confecção}

O procedimento de confecção dos contatos de controle consiste basicamente na evaporação e subsequente deposição do metal (ouro e/ou titânio) sobre a superfície da amostra.

Utilizando um pequeno pedaço de acetato (suficiente para cobrir por completo a amostra) com um furo central de aproximadamente $1 \mathrm{~mm}$ de diâmetro, colocamo-lo sobre a amostra, tomando o cuidado de posicionar o furo sobre a região de interesse, conforme ilustra a figura 3.13. Feito isso, a amostra é colocada numa câmara de vácuo, dentro da qual encontra-se um cadinho metálico verticalmente alinhado com a amostra e que sustenta o metal a ser evaporado, conforme ilustra a figura 3.14.

O aquecimento do metal é feito através do efeito Joule, ao aplicarmos uma corrente elétrica constante através do cadinho, e o fluxo de evaporação é medido através da oscilação de um cristal próximo da amostra, cuja freqüência muda conforme os átomos do metal evaporado são depositados sobre ele. Inicialmente, a evaporação é inconstante e por isso o processo começa com o obturador ainda fechado (ou seja, sem expor a amostra), mas após alguns segundos abre-se o obturador e a amostra é exposta. Conhecendo a taxa de deposição do ouro/titânio no cristal (da ordem de $\AA / \mathrm{s}$ e supostamente igual àquela sobre a amostra), podemos depositar o filme metálico com acurácia e precisão de um ou dois nanometros.

Os primeiros filmes metálicos com os quais trabalhamos (confeccionados no Instituto de Física 


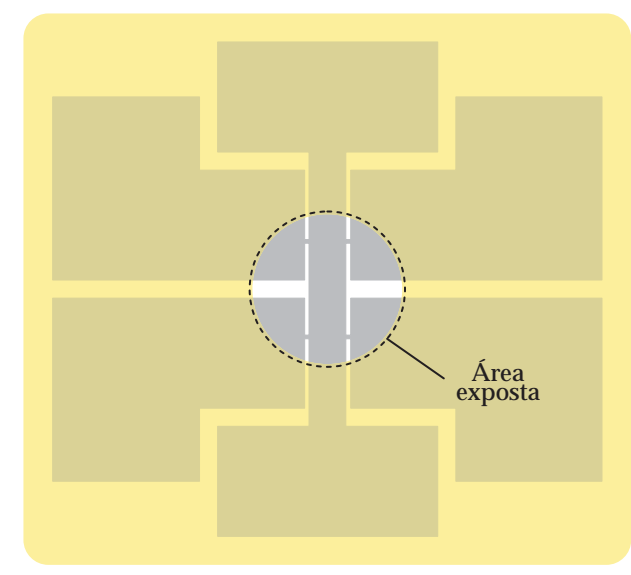

Figura 3.13.: a região da amostra abaixo do furo no acetato (amarelo) fica exposta ao fluxo de ouro/titânio, que ali forma um filme delgado desse metal (20 nm no caso do ouro e $80 \mathrm{~nm}$ no do titânio). A região protegida permanece inalterada.

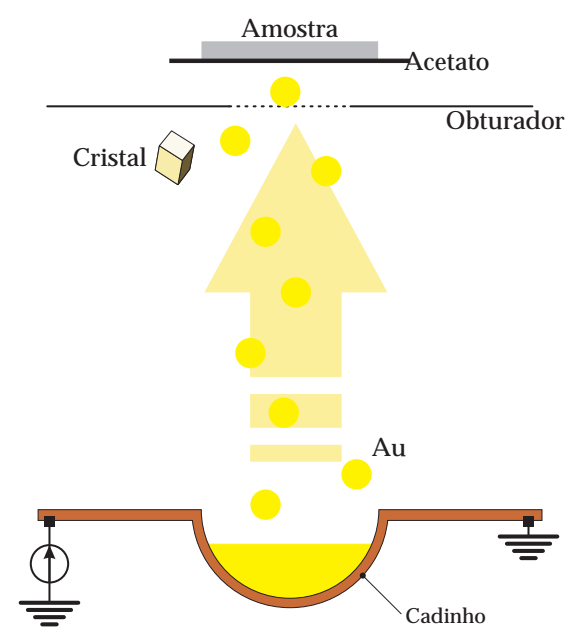

Figura 3.14.: câmara de evaporação do ouro e titânio, sob vácuo. O metal no cadinho é fundido através do efeito Joule e o fluxo de evaporação, medido através das oscilações do cristal. O obturador aberto expõe a amostra ao metal evaporado.

da USP de São Carlos, IFSC) eram feitos de ouro apenas (500 nm), mas ocorre que o ouro difunde no GaAs mesmo a temperatura ambiente, de modo que após algum tempo ele conecta-se com o gás de elétrons, destruindo a amostra. Por conta disso, mais recentemente (no Instituto de Física da Universidade de Campinas, UNICAMP) passamos a depositar um filme de titânio de $80 \mathrm{~nm}$, que funciona como barreira de difusão, antes do ouro (20 nm).

É possível também utilizar um processo mais refinado, no qual o acetato é substituído por fotorresiste sensibilizado e o posicionamento, feito através de uma alinhadora, similarmente ao processo de litografia da barra-Hall. Mas isto torna o processo mais oneroso e contribui pouco para a melhoria da qualidade do gate, conforme pudemos verificar. Além disso, este método não poderia ser utilizado nas amostras com super-rede de antipontos pois o fotorresiste cobriria os furos do PMMA (a seguir), impedindo o ouro de ficar em contato direto com a superfície da amostra nessas regiões.

Finalmente, colamos com prata ou soldamos com índio um terminal de ouro no gate, através do qual conectamos a amostra aos instrumentos eletrônicos.

\section{Funcionamento}

O efeito básico do contato de controle é fixar externamente o potencial da superfície, forçando a heteroestrutura a ajustar-se a ele através da redistribuição de cargas. A figura 3.15 ilustra essa transferência para uma amostra de poço-quântico duplo: fixamos a energia dos elétrons nos poços-

quânticos em zero aterrando a amostra através do dreno. Simultaneamente, fixamos a energia potencial elétrica na superfície em $-e V_{G S}$ através de uma fonte de tensão. Quando $V_{G S}>0$ as bandas de condução e de valência são dobradas para baixo, reduzindo a energia dos elétrons na 


\section{Processos e equipamentos}

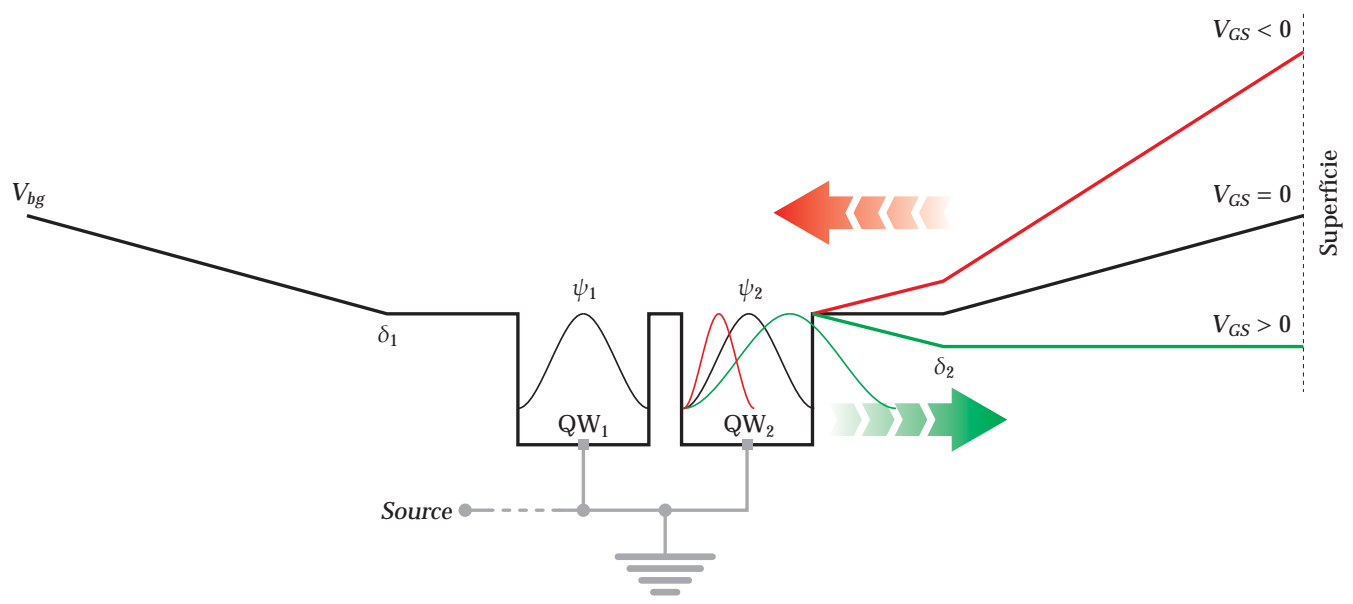

Figura 3.15.: representação da influência do front-gate (tensão $V_{G S}$ ) no perfil de potencial da banda de condução (por clareza, omitimos a banda de valência) de uma heteroestrutura de poços-quânticos duplos aterrados. Quando $V_{G S}>0$ os elétrons são atraídos para a superfície (seta verde), reduzindo a concentração deles no $Q W_{2}$; quando $V_{G S}<0$, eles são repelidos (seta vermelha) e a concentração aumenta. Este rearranjo de cargas também modifica a função de onda dos elétrons e, por conseguinte, a mobilidade deles. Os elétrons no poço-quântico 1 não são afetados significativamente por $V_{G S}$, embora o sejam (similarmente) pelo back-gate $\left(V_{b g}\right)$.

superfície e, portanto, favorecendo a transferência de cargas do $\mathrm{QW}_{2}$ para a dopagem $\delta_{2}$ e para a superfície (mas não para o gate: a corrente no ramo que o alimenta é idealmente nula). A concentração do $\mathrm{QW}_{1}$ permanece aproximadamente constante [85, 86]. Por outro lado, $V_{G S}<0$ repele os elétrons da superfície e da dopagem para o poço-quântico, aumentando a concentração de elétrons em $\mathrm{QW}_{2}$. Representamos este fenômeno dobrando as bandas de condução e de valência para cima. Novamente, a concentração de portadores em $\mathrm{QW}_{1}$ permanece inalterada.

A densidade de portadores em $\mathrm{QW}_{1}$ pode ser alterada através de um back-gate (fig. 3.15), um contato de controle construído atrás da heteroestrutura; no substrato, por exemplo (como o contato body [84] do MOSFET na figura 3.12). A fenomenologia é exatamente a mesma do então front-gate, acima explicado. Nós não utilizamos back-gate.

A aplicação da tensão de gate também tem influência na mobilidade dos elétrons, haja vista que a modificação nas funções de onda dos elétrons altera sua sobreposição (overlap) com os centros espalhadores [47]. Por exemplo: ainda na situação descrita acima, quando a superfície repele os elétrons do $2 \mathrm{DES}\left(V_{G S}<0\right)$, a despeito de qualquer variação na densidade de portadores em $\mathrm{QW}_{2}$, a função de onda desses elétrons é deslocada para a esquerda; para longe da dopagem $\delta_{2}$. Logo, podemos esperar uma redução na taxa de espalhamento devido aos íons da dopagem ou, equivalentemente, um aumento na mobilidade desses elétrons. Mas diferentemente da concentração, a dependência da mobilidade com a tensão de gate está intimamente relacionada com a heteroestrutura. 


\subsubsection{A rede de antipontos-quânticos}

A (super-) rede de antipontos-quânticos (ou antidots) é essencialmente um padrão bidimensional de buracos mecânicos aproximadamente cilíndricos num filme de PMMA (polimetilmetacrilato), um polímero da família do vinil, que recobre a superfície da amostra e preenchidos com um condutor: figura 3.16. Este padrão ocupa toda a região de interesse e sua função em nosso trabalho é simular um padrão organizado (hexagonal, no caso) de centros espalhadores.

\section{Confecção}

O primeiro passo do processo é depositar o filme de PMMA (200 nm de espessura) sobre a superfície da amostra, exatamente como depositamos o fotorresiste para a litografia da barra-Hall. A diferença reside apenas na receita.

Os buracos no filme de PMMA são feitos por eletrolitografia, ou seja, são literalmente desenhados com um feixe eletrônico (e-beam) de alta energia (algumas dezenas de keV). Em verdade qualquer desenho pode ser feito através de um software CAD (computer aided desing) e, dependendo do equipamento, até mesmo fotografias podem ser impressas na superfície da amostra. No nosso caso, utilizamos o microscópio eletrônico de varredura (SEM, scanning electron microscope) do Laboratório de Sistemas Integrados (LSI) da Escola Politécnica da USP (EPUSP), e nosso desenho consiste apenas numa matriz hexagonal de pontos com $0,4 \mu \mathrm{m}$ de distância entre eles. O diâmetro desses furos $(\sim 0,2 \mu \mathrm{m})$ é controlado pelo tempo de exposição de cada ponto ao feixe de elétrons (alguns microsegundos).

Após posicionada na câmara de vácuo do SEM, precisamos posicionar o foco do feixe de elétrons no centro da região de interesse, a partir do qual a super-rede será desenhada. Como o microscópio gera imagens a partir da difração do feixe de elétrons, precisamos dele ligado para podermos observar e posicionar o e-beam. Por outro lado, não podemos "iluminar" a região de interesse com o feixe pois ele sensibilizaria o PMMA, inutilizando-o para a exposição posterior do padrão que nos interessa. Para resolver este problema, reduzimos o campo de visão, procuramos por referências nas periferias da barra-Hall e, com base no conhecimento prévio de suas dimensões, posicionamos manualmente o feixe desligado no centro da região de interesse. Feito isso basta executar o software do SEM e deixá-lo desenhando a super-rede.

Depois de exposto ao feixe de elétrons, efetuamos a revelação, processo químico no qual as regiões no PMMA sensibilizadas pelo feixe (os pontos) são removidas. A reação química ocorre à temperatura constante de $25^{\circ} \mathrm{C}$, onde as moléculas sensibilizadas de PMMA ligam-se com o revelador (ARP-600) e são removidas por agitação manual. Neste estágio o PMMA aparenta-se com uma peneira, cobrindo toda a superfície da amostra, exceto nas regiões dos furos: figura 3.16.

Embora o procedimento descrito acima seja basicamente simples, existe um sem número de parâmetros que precisam ser otimizados para obtermos bons resultados. Exemplos são a intensidade do feixe e o tempo de exposição de cada antidot. Particularmente, um dos pontos de maior dificuldade foi a influência dos contatos de índio (necessariamente já presentes quando da exposição 


\section{Processos e equipamentos}
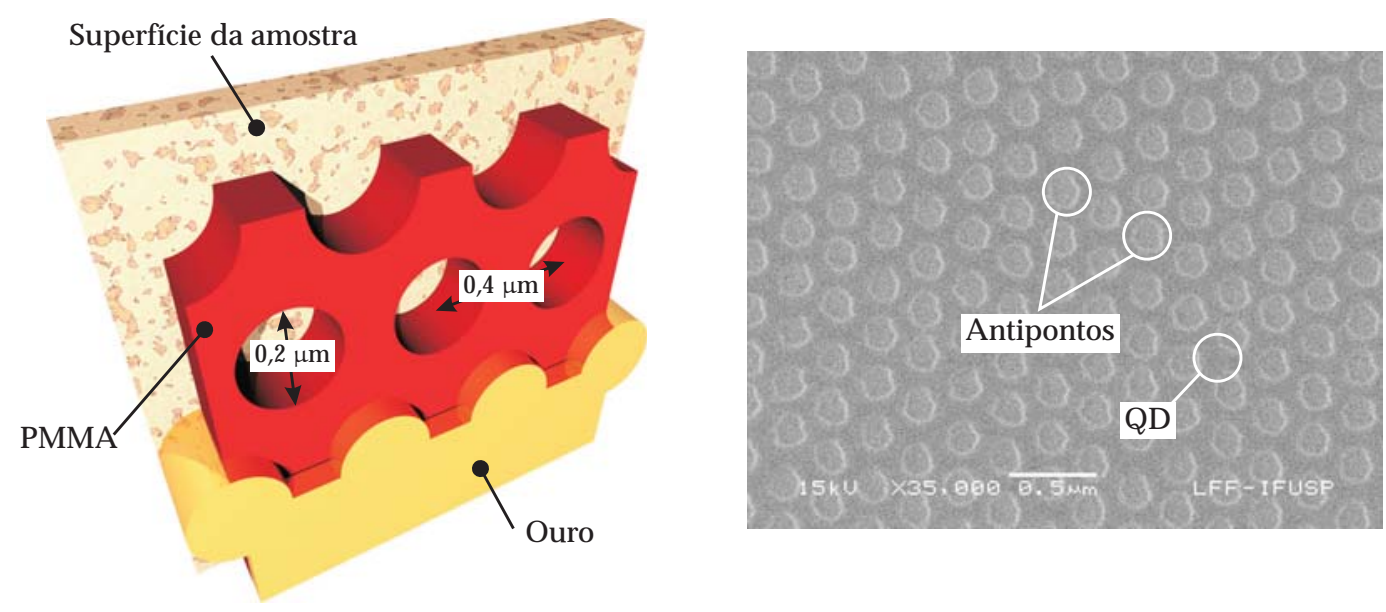

Figura 3.16.: à esquerda, representação da rede de antipontos-quânticos. Cada furo no PMMA é um antipontoquântico e entre eles, os pontos-quânticos de forma triangular. À direita, imagem da rede obtida no próprio SEM, com ampliação de 35 mil vezes. Há aproximadamente meio milhão de antipontos sobre toda a região de interesse.

ao e-beam $)^{9}$ na espessura do filme de PMMA, tornando-o não uniforme; outro foi nossa escolha de antidots distanciados de $0,4 \mu \mathrm{m}$, bastante próximo da resolução do aparelho. De fato, consumimos quase seis meses para conseguir super-redes aceitáveis e ainda assim o sucesso do processo é estatístico: somente $20 \%$ das amostras apresentam bons resultados.

Finalmente, recobrimos a superfície da amostra com ouro e instalamos um terminal de controle, conforme explicado na seção 3.3.3. Esta parte do processo foi feita no Instituto de Física da USP de São Carlos e o resultado final pode ser visto na figura 3.16.

\section{Funcionamento}

Podemos ver na figura 3.16 que, depois de finalizada, a super-rede de antipontos-quânticos é um contato de controle híbrido dos tipos Schottky (nos furos) e MOS (entre eles).

Ao fixarmos o potencial no terminal de controle em $V_{G S}$, o potencial na superfície da amostra será fixado neste valor somente nas regiões dos furos, onde o ouro está em contato com a superfície (barreira Schottky); nos interstícios, onde há PMMA separando a superfície do ouro, o potencial da superfície será ligeiramente menor (em módulo), dando origem a um potencial eletrostático que reflete a geometria estabelecida pela litografia, conforme ilustra a figura 3.17. Em outras palavras, as bandas de condução e de valência são modificadas (cf. fig. 3.15) mais nas regiões dos furos que dos interstícios.

Este padrão é difundido ao longo da heteroestrutura, da superfície até o poço-quântico mais próximo, onde o front-gate ainda tem influência [85, 86]. Por conseguinte, o 2DES fica submetido a um potencial de espalhamento periódico conhecido e, dependendo da razão entre a distância entre eles e o caminho livre médio, sua influência pode ser analisada clássica $[87,88]$ ou quanticamente [36,

\footnotetext{
${ }^{9}$ Caso contrário o PMMA sublimaria durante a difusão dos contatos, a $400{ }^{\circ} \mathrm{C}$, conforme pudemos verificar.
} 
Figura 3.17: energia potencial da superfície em função da posição no plano $x y$. A presença da super-rede de antipontos-quânticos faz com que a tensão aplicada no terminal de controle não seja a mesma em todo ponto $(x, y)$ da superfície: nos furos, onde o ouro está em contato com a superfície, ela é igual a $-e V_{G S}$; nos interstícios, onde há PMMA isolante, é um pouco inferior (em módulo).

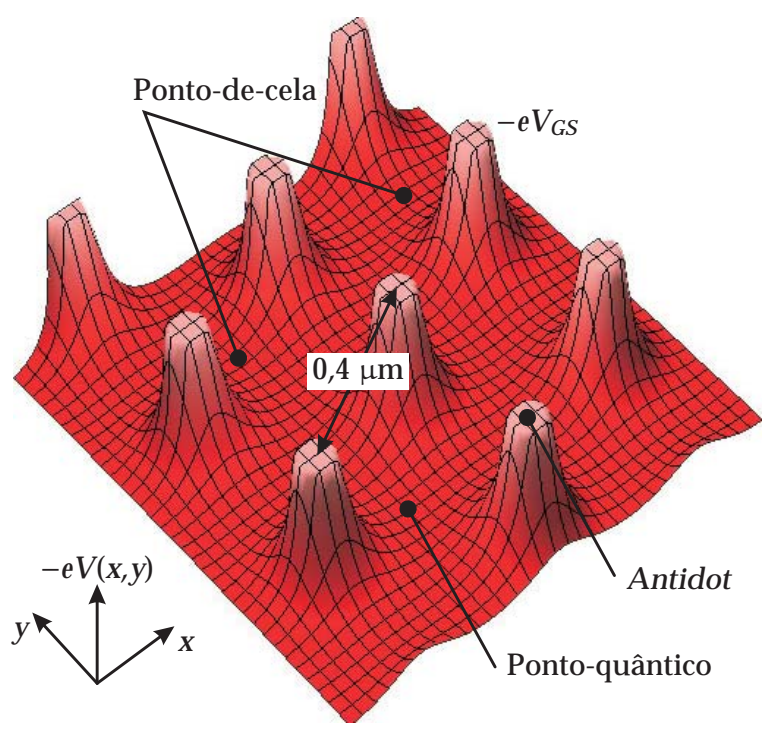

89]. No nosso caso, o comprimento de onda dos elétrons no nível de Fermi está entre 50 e $80 \mathrm{~nm}$, apenas algumas vezes menor que a distância entre os furos $(0,4 \mu \mathrm{m})$, de modo que os fenômenos observados são manifestações do estado quântico.

A despeito de interpretarmos a super-rede de antipontos-quânticos como um potencial de espalhamento periódico, ela é essencialmente um gate e como tal altera a concentração e a mobilidade dos elétrons, conforme vimos anteriormente. Contudo, devido à presença do PMMA e à pequena área de contato do ouro com a superfície da amostra (aproximadamente 10\%), a variação é pequena, conforme veremos no próximo capítulo.

Finalmente, observe que quando $V_{G S}<0$ o potencial eletrostático de cada furo é repulsivo, em oposição àquele de um ponto-quântico; daí o nome "antiponto-quântico" (quando $V_{G S}>0$ são os interstícios que assumem o papel de antidots). E particularmente no caso da rede hexagonal, o potencial da rede apresenta mínimos locais nos interstícios, tornando possível o confinamento de elétrons ali. Isto é, formam-se pontos-quânticos ali (fig. 3.17). Por esta razão, usamos os termos super-rede de antipontos e de pontos-quânticos como sinônimos.

\subsection{Equipamentos}

Todos os estudos apresentados aqui têm como base medidas de magnetorresistência e do efeito Hall em baixas temperaturas ( 0,05 a $5 \mathrm{~K})$. Elas foram realizadas em parte no próprio Laboratório de Novos Materiais Semicondutores (LNMS) do Instituto de Física da USP/SP e em parte no Laboratorie du Champs Magnetiques Intenses (LCMI) do Centre National de la Recherche Scientifique (CNRS), na França. As instalações nesses dois laboratórios são conceitualmente iguais, embora difiram por alguns equipamentos utilizados (especialmente no caso do sistema de vácuo, que não trataremos aqui). 


\section{Processos e equipamentos}

\subsubsection{Criogenia e vácuo}

As baixas temperaturas utilizadas neste trabalho foram obtidas através de três criostatos de banho (bath cryostat): de hélio-4, de hélio-3 e de diluição. No primeiro a amostra fica imersa em ${ }^{4} \mathrm{He}$ e atinge temperaturas pouco superiores a 1,4 K aproximadamente. Na segunda técnica de refrigeração a amostra fica imersa em ${ }^{3} \mathrm{He}$, entre 1,4 e 0,25 K. Finalmente, no criostato de diluição (dilution fridge) a amostra fica imersa numa mistura de hélio-3/hélio-4 que atinge temperaturas tão baixas quanto $50 \mathrm{mK}[90]$.

\subsubsection{Eletrônica}

A figura 3.18 ilustra a instalação eletrônica utilizada no LCMI, que difere daquela no IF-USP/SP apenas pela inexistência do ramo associado ao segundo lock-in, o que nos impede de medir $V$ e $V_{H}$ simultaneamente. Remediamos isto alternando a entrada do amplificador entre os contatos 5 (neste caso medimos $V$ ) e $2\left(V_{H}\right)$, mantendo o contato 6 inalterado (comum a ambas as medidas).

A idéia básica da medida é fixar uma corrente elétrica que percorre a amostra com uma fonte de corrente e medir a diferença de potencial paralela $(V)$ e perpendicularmente $\left(V_{H}\right)$ ao fluxo de cargas com um multímetro. O que difere disto é para otimizar a medida. Então acompanhemos o esquema: primeiramente, visando reduzir o ruído eletrônico nas medidas, utilizamos um lock-in (EG\&G 5210) ao invés de um multímetro para medir $V$ e $V_{H}$. Este equipamento (basicamente, um multímetro melhorado) espera receber como entrada o sinal a ser medido modulado por um sinal de referência ac conhecido. Este sinal pode ser fornecido externamente ou, como preferimos, pelo próprio lock-in, na forma de uma fonte de tensão de onda quadrada de 1 V/11 Hz (ajustáveis). Assim, utilizamos este sinal para alimentar a amostra (contatos source e drain) e como referência para ambos os lock-ins. A corrente é definida e estabilizada através da carga resistiva $R_{L}$, escolhida através da chave $\mathrm{CH}$, em série com a amostra. Esta chave permite-nos ainda verificar o caráter ôhmico dos contatos: a corrente elétrica na amostra, dada por $1 \mathrm{~V} / R_{L}$, varia conforme escolhemos valores diferentes de $R_{L}$. Como resultado, a tensão $V$ sobre a amostra (lida no visor do lock-in) deve variar conforme a primeira lei de $\mathrm{Ohm}$.

As diferenças de potencial $V$ e $V_{H}$ são então medidas pelos lock-ins [opcionalmente, elas podem ser pré-amplificadas analogicamente (EG\&G 5186)] e enviadas a um conversor analógico-digital (HP 34401A), que por seu turno envia o resultado da medida para um computador (via GPIB, gerenal purpose interface bus), registrando-os em arquivos de texto. O computador também controla o campo magnético, através de uma fonte OXFORD IPS 120A-10V.

Recusos adicionais são o terminal de controle e o LED vermelho. O primeiro é controlado por uma fonte de tensão e o segundo, por uma de corrente (KEITHLEY 224), ambos operados manualmente. A iluminação da amostra tem efeito similar a aplicar $V_{G S}>0$, ou seja, é utilizado para aumentar a concentração de portadores, geralmente como ferramenta na determinação das propriedades do 2DES [91]. 


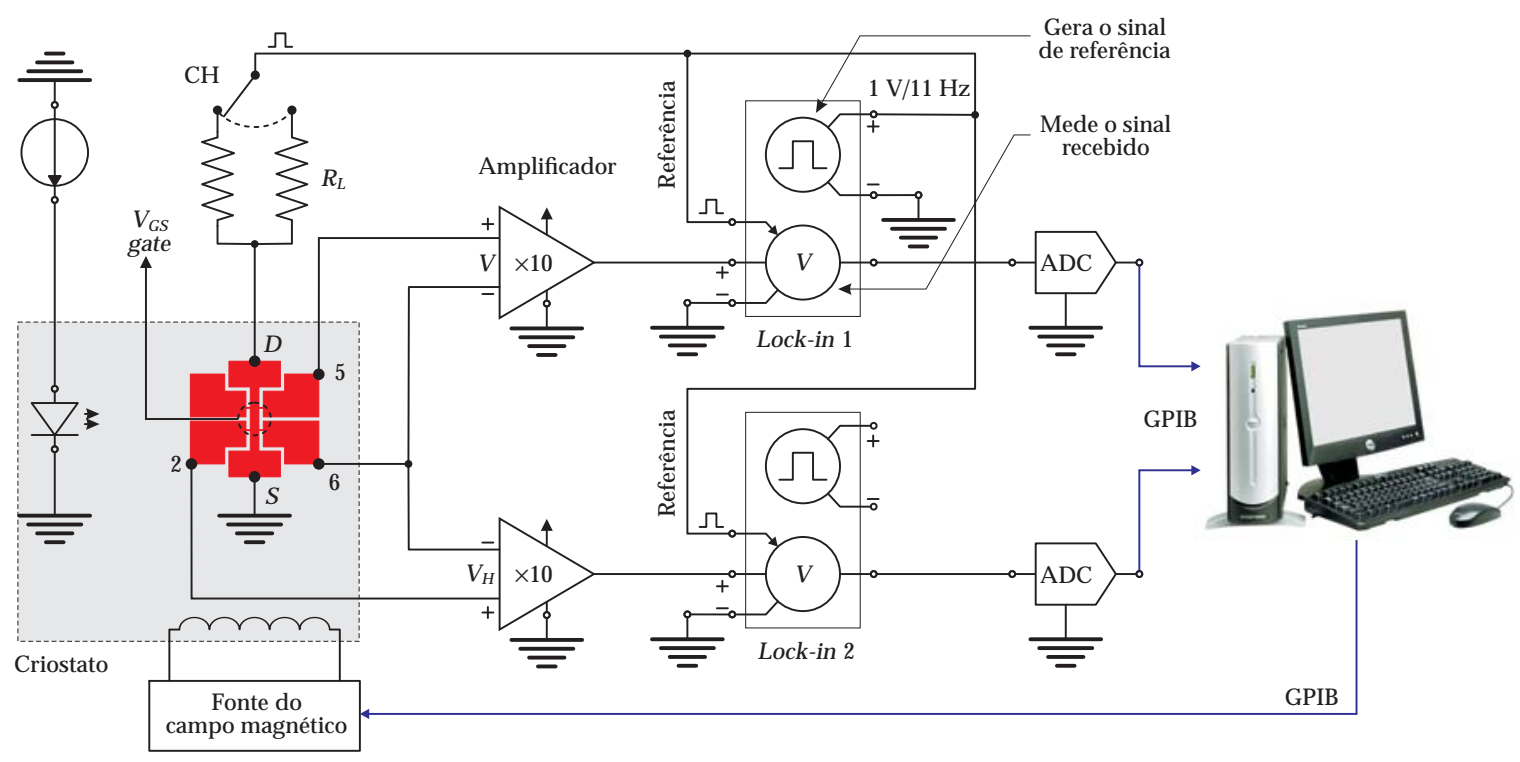

Figura 3.18.: esquema da instalação elétrica das medidas de transporte. O computador instrui a fonte IPS a variar o campo magnético e recebe dos lock-ins as tensões $V$ e $V_{H}$, registrando-as em arquivos de texto. A tensão de gate $\left(V_{G S}\right)$ é controlada manualmente por uma fonte de tensão. Alternativamente, um LED vermelho pode ser utilizado para modificar a concentração de portadores na amostra, mas não utilizamos este recurso. A região em cinza representa o criostato (baixa temperatura). 
3. Processos e equipamentos 


\section{4}

\section{Resultados}

\subsection{Estados de borda contra-rotativos}

O primeiro resultado que apresentaremos é uma evidência da existência de estados de borda contra-rotativos (que definiremos em breve), conforme previsto em 1992 por Johnson et al [1, 39]. $O$ fenômeno manifesta-se diretamente no gráfico $R_{H} \times B$ assim: quando certos valores de tensão de gate $^{1}$ são aplicados na superfície da região de interesse (fig. 3.11), a rede de pontos-quânticos interfere na dinâmica do 2DES de tal maneira que $V_{H}$ passa a ser dada por uma outra regra de quantização, diferente de (2.5). Veremos também que, conforme nossos resultados, é necessário, porém não suficiente, que haja dois canais de condução independentes (um sistema de bicamada, no nosso caso).

\subsubsection{Resultados}

A figura 4.2 apresenta as medidas do efeito Hall e da magnetorresistência para alguns valores diferentes de tensão de gate $\left(V_{G S}\right)$. Quando $V_{G S}=0$, a concentração de portadores é de $0,6 \times 10^{15} \mathrm{~m}^{-2}$ num poço-quântico e de $0,9 \times 10^{15} \mathrm{~m}^{-2}$ no outro; a mobilidade média é de $5,3 \mathrm{~m}^{-2} / \mathrm{Vs}$. Essas informações são obtidas da região $B \lesssim 1 \mathrm{~T}$ do gráfico $R$ e $R_{H} \times B$, conforme explicamos no capítulo 2 (veja a figura 4.1).

${ }^{1}$ Diferença de potencial entre gate e source, cf. sec. 3.3.3. 


\section{Resultados}

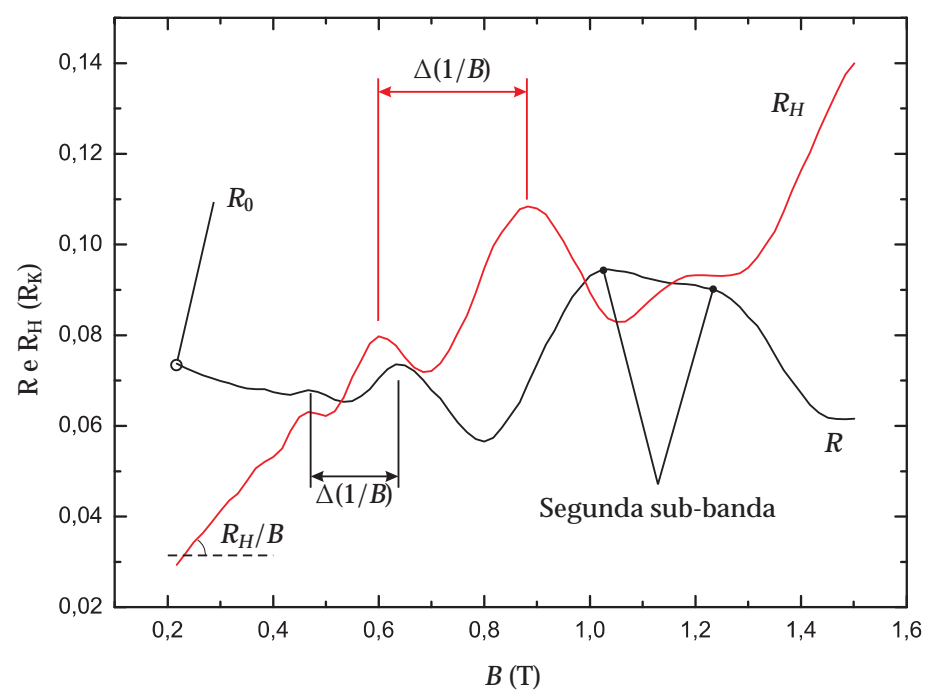

Figura 4.1.: medidas dos efeitos Hall e Shubnikov-de Haas da amostra $A$ para $V_{G S}=0$. O coeficiente angular de $R_{H} \times B$ para $B \lesssim 0,3$ T é $4064 \Omega / \mathrm{T}$, de modo que a concentração total de portadores é $n=1,5 \times 10^{15} \mathrm{~m}^{-2}, \mathrm{cf}$. (2.2). E como $R_{0}=1902 \Omega$ (e, portanto, $\rho_{0}=R_{0} / \beth=R_{0} / 2,5=761 \Omega$ ), a mobilidade de transporte é $\mu=5,3 \mathrm{~m}^{2} / \mathrm{Vs}$, ainda conforme a equação 2.2. Por outro lado, o período das oscilações de magnetorresistividade, que podem ser observadas tanto em $R \times B$ como em $R_{H} \times B$, é $\Delta(1 / B) \approx 0,53 \mathrm{~T}^{-1}$. Nesta região não há resolução de spin, de modo que vale (2.11). Então, a concentração da sub-banda que dá origem às oscilações observadas é de $n_{1}=0,9 \times 10^{15} \mathrm{~m}^{-2}$. Na região entre 1,0 e 1,4 T podemos observar a influência da segunda sub-banda em ambas as curvas. A concentração de elétrons nela é simplesmente $n-n_{1}=0,6 \times 10^{15} \mathrm{~m}^{-2}$.

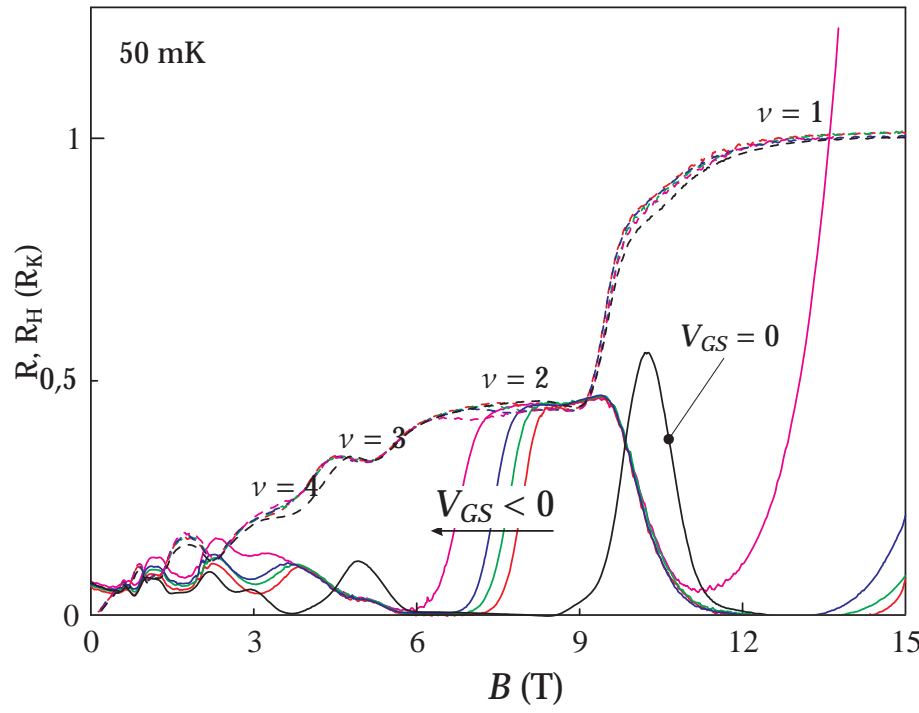

Figura 4.2.: efeito Hall e magnetorresistência da amostra $A$ para várias tensões de gate aplicadas. Quando $V_{G S} \neq 0 \mathrm{~V}$ a resistência na região em que $N=2$ torna-se quantizada, conforme (4.1). Essas medidas foram feitas no Laboratorie du Champs Magnetics Intenses do Centre National de la Recherche Scientifique (CNRS) de Grenoble (França), num criostato de diluição (dilution fridge): $T=50 \mathrm{mK}$. 
Ainda para $V_{G S}=0$ e $B$ intenso, os gráficos de $R$ e $R_{H} \times B$ comportam-se conforme o esperado: quando $v=N \in \mathbb{N}, R=0$ e $R_{H}=R_{K} / N$, indicando que a condução de corrente ocorre através dos estados de borda; quando $v \notin \mathbb{N}, R_{H}$ transita entre os platôs e $R$ assume valores finitos, evidenciando a existência de correntes dissipativas no interior da amostra.

Mas quando $-0,5 \leq V_{G S} \leq-0,1 \mathrm{~V}$, o pico da magnetorresistência na região onde $1<v<2$ $(B \approx 10 \mathrm{~T}$ ) desloca-se para a esquerda, para a região onde $N=2$, e alarga-se. Ali, $R$ deixa de ser nulo e assume o valor constante $R_{K} / 2$, como $R_{H}$ e com igual acurácia.

A figura 4.3a resume o que esta acontecendo: quando $V_{G S}=0$ a presença da rede de antipontosquânticos passa desapercebida pelos elétrons do 2DES, levando-nos de volta à situação ilustrada pela figura 2.9. Por outro lado, ao aplicarmos $V_{G S} \neq 0$ os níveis de Landau são modulados conforme o potencial periódico da rede, exatamente como fazem as impurezas (seção 2.2), tornando possível a existência de "estados de borda" nas bordas [38] da rede de antipontos. Assim, quando $v=2$ um (= M) canal de condução (um estado de borda) oriundo do contato 2 é refletido pela rede e segue para o contato 6 ao invés do 3. Da mesma forma, um canal de condução oriundo do contato 5 retorna para o 3 ao invés de ir para o 6. Esta situação pode ser descrita utilizando-se a equação de Landauer-Büttiker (2.13), de forma análoga àquela feita na seção 2.4.1, de onde concluímos que

$$
\frac{R}{R_{K}}=\frac{M}{N(N-M)} \quad \text { e } \quad \frac{R_{H}}{R_{K}}=\frac{1}{N}
$$

Assim, quando $N=2$ e $M=1$, temos $R=R_{H}=R_{K} / 2$, conforme observamos. Além disso, $N-M=1$, como observado em amostras com antipontos-quânticos mas apenas uma sub-banda [92]. Observe ainda que $R_{H}$ não sofre alteração de seu valor esperado (eq. 2.5) e que quando $M=0$ obtemos o resultado usual $R=0$. Realmente, vimos que a ausência de resistência quando $v \in \mathbb{N}$ decorre da inexistência de espalhamentos entre os canais pretos e vermelhos (fig. 2.9). Mas na situação que encontramos, $M=1$ canal preto oriundo do contato 2 dirige-se para o 6, e ali mistura-se com os vermelhos. Agora o potencial do contato 6 não é mais igual ao do 5, posto que ali misturam-se elétrons com energias $\mu_{2}$ e $\mu_{5}$. Trata-se de um espalhamento coerente.

Conforme modelamos na equação 4.1, a presença ou ausência do canal desgarrado só passa a ser percebida pelos outros canais no contato seguinte, onde ocorre a mistura de elétrons com energias diferentes.

Outra forma de se obter o mesmo resultado é trocar a super-rede de antipontos por um gate que afunila a região de interesse, conforme ilustramos na figura 4.3b: ao aplicarmos uma tensão negativa suficientemente intensa, o perfil de potencial das bandas de condução e de valência são modificados, tornando a região abaixo do gate inacessível aos elétrons (o gate construído com este fim chama-se split-gate). Isto equivale a controlarmos a espessura da região de interesse no ponto de estrangulamento. Ali, pode ocorrer, como ilustramos, a reflexão do nível de Landau mais interno, exatamente da mesma maneira que ocorreu com a nossa rede de antipontos. Por conseguinte, vale (4.1) [43].

Mas voltemos à figura 4.2: abaixo de $6 \mathrm{~T}$ podemos identificar em $R_{H} \times B$ o platô $v=3 \mathrm{e}$, com alguma 


\section{Resultados}
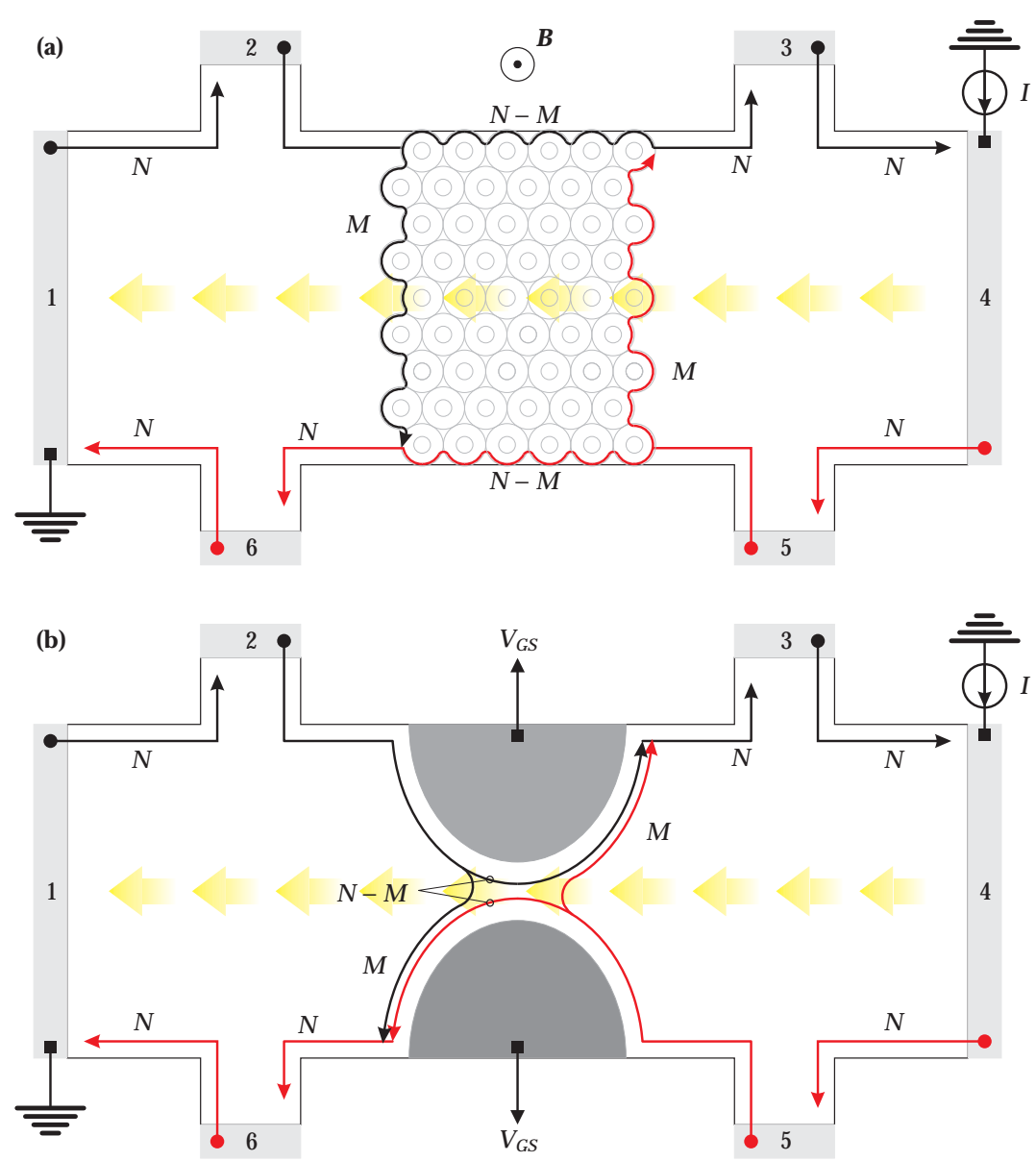

Figura 4.3.: representação do fluxo de cargas através de estados de borda (a) em nossas amostras, com superrede de antipontos-quânticos, e (b) numa amostra com split-gate. Devido à presença da super-rede em (a) e ao split-gate em (b), $M$ níveis de Landau são desviados, misturando estados que antes permaneciam disjuntos. Como resultado, em ambas as amostras a resistência é dada por (4.1) (quando $v \in \mathbb{N}$ ). A resistência Hall ainda obedece (2.5). 
Figura 4.4: Quando $r=1$, nenhum elétron atravessa a rede, tornando desconexos os dois lados dela.
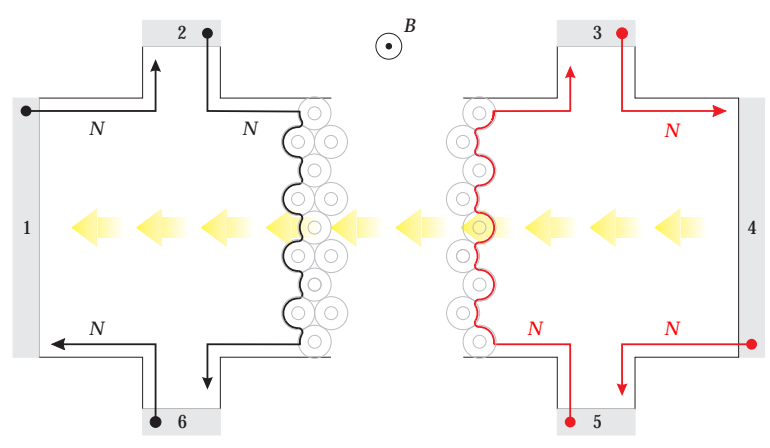

dificuldade, o 4 . No que concerne o terceiro platô, observe que para $V_{G S}=0$ a magnetorresistência apresenta um pico de altura aproximadamente igual a $0,11 R_{K}$, que confere aproximadamente com a previsão de (4.1) para $(N, M)=(3,1): R=0,17 R_{K}$. Por outro lado, no intervalo $-0,5 \leq V_{G S}<0 \mathrm{~V}$ a magnetorresistência é aproximadamente igual a $0,03 R_{K}$, que independe de $V_{G S}$ e que não pode ser descrita pela equação 4.1. Mas observe a figura 4.3: na dedução de (4.1) a suposição de que $M$ é um número natural implica que todos os elétrons de um nível de Landau são desviados pela rede de antipontos, o que não é necessariamente verdade. De fato, podemos dizer que apenas uma fração $r$ de $M$ é desviada conforme a figura 4.3a substituindo $M$ por $r M$ na equação 4.1:

$$
\frac{R}{R_{K}}=\frac{r M}{N(N-r M)}
$$

Assim, quando $r=1$ vale (4.1) e quando $r=0$, a equação 2.5. Então, quando $v=3$ e $V_{G S}=0$, aproximadamente $75 \%$ dos elétrons no nível de Landau mais interno são desviados através da rede, enquanto os outros $25 \%$ permanecem nas bordas da amostra $(r \approx 0,75)$, de modo que $R=0,11 R_{K}$. Analogamente, para $v=4$ apenas $25 \%$ são desviados $(r=0,25)$, resultando em $R=0,03 R_{K}$.

Duas observações importantes: primeira, note que fazermos $r \in[0,1]$ não implica em condução dissipativa, haja vista que mantivemos a suposição (na equação de Landauer-Büttiker) de que o equilíbrio de canais com energias diferentes só ocorre nos contatos. Observe também que a resistência Hall permanece inalterada, num platô, o que corrobora nossa suposição; segunda, a equação 4.2 nos permite explicar qualquer valor de $R$ com uma escolha apropriada (e arbitrária) de $r^{2}{ }^{2}$ de modo que por si só ela não representa conhecimento algum; ela só tem mérito se considerada conjuntamente com (4.1) e por conta do que observamos quando $v=2$.

Para $v>4$ ( $B \lesssim 3 \mathrm{~T}$ na figura 4.2), os platôs são suprimidos devido à mudança de regime do transporte de cargas.

Na região em que $v=1, R$ se comporta de forma curiosa: quando $V_{G S}=-0,5 \mathrm{~V}$ a magnetorresistência cresce para além de $R_{K}$, e este comportamento coexiste com o platô $v=1$ de $R_{H} \times B$. Este crescimento possivelmente está associado à uma transição condutor-isolante do 2DES sob inflência da rede de antipontos-quânticos quando $v$ aproxima-se da unidade. Segundo (4.1), fazendo $M \rightarrow N=1, R \rightarrow \infty\left(\mathrm{e} R_{H}=R_{K}\right)$. Nesta situação, ilustrada pela figura 4.4, não há elétrons atraves-

\footnotetext{
${ }^{2}$ De fato, quaisquer que sejam $N, M \in \mathbb{N}$ e $R$ (em unidades de $\left.R_{K}\right), r=N^{2} R /[M(1+N R)](\in[0,1])$ resolve o problema.
} 


\section{Resultados}

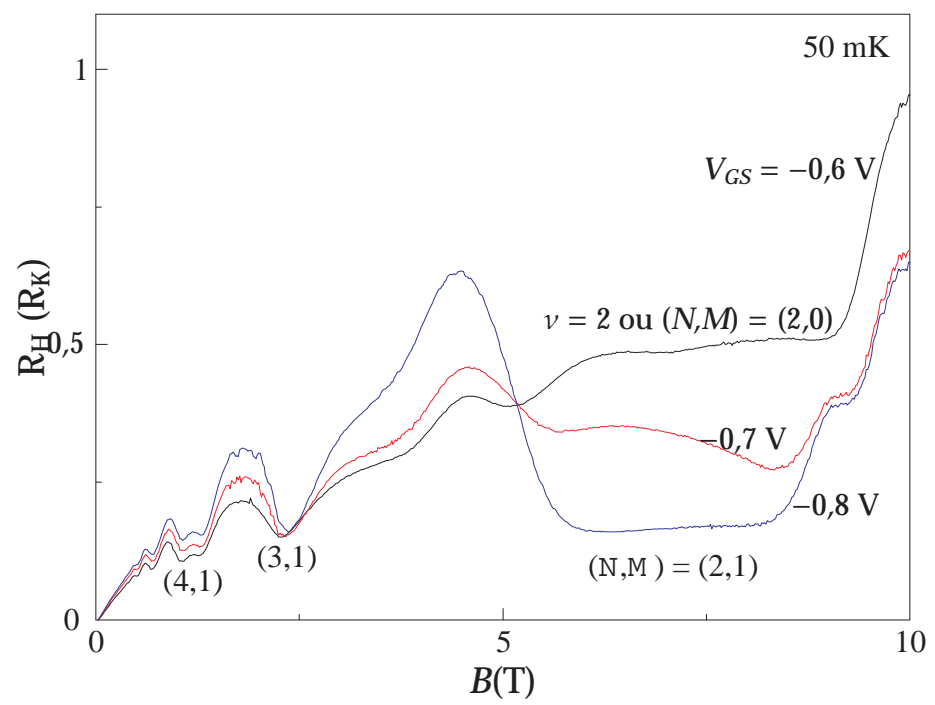

Figura 4.5.: efeito Hall e magnetorresistência da amostra $A$ para $V_{G S}<-0,5$ V. $T=50 \mathrm{mK}$.

sando a super-rede, embora haja uma corrente de deslocamento. Ou seja, o potencial eletroquímico oscilante à direita da rede de antipontos, definido pelo lock-in, induz oscilações no outro lado. A super-rede se comporta como um capacitor, cuja resistência é idealmente infinita.

Por outro lado, a situação ilustrada pela figura 4.4 só é possível, segundo a equação de LandauerBüttiker, se $I=0$. Decorre daí que todos os seis contatos têm o mesmo potencial, de modo que (4.1) perde sentido. Isto ocorre porque como não há transferência de elétrons de um lado ao outro da amostra, é como se tivéssemos duas amostras independentes, conectadas a eletrodos independentes (e disto decorre que $\mu_{1}=\mu_{2}=\mu_{6} \mathrm{e} \mu_{3}=\mu_{4}=\mu_{5}$ ). E a condição adicional de que haja uma corrente $I$ comum a ambas as amostras só pode ser satisfeita se $I=0$, fazendo $\mu_{i}$ ser o mesmo, indenpendentemente do terminal.

Porém, esta dificuldade pode ser sobrepujada se aceitarmos que sempre existe uma "corrente de fuga" não-dissipativa através da super-rede de antipontos-quânticos, permitindo que $r \rightarrow 1$, embora sempre diferente de um. A característica não-dissipativa desta corrente é assegurada pela presença do platô em $R_{H} \times B(v=1)$. Alternativamente, pode haver uma corrente de indução através da rede, posto que a corrente aplicada na amostra é alternada. Esta possibilidade pode ser verificada estudando a amostra em função da freqüência do sinal de entrada, mas isto não foi feito aqui.

Observe ainda que o comportamento de $R \times B$ para $-0,5<V_{G S}<0 \mathrm{~V}$ é similar ao que discutimos acima e reproduz a mesma seqüência do início do platô $v=2$, i.e., $V_{G S}$ torna-se mais negativo da direita para a esquerda. Embora os dados sejam escassos neste caso e não possamos assegurar que este crescimento em $R$ de fato ocorre simultaneamente com o platô $v=1$, podemos observar que, no começo do platô, $R=0$ para todos os $V_{G S} \neq-0,5 \mathrm{~V}$. Ou seja, $r=0$ e a condução é aquela do IQHE; pelas bordas. Mas conforme o campo magnético torna-se mais intenso, $R$ torna-se diferente de zero a partir de $B$ distintos para valores diferentes de $V_{G S}$. Isto ocorre mesmo para $V_{G S}=-0,5 \mathrm{~V}$, exceto que $R$ não chega a ser zero, mas passa por um valor mínimo em 11,5 T. 
Figura 4.6: um ponto-de-cela do potencial hexagonal da rede de antipontos-quânticos, por onde os elétrons migram de um ponto-quântico para o outro ou não, dependendo da diferença de energias do elétron e do ponto de cela.

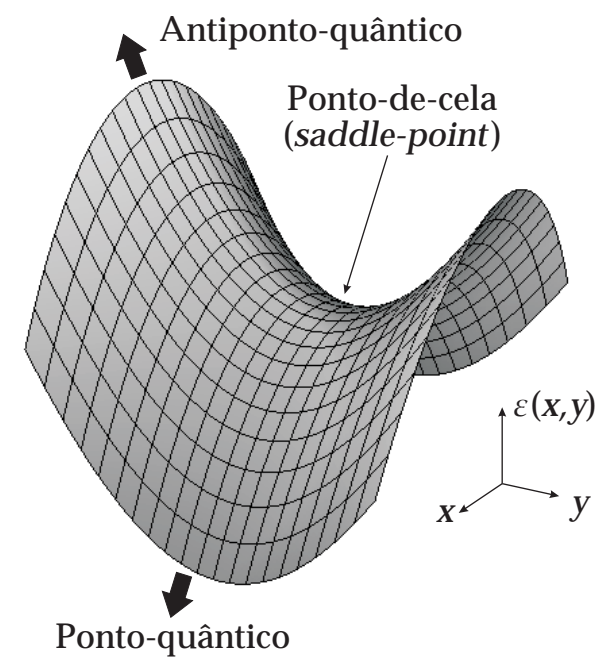

A seqüência é natural: quanto menos negativo é a tensão de gate, mais próximo da "conduçãopadrão" do efeito Hall quântico inteiro está o 2DES. Inversamente, conforme a super-rede de antipontos-quânticos torna-se mais negativa, mais influencia o 2DES, levando $r$ de zero $\left(V_{G S}=0 \mathrm{~V}\right)$ até quase $1\left(V_{G S}=-0,5 \mathrm{~V}\right)$.

É importante perceber que a presença do platô em $R_{H}$ é crucial para a nossa análise. Caso contrário, tratar-se-ia de uma condução dissipativa entre platôs, atualmente explicada por meio de transições entre estados localizados e estendidos induzidas pelas impurezas da amostra [53]. Nada teríamos a acrescentar neste caso.

Finalmente, observe que nenhuma variação em $R_{H}$ é prevista ou observada. Contudo, quando o potencial no contato de controle é ainda mais negativo, menor que $-0,5 \mathrm{~V}$, a quantização em $R$ é destruída e os platôs do efeito Hall quântico inteiro são modificados, conforme apresentamos na figura 4.5 para a amostra $A$. De fato, a sequencia usual de $R_{H}$ (eq. 2.5 , em unidades de $R_{K}$ ) $1 / 2,1 / 3$ e $1 / 4$ é substituída por $1 / 5,1 / 5$ e $1 / 6$, respectivamente.

Este fenômeno é mais visível para $v=2$, e especial atenção deve ser dada para o fato de que $R$ volta a ser zero para $v$ inteiro (não mostrado) e de que $R_{H}$ ainda é quantizada. Isto indica que o nível de Fermi está num gap dos níveis de Landau (princípio adiabático) e que o transporte é não-dissipativo, i.e., o transporte continua a ocorrer através de estados de borda.

Em seus dois artigos de 1992, Johnson et al resolveram a equação de Schrödinger com (2.6), sendo $V(\hat{r})$ o potencial de uma rede bidimensional semi-infinita de pontos-quânticos, e mostraram que para certos valores de $\Phi / \Phi_{0}$ ( $\Phi$ é o fluxo magnético numa célula da rede de pontos-quânticos e $\Phi_{0}$ é o quantum de fluxo magnético), existem estados de bordas que percorrem a rede no sentido contrário ao usual, alcunhados de estados de borda contra-rotativos: figura 4.7.

Quando a tensão no contato de controle negativa é suficientemente intensa, forma-se um potencial de confinamento nos interstícios dos antipontos-quânticos. Assim, a rede hexagonal de antipontosquânticos coexiste com uma rede também hexagonal de pontos-quânticos triangulares, induzidos por $V_{G S}$ (por isso utilizamos indistintamente os termos rede de pontos-quânticos e de antipontos- 


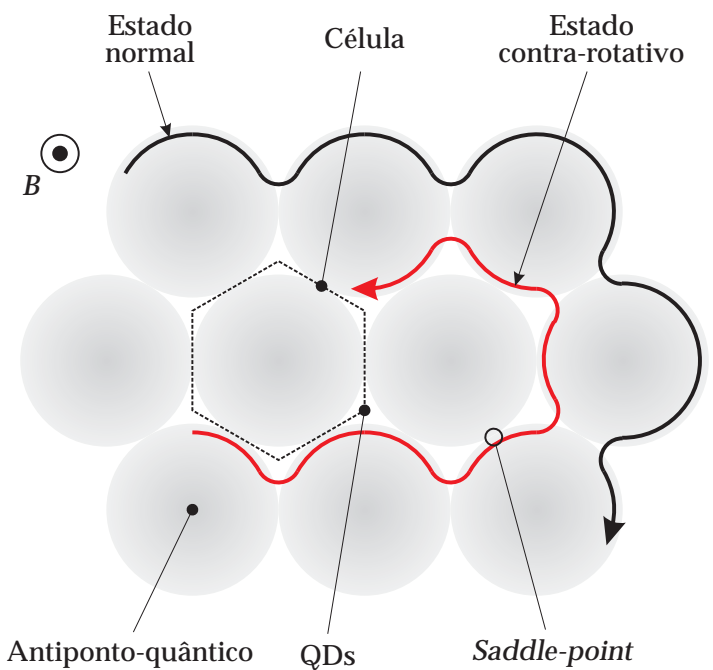

Figura 4.7.: representação dos estados de borda normais e contra-rotativos na super-rede de antipontos-quânticos, segundo Johnson et al [1, 39].

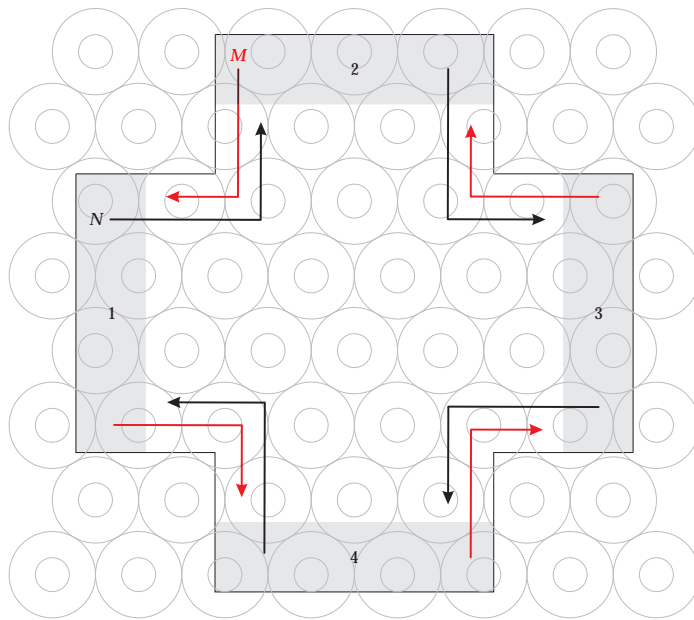

Figura 4.8.: representação do fluxo de cargas através dos estados de borda normais e contrarotativos numa amostra de quatro contatos.

quânticos).

Entre os pontos-quânticos existem os pontos-de-cela (saddle points) do potencial de confinamento (veja as figuras 3.17, 4.6 e 4.7). É através destes pontos da rede que os elétrons podem migrar, por tunelamento ou difusão, de um ponto-quântico para o outro, ou ainda interagir com elétrons no ponto-quântico vizinho. Por exemplo, se a probabilidade de transmissão do elétron através do ponto-de-cela for igual a um, ele poderá percorrer livremente a rede de pontos-quânticos no sentido anti-horário (considerando o campo magnético apontando para o leitor). Este elétron está num estado de borda dito contra-rotativo. Por outro lado, quando a probabilidade de transmissão é próxima de zero, o elétron fica confinado no ponto-quântico, percorrendo-o no sentido horário: ele está num estado de borda dito normal. Ainda nesta situação, os elétrons em estados estendidos, oriundos dos contatos, não terão acesso ao interior da rede. Em situações intermediárias podemos ter tanto estados normais como contra-rotativos. É o que acontece em nossas amostras.

Johnson et al descreveram o transporte balístico numa rede quadrada de pontos-quânticos aplicando a equação de Landauer-Büttiker numa amostra com quatro contatos, conforme ilustrado pela figura 4.8: com o campo magnético apontando para o leitor, as setas pretas indicam o sentido de rotação dos elétrons em estados de borda normais, enquanto as vermelhas indicam os estados contra-rotativos.

Então, qualquer que seja o contato, $N$ estados normais saem dele e atingem o contato seguinte (no sentido horário). Adicionalmente, este contato insere $M$ estados contra-rotativos na amostra, 


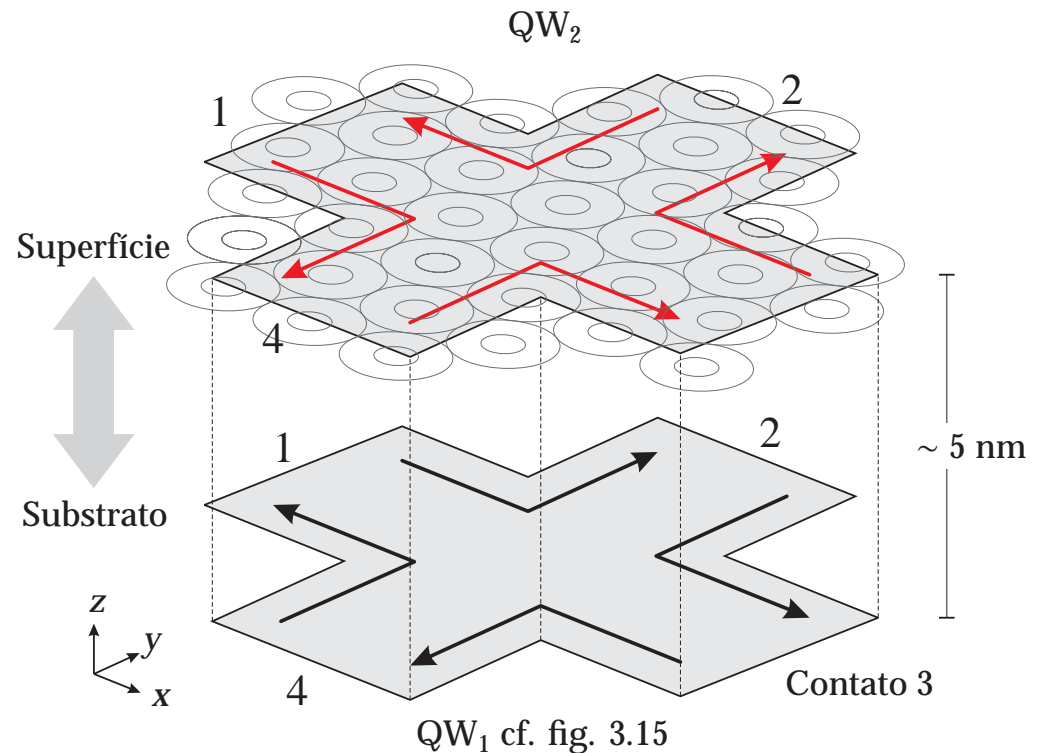

Figura 4.9.: os estados normais e contra-rotativos localizam-se cada qual num poço-quântico. É a separação espacial das funções de onda dos estados simétrico e antisimétrico, na direção do crescimento, que reduz a interação entre eles, permitindo que haja estados contra-rotativos.

que atingem o contato anterior. Assim, a matriz de transmissão é

$$
T=\left(\begin{array}{cccc}
0 & M & 0 & N \\
N & 0 & M & 0 \\
0 & N & 0 & M \\
M & 0 & N & 0
\end{array}\right)
$$

e, fazendo $V_{1}=0$ para simplificar, a equação de Landauer-Büttiker nos permite concluir que

$$
\frac{R_{H}}{R_{K}}=\frac{N-M}{N^{2}+M^{2}}
$$

No caso do platô anômalo associado a $v=2\left(R_{H} \approx 1 / 5\right)$, e equação acima nos permite descrevê-lo através do par $(N, M)=(2,1)$, que dá $R_{H}=1 / 5$. Ou seja, dois estados normais coexistem com um contra-rotativo. Analogamente, o platô associado $v=3\left(R_{H} \approx 1 / 5\right)$ pode ser substituído por $(3,1)$, dando $R_{H}=1 / 5$. E finalmente, para o platô $v=4\left(R_{H} \approx 1 / 6\right)$ fazemos $(4,1): R_{H}=3 / 17 \approx 1 / 6$. Assim, a introdução de um estado contra-rotativo em todos os casos parece explicar o comportamento anômalo dos platôs do efeito Hall quântico.

Ainda segundo os dois trabalhos de Johnson et al [1, 39], supõe-se que os estados normais e contra-rotativos percorram a amostra independentemente, só interagindo entre si nos contatos. Acreditamos que este requisito tenha sido satisfeito quando utilizamos uma heteroestrutura de poços-quânticos duplos: o distanciamento, na direção do crescimento, das funções de onda dos estados simétrico e antisimétrico do DQW reduz a sobreposição entre elas e, com isso, as intera- 


\section{Resultados}

ções interbanda. Além disso, como a presença do contato de controle na superfície da amostra (front-gate) não é percebido pela sub-banda mais profunda [85, 86], assim também o é a rede de pontos/antipontos-quânticos. Logo, se há estados contra-rotativos eles devem estar no poçoquântico mais próximo da superfície: fig. 4.9.

Observe que a configuração utilizada por Johnson et al não prevê o valor da resistência $R$, que em nossas amostras permaneceu como esperado: $R=0$ para $v$ inteiro. Visando contornar isto, procuramos definir um modelo teórico que determinasse tanto $R_{H}$ como $R$, mas nenhuma das possibilidades experimentadas funcionou tão bem quanto aquela proposta por Johnson et al.

Resumindo, os dados e argumentações apresentadas até aqui constituem uma evidência da existência de estados de borda contra-rotativos, previstos teoricamente por Johnson et al [1,39] em 1992, mas até então não observados. Outros experimentos comprobatórios precisam ser feitos e a reprodutibilidade precisa ser melhorada, mas o simples comportamento anômalo do efeito Hall quântico inteiro é, por si só, surpreendente. Até onde sabemos, há apenas mais um relato de comportamento anômalo do efeito Hall quântico em matrizes de pontos-quânticos, mas envolvendo o efeito Hall quântico fracionário $(v<1)$ [42], cuja origem é distinta da do IQHE.

\subsubsection{QDIPs?}

Vamos agora apresentar uma experiência teórica (gedanken experiment) na qual pretendemos mostrar que é possível utilizar a rede hexagonal de antipontos-quânticos na fabricação de QDIPs transversais, com algumas vantagens sobre a estrutura tradicional, apresentada na seção 1.1.

A heteroestrutura em questão consiste num poço-quântico simples, com uma rede de antipontosquânticos na superfície e uma dopagem planar remota: fig. 4.10. O poço-quântico faz o papel de canal de condução dos elétrons e os pontos-quânticos são induzidos dentro do poço-quântico pelo contato de controle: conforme vimos, para $V_{G S}$ negativa e suficientemente intensa, a rede de antipontos-quânticos hexagonal induz, em seus interstícios, uma rede também hexagonal de pontos-quânticos.

Os parâmetros da heteroestrutura, em especial as dimensões do poço-quântico e dos antipontosquânticos, devem ser dimensionados de modo que haja duas sub-bandas no poço-quântico, sendo o estado fundamental localizado, nos pontos-quânticos (com energia $\varepsilon_{0}$ inferior ao ponto-de-cela), e o excitado, estendido ( $\varepsilon_{1}$, acima do ponto-de-cela).

A dopagem deve ser planar e remota para permitir alta mobilidade no canal (curto tempo de resposta) e para que a influência do contato de controle seja mais efetiva. Além disso, a concentração de dopantes deve ser baixa (não-degenerada), para que a região não se torne um canal secundário, e definida de modo a manter desocupado o estado excitado, para manter nula a corrente de escuro. É possível também utilizar um back-gate tradicional para controlar essa transferência [85, 86, 93].

Na situação ideal, quando $V_{G S}<0$ teremos elétrons aprisionados nos pontos-quânticos (estado fundamental) e nenhum no estado excitado (acompanhe pela figura 4.10). Quando um fóton de energia $\varepsilon_{1}-\varepsilon_{0}$ incide sobre a amostra, ele provoca a transição de um elétron no estado fundamental

\footnotetext{
${ }^{3}$ Se a dopagem se estendesse por toda a heteroestrutura, a influência do gate limitar-se-ia às proximidades da superfície.
} 


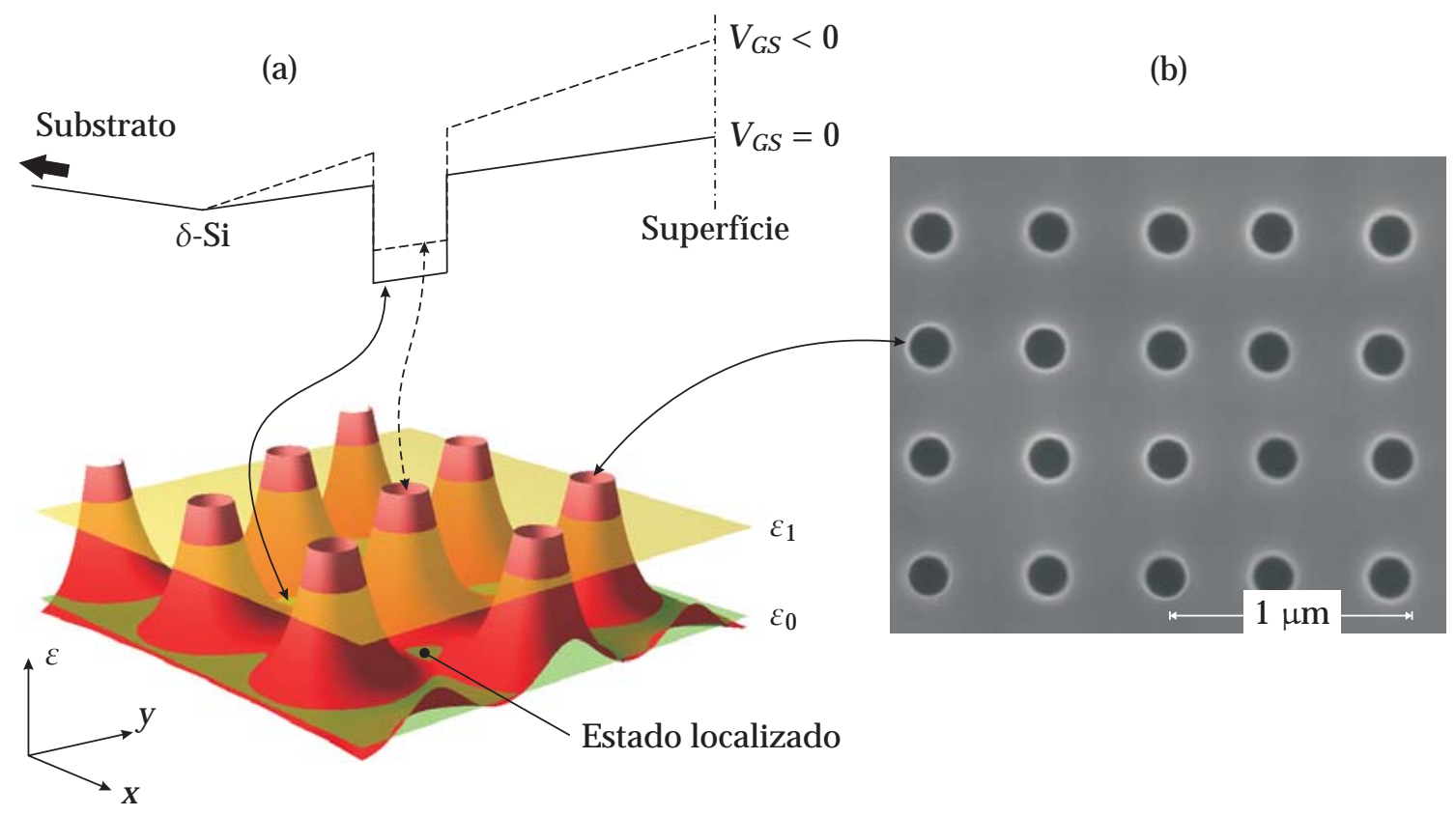

Figura 4.10.: (a) fotodetector baseado em pontos-quânticos induzidos pela rede de antipontos-quânticos. Quando $V_{G S}<0$ o potencial da banda de condução nas regiões do poço-quântico sob os antipontos-quânticos é maior que o dos interstícios (pontos-quânticos). Adicionalmente, o estado fundamental tem energia inferior ao ponto-de-cela e, portanto, é localizado; já o estado excitado tem energia superior e, logo, é estendido. Idealmente apenas o estado fundamental está inicialmente ocupado, e uma transição para o estado excitado é intermediada por um fóton de energia apropriada. No estado excitado, o elétron é arrastado para fora da amostra pela tensão $V_{D S}$ e delata a incidência do fóton. (b) Rede quadrada de antipontos-quânticos sobre GaAs feita pelo FIB do Centro de Componentes Semicondutores (CCS) da Universidade de Campinas (UNICAMP).

para o excitado. Como este estado é estendido, a diferença de potencial $V_{D S}$ (no plano perpendicular ao do crescimento; veja a figura da página 43) arrasta-o para os contatos nas bordas da amostra, sendo então detectado pelos circuitos externos.

Em suma, o funcionamento é idêntico ao dos QDIPs transversais tradicionais, exceto que os pontos-quânticos não são auto-organizados [45], mas induzidos eletricamente. A vantagem é que temos total controle das dimensões e da distribuição deles no plano perpendicular ao do crescimento (já que não estamos sujeitos às flutuações inerentes à ao precesso de auto-formação dos pontos-quânticos crescidos por MBE), o que implica numa raia de detecção mais estreita, i.e., maior acurácia na detecção do fóton. Outra vantagem é que a regularidade da rede de pontos-quânticos contribui para melhorar a mobilidade do 2DES. Além disso, pequenas variações em $V_{G S}$ nos permite controlar $\varepsilon_{1}-\varepsilon_{0}$, ou seja, a faixa de detecção.

Mas há uma desvantagem: a estrutura que propomos aqui não permite o empilhamento de regiões-ativas. Isto significa que a corrente fotoexcitada deve ser muito baixa, o que não é bom. Por outro lado, isto também implica numa corrente de escuro baixa, o que é bom.

As primeiras tentativas de se fabricar pontos-quânticos utilizavam fotolitografia e eletrolitografia, como nos antipontos-quânticos que utilizamos. Na época essas técnicas mostraram-se incapazes de 


\section{Resultados}

produzir pontos-quânticos com dimensões controladas ou pequenos o suficiente para garantir os efeitos de confinamento. Além disso, as estruturas produzidas por essas técnicas apresentavam má qualidade cristalina, com altas densidades de impurezas e defeitos estruturais proveninentes dos tratamentos químicos. Contudo, hoje temos à nossa disposição equipamentos mais modernos, como o FIB (focused ion beam), que nos permite construir antipontos-quânticos de algumas dezenas de nanometros (fig. 4.10) sem a necessidade de tratamento químico posterior. Além disso, como os pontos são induzidos eletricamente nos interstícios, é possível controlar suas dimensões através de $V_{G S}$.

\subsection{Localização fraca e interações elétron-elétron em 2DES com pontos-quânticos}

No trabalho [45] apresentamos um estudo das concentrações dos elétrons e suas mobilidades (quântica e de transporte) num 2DES próximo de uma camada tensionada de arseneto de índio, de espessura $d_{\text {InAs. }}$ À medida que esta espessura crescia, a tensão acumulada durante o crescimento prejudicava as mobilidades do 2DES. Quando $d_{\text {InAs }} \approx 1,5 \mathrm{MC}$, a tensão é liberada através da formação de pontos-quânticos. E neste momento, as mobilidades cresciam, chegando a igualaremse àquelas observadas quando nenhuma camada de InAs era crescida.

Os métodos de extração das concentrações de elétrons e suas mobilidades (cap. 2) baseiam-se na suposição de que os campos magnéticos aplicados não alteram apreciavelmente as propriedades do 2DES, de sorte que essas propriedades (obtidas quando $B \neq 0$ ) são aquelas para $B=0$ (isto nem sempre é verdadeiro, cf. 82). Por outro lado, os efeitos de localização-fraca e interações entre elétrons constituem métodos alternativos no limite $B \rightarrow 0$ que podem corroborar ou não os resultados obtidos dos efeitos Hall e Shubnikov-de Haas. Ademais, eles são sensíveis ao tempo de relaxação de fase dos (quasi-) elétrons, característica geralmente ignorada no transporte de cargas.

Assim, a idéia aqui é verificar se a formação dos pontos-quânticos também influi no tempo de relaxação de fase $\left(\tau_{\varphi}\right)$, e veremos que isto de fato ocorre.

\subsubsection{Resultados}

A figura 4.11 apresenta o gráfico da condutividade em campo nulo da amostra 1,75 MC em função da temperatura (as outras amostras apresentam resultados similares). Ele mostra um comportamento "anômalo" de $\sigma(T)$, já que conforme a lei de Wiedemann-Franz a condutividade de um gás bidimensional de elétrons deve ser proporcional a $T^{-1}[69$, p. 253]. Isto ocorre porque, devido à baixa temperatura e mobilidade das amostras, o transporte de cargas ocorre no regime de difusão quântico (sec. 2.5) e, neste caso,

$$
\sigma(T)=\sigma(0)+\delta \sigma_{\mathrm{wL}}(T)+\delta \sigma_{\mathrm{EEI}}(T)
$$




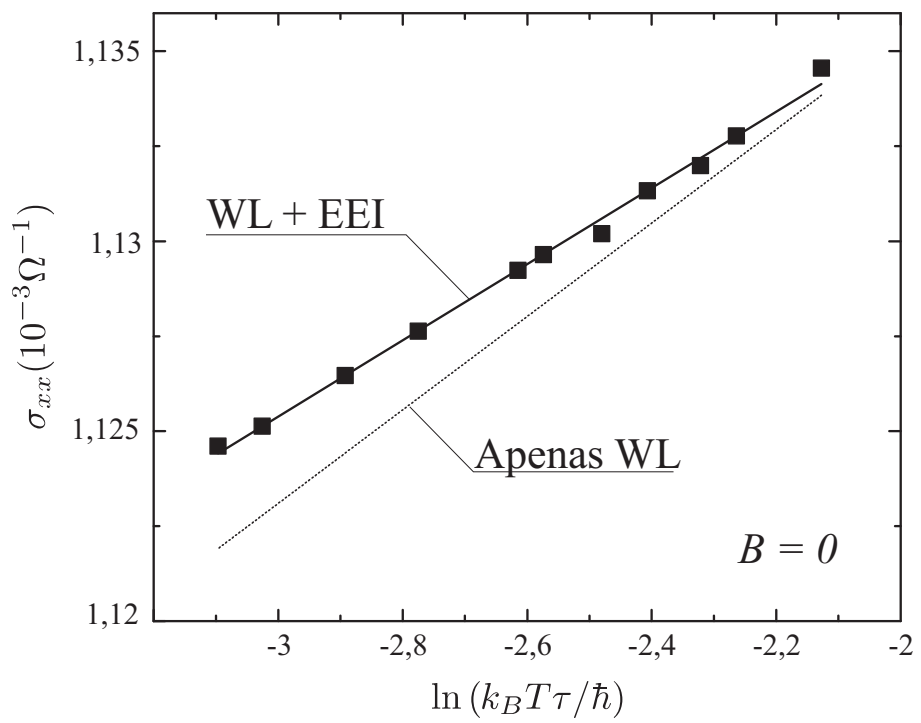

Figura 4.11.: condutividade em campo nulo da amostra 1,75 MC: tanto a localização fraca como as interações entre elétrons estão presentes $(\alpha, p=1$ e $\lambda=-0,185$ na eq. 4.3). A incerteza nos pontos experimentais é da ordem do tamanho dos símbolos.

Aqui, $\delta \sigma_{\mathrm{WL}}$ e $\delta \sigma_{\mathrm{EEI}}$ são as correções da condutividade clássica $[\sigma(0)]$ devido à localização-fraca e às interações elétron-elétron $[72,94,95,96]$, respectivamente:

$$
\left\{\begin{array}{c}
\delta \sigma_{\mathrm{WL}} \\
\delta \sigma_{\mathrm{EEI}}
\end{array}\right\}=\frac{e^{2}}{\pi h}\left\{\begin{array}{c}
\alpha p \\
\lambda
\end{array}\right\} \ln \left(\frac{k_{B} T \tau}{\hbar}\right),
$$

onde $\alpha$ é igual a 1 para interação spin-órbita fraca ou $1 / 2$ para forte. $p$ é o expoente da dependência com a temperatura do tempo de espalhamento inelástico $\left(\tau_{\varphi} \propto T^{-p}\right)$ e $\lambda$ é a constante de interação [97].

Fazendo $\alpha=1$ (interação spin-órbita fraca característica do GaAs) e $p=1$ (mais a frente) na equação 4.3, e ajustando-a aos dados experimentais da figura 4.11, encontramos $\lambda=-0,185$ e $\sigma(0)=1,16 \times 10^{-3} \Omega^{-1}$. Este resultado está representado na figura pela reta contínua e significa que tanto a localização-fraca como as interações elétron-elétron estão presentes no 2DES e são apreciáveis. De fato, se fizéssemos $\lambda=0$, indicando que não há interação entre os elétrons, obteríamos o comportamento representado pela reta pontilhada.

Agora vejamos o que acontece quando aplicamos o campo magnético $B$ perpendicularmente ao plano dos elétrons. A fig. 4.12 ilustra o gráfico da correção da magnetocondutividade clássica da amostra 1,75 MC, donde podemos fazer duas observações imediatamente: primeiro, $\Delta \sigma$ decresce com a temperatura. Isto acontece porque o tempo de espalhamento inelástico depende da temperatura $\left(\tau_{\varphi} \propto T^{-p}\right)$ [71, p. 5]; segundo, não há pico de anti-localização, o que nos permite concluir que a interação spin-órbita é fraca (esta é uma característica do GaAs), o que justifica termos feito $\alpha=1$ anteriormente. 

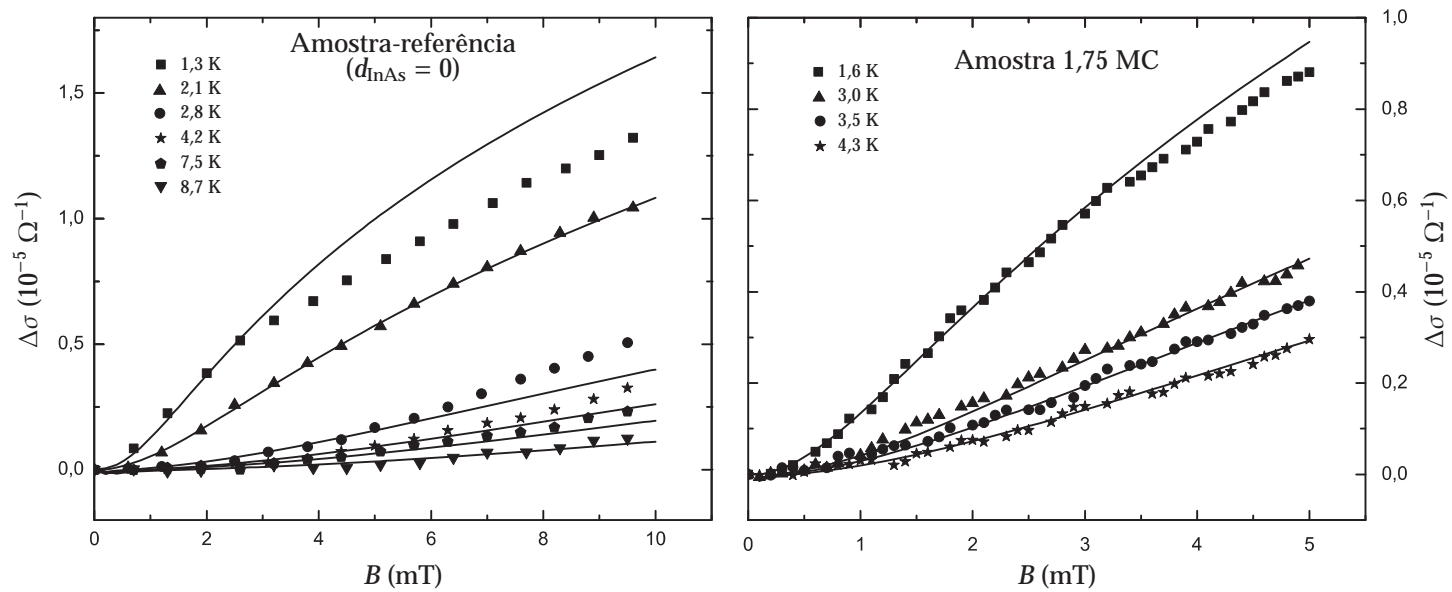

Figura 4.12.: correção da magnetocondutividade experimental (pontos) e teórico das amostras referência (sem camada de InAs) e 1,75 MC, devido à localização-fraca, eq. 4.4.

A partir da fig. 4.12 calculamos a correção da magnetocondutividade experimental: ${ }^{4}$

$$
\Delta \sigma \doteq \frac{1}{\rho(B)}-\frac{1}{\rho_{0}} \approx-\frac{\Delta \rho}{\rho_{0}^{2}}
$$

onde $\rho_{0}$ é a resistividade para $B=0$ e fizemos a aproximação $\rho(B) \approx \rho_{0}$ na segunda passagem pois $\Delta \rho(B) \ll \rho_{0}$. O resultado está na figura $4.12 \mathrm{e}$, da mesma forma que a dependência com a temperatura, $\Delta \sigma$ tem duas fontes de correção: localização-fraca e interações elétron-elétron.

Conforme Minkov et al [31], a correção da magnetocondutividade clássica (de Drude; constante) de um 2DES confinado num poço-quântico de InGaAs devido à localização-fraca é dada por

$$
\delta \sigma(B)=\frac{1}{2 \pi R_{K}}\left[F_{t}\left(b_{\varphi}, b_{\mathrm{so}}\right)-F_{s}\left(b_{\varphi}\right)\right] ; \quad b_{\varphi, \mathrm{SO}} \doteq \frac{B_{\varphi, \mathrm{SO}}}{B} .
$$

$B_{\varphi}\left(B_{\mathrm{SO}}\right)$ é a intensidade do campo magnético no qual um elétron percorre, por difusão e durante o tempo $\tau_{\varphi}\left(\tau_{\mathrm{so}}\right)$, uma trajetória que encerra uma área tal que contenha exatamente um quantum de fluxo magnético. São parâmetros úteis que substituem $\tau_{\varphi}$ e $\tau_{\mathrm{so}}$, respectivamente.

$F_{t}$ e $F_{S}$ são as contribuições dos elétrons em estados triplete e singlete, respectivamente. Ambos os termos dependem de $\tau_{\varphi}$ (que está associado à parte espacial da função de onda do 2DES), mas o segundo não depende do tempo de relaxação de spin, já que num espalhamento entre estados singlete não há mudança de spin. O primeiro tem uma expressão complicada [31, eq. 1] e contribui negativamente para magnetocondutividade $(\Delta \sigma<0)$, enquanto $F_{s}\left(b_{\varphi}\right)=\psi\left(b_{\varphi}+1 / 2\right)-$ $\ln \left(b_{\varphi}\right)$ contribui positivamente ( $\psi$ é a função Digama).

Quanto a correção devido às interações intereletrônicas, Zala et al [97] trataram o caso de potenciais de espalhamento de curto alcance, enquanto Gornyi et al [98] consideraram os potenciais do tipo coulombiano (longo alcance). Em ambos os casos, os termos de Hartree contribuem positivamente

${ }^{4}$ Alternativamente, podemos utilizar $\Delta \sigma \approx-\beth \Delta R / R_{0}$, já que $\rho=R / \beth$ (sec. 2.1). 
para a magnetocondutividade, ao passo que os termos de Fock (exchange) contribuem negativamente. Independentemente disto, para os valores de temperatura $(<5 \mathrm{~K})$ e de campo magnético $(<5 \mathrm{mT})$ aos quais nossas amostras estiveram expostas, a $\delta \sigma(B)$ calculada (teórica) é $10^{4}$ vezes menor que a $\Delta \sigma$ observada. Logo, podemos dizer que a $\Delta \sigma$ observada é devida (quase) exclusivamente a localização-fraca. De fato, a figura 4.12 mostra como o comportamento previsto (eq. 4.4), representado pelas linhas contínuas, reproduz muito bem os dados experimentais. as curvas contínuas ilustram o comportamento teórico (4.4) ajustado aos dados experimentais.

Os parâmetros de ajuste ${ }^{5}$ da equação 4.4 são $B_{\varphi}$ e $B_{\mathrm{SO}}$, a partir dos quais obtemos diretamente $\tau_{\varphi}$ e $\tau_{\text {so }}$ usando a relação já conhecida $\tau_{\varphi, s o}=\hbar /\left(4 e D B_{\varphi, s o}\right)$. Analisando a amostra 1,75 MC (representativa) desta forma para várias temperaturas construimos a figura 4.13. Nela, vemos que a taxa de decoerência aumenta linearmente com a temperatura, uma evidência de que a quebra de fase ocorre através de espalhamentos elétron-elétron [43, p. 21] (adiante).

Por outro lado, $\tau_{\mathrm{so}}>\tau_{\varphi}$, o que corrobora nossa observação anterior de que as interações spinórbita são fracas. Em semicondutores da família III-V ${ }^{6}$ (GaAs, InAs, AlAs, etc) a simetria de inversão da rede de Bravais (bulk inversion asymmetry) é destruída pela presença de dois átomos na base. Com isto, a interação spin-órbita passa a depender do vetor de onda $k$. Efeito semelhante ocorre devido a assimetria nas heterointerfaces, causada pelos potenciais de confinamento (structure inversion asymmetry). O primeiro ficou conhecido como o termo de Dresselhauss [100] da interação spin-órbita e o segundo, de Rashba [99]. O gap de spin devido ao termo de Rashba é de $2 \hbar \alpha_{0} E k_{F}=2.2 \mathrm{neV}$, que não pode explicar o gap observado $\hbar \sqrt{2 /\left(\tau_{\mathrm{so}} \tau\right)}=0,06-0,228 \mathrm{meV}$ [29]. Logo, podemos concluir que as interações spin-órbita ocorrem majoritariamente devido ao mecanismo de Dresselhauss. Isto está de acordo, por exemplo, com os cálculos auto-consistentes de Minkov et al [31] e com os resultados experimentais de Desrat et al [29].

É interessante observar também que $\tau_{\mathrm{so}}$ não depende da temperatura (na fig. 4.13). Isto também está de acordo com resultados anteriores [102, p. 366].

Então, $\tau_{\varphi}$ é o principal parâmetro da localização-fraca; que define sua magnitude e dependência com a temperatura. E na ausência de impurezas magnéticas, como é o caso, a relaxação da fase dos elétrons no sistema bidimensional ocorre através de espalhamentos elétron-fônon e elétron-elétron (apenas mecanismos de espalhamento que modifiquem a fase aleatoriamente tanto no tempo quanto no espaço contribuem para $\tau_{\varphi}$ ). O primeiro implica em $\tau_{\varphi}^{-1} \propto T^{2}$ e o segundo, em $\propto T$ [43, p. 21]. Isto posto, vemos pela figura 4.13 que não há influência de fônons. De fato, conforme [103, 104], a taxa de espalhamento por interações elétron-fônon para o GaAs na maior temperatura utilizada em nossas medidas é $\sim 3 \times 10^{8} \mathrm{~s}^{-1}$; duas ordens de grandeza menor que $\tau_{\varphi}^{-1}$ obtido dos dados experimentais.

Já a taxa de espalhamento elétron-elétron é dada por [105]

$$
\frac{1}{\tau_{\mathrm{ee}}(T)}=\left[1+\frac{3\left(F_{0}^{\sigma}\right)^{2}}{\left(1+F_{0}^{\sigma}\right)\left(2+F_{0}^{\sigma}\right)}\right] \frac{k_{B} T}{g \hbar} \ln \left[g\left(1+F_{0}^{\sigma}\right)\right]+\frac{\pi}{4}\left[1+\frac{3\left(F_{0}^{\sigma}\right)^{2}}{\left(1+F_{0}^{\sigma}\right)^{2}}\right] \frac{\left(k_{B} T\right)^{2}}{\hbar E_{F}} \ln \left(\frac{E_{F} \tau}{\hbar}\right),
$$

\footnotetext{
${ }^{5}$ Utilizamos o software MathCAD para fazer os ajustes de mínimos quadrados.

${ }^{6}$ Em verdade, as famílias III-V e II-VI são as mais conhecidas e estudadas sob este aspecto.

${ }^{7}$ Aqui $\alpha_{0}=5.5 \mathrm{eVA}^{2}$ para o GaAs [101], $E \sim 10^{3} \mathrm{~V} / \mathrm{m}$ é o campo elétrico médio no poço-quântico e $k_{F}=\sqrt{2 \pi n_{S}}$ é o vetor de onda de Fermi. $n_{S}$ é a concentração total de portadores, obtida das medidas do efeito Hall clássico.
} 


\section{Resultados}
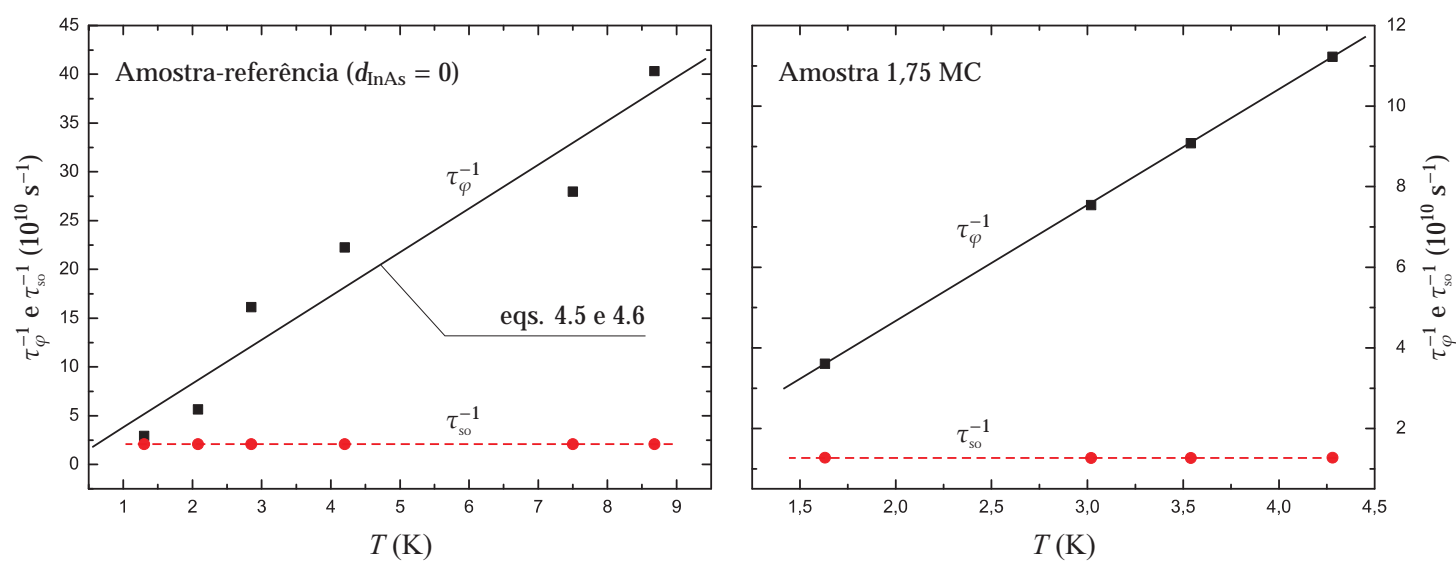

Figura 4.13.: dependência com a temperatura das taxas de decoerência e espalhamento spin-órbita. As retas representam o resultado teórico, equações 4.5 e 4.6 .

resultado que leva em consideração ambos os estados de triplete e singlete dos elétrons no sistema bidimensional. $g=R_{K} / R$ é a condutância adimensional, $R$ é a resistência, $E_{F}$ é a energia de Fermi e $F_{0}^{\sigma}$ é a constante do líquido de Fermi associada ao estado triplete, que reflete a intensidade da interação de troca de spin (spin-exchange): para $F_{0}^{\sigma}<0$ a interação tende a alinhar os spins, atingindo uma instabilidade de Stoner quando $F_{0}^{\sigma}=-1$.

Outro tipo de espalhamento inelástico que pode ocorrer no caso das amostras com pontosquânticos $\left(d_{\text {InAs }} \geq 1,5 \mathrm{MC}\right)$ é aquele entre os elétrons do sistema bidimensional e aqueles capturados pelos QDs. Conforme [108, 109], a taxa de espalhamento devido a este processo é dada por

$$
\frac{1}{\tau_{\mathrm{QD}}(T)}=\frac{\left(k_{B} T\right)^{2}}{\hbar E_{\mathrm{el}}} \frac{N_{0 D}}{N_{2 D}}\left|\ln \left(\frac{k_{B} T}{\Delta}\right)\right|^{3}
$$

onde $E_{\mathrm{el}}$ é uma energia eletrônica da ordem de alguns décimos de elétron-volts, $\Delta$ é um valor característico da energia de tunelamento entre os elétrons do sistema bidimensional e aqueles localizados nos QDs (da ordem de uma fração de elétron-volt), $N_{O D}$ e $N_{2 D}$ são as densidades de estados localizados e $2 \mathrm{D}$, respectivamente.

A figura 4.13 mostra $\tau_{\varphi}^{-1}(T)$ para a amostra 1,75 MC. A curva representa o resultado teórico $\tau_{\mathrm{ee}}^{-1}+\tau_{1}^{-1}$, calculado através das equações $4.5 \mathrm{e} 4.6$ com os parâmetros de ajuste $F_{0}^{\sigma}=-0,24, E_{\mathrm{el}}=0,1 \mathrm{eV}$ e $\Delta=30 \mathrm{meV}$, e tomando $N_{0 D}=1,0 \times 10^{15} \mathrm{~m}^{-2}$ [3] e $N_{2 D}=1,97 \times 10^{16} \mathrm{~m}^{-2}$ (obtido das medidas de transporte).

$\mathrm{O}$ valor de $F_{0}^{\sigma}$ depende do parâmetro $r_{s}$ através da relação

$$
F_{0}^{\sigma}=-\frac{1}{2 \pi} \frac{r_{s}}{\sqrt{2-r_{s}^{2}}} \ln \left[\frac{\sqrt{2}+\sqrt{2-r_{s}^{2}}}{\sqrt{2}-\sqrt{2-r_{s}^{2}}}\right] \quad \text { para } r_{s}^{2}<2,
$$

\footnotetext{
${ }^{8}$ Até então considerava-se apenas o estado singlete, de onde obtinha-se $\tau_{\text {ee }}^{-1} \propto T^{2}$ para altas temperaturas e $\propto T$ para baixas [106, 107].
} 


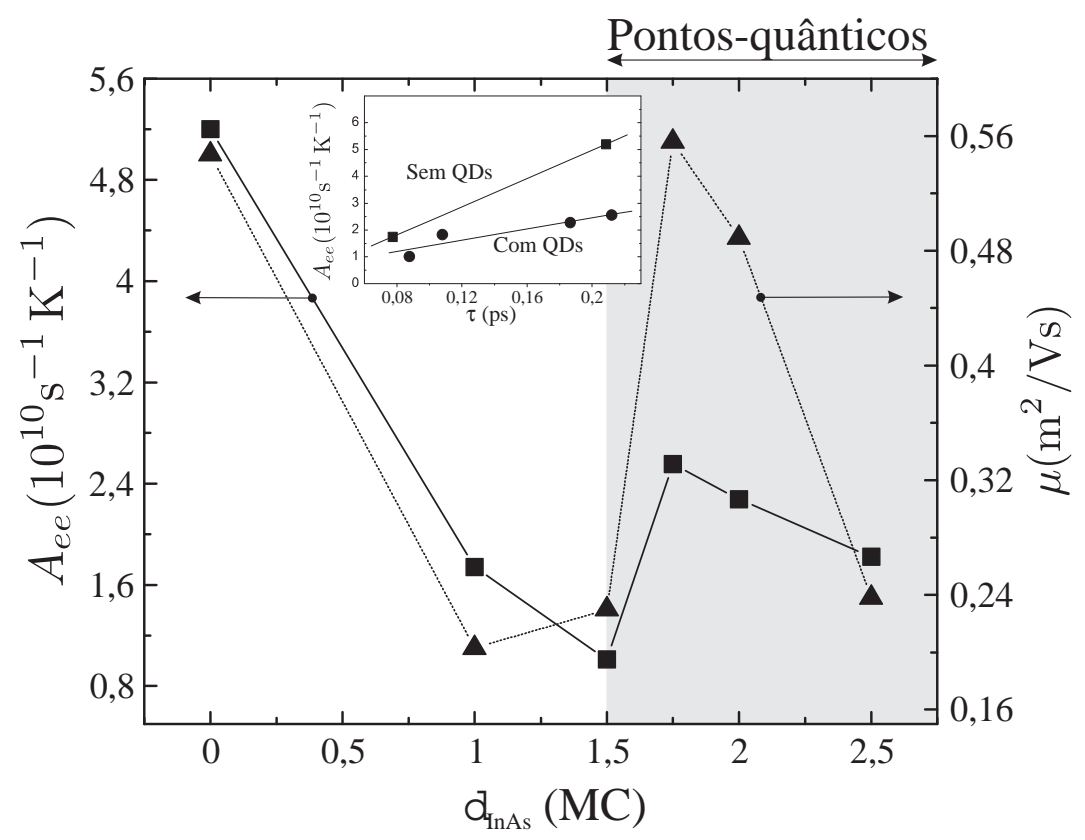

Figura 4.14.: o coeficiente $A_{e e}$ e a mobilidade de transporte $\mu$ apresentam o mesmo comportamento em função de $d_{\text {InAs }}$. Isto ocorre por quê ambos dependem de $\tau$, o tempo de espalhamento elástico, que varia conforme tensão mecânica é acumulada durante o crescimento epitaxial, conforme explica a referência 80.

sendo $r_{s}$ a razão das energia de interação coulombiana e cinética, dado por $\sqrt{2} e^{2} /\left(\varepsilon_{s} \hbar v_{F}\right)$. $\varepsilon_{s}$ é a constante dielétrica e $v_{F}$ é a velocidade de Fermi. O valor teórico de $F_{0}^{\sigma}(=-0,24)$ foi calculado usando $\varepsilon_{s}=12,9(\mathrm{GaAs})$. Experimentalmente obtivemos $F_{0}^{\sigma}=-0,20$ para a amostra 1,75 MC.

Assim, podemos concluir que a decorerência ocorre através de interações elétron-elétron e elétron-(elétron localizado) nas amostras com pontos-quânticos (apenas o primeiro está presente nas amostras sem pontos-quânticos). A figura 4.13 mostra a dependência linear de $1 / \tau_{\varphi}$ com a temperatura, uma evidência de que o segundo termo em (4.5) é muito menor que o primeiro. Além disso, como o comportamento de $\ln \left(k_{B} T / \Delta\right)$ não é muito diferente do de $\Delta / k_{B} T$, a equação 4.6 se torna linear com $T$, de modo que podemos escrever $1 / \tau_{\varphi}=A_{\mathrm{ee}} T$.

A figura 4.14 mostra o coeficiente angular $A_{\mathrm{ee}}$ e a mobilidade de transporte $\mu$ para todas as amostras, i.e., em função da espessura nominal da camada de InAs $\left(d_{\text {InAs }}\right)$. O comportamento similar é uma conseqüência da dependência em $\tau$, que por sua vez sofre alterações com a evolução dos pontos-quânticos, conforme explicado por Pagnossin et al [80]: antes da formação dos pontosquânticos $\left(d_{\text {InAs }} \leq 1,5 \mathrm{MC}\right)$, a tensão mecânica acumulada durante o crescimento epitaxial aumenta a taxa de relaxação do momento, ou seja, reduz tanto $\tau$ quanto as mobilidades quântica e de transporte. Com a formação dos pontos-quânticos $\left(d_{\text {InAs }} \approx 1,6 \mathrm{MC}\right)$, a tensão é liberada e tanto $\tau$ como as mobilidades voltam a crescer. Prosseguindo o crescimento, a tensão volta a acumular e, como anteriormente, as mobilidades são reduzidas.

Observe que $A_{\mathrm{ee}} \propto \tau_{\varphi}^{-1}$, o que significa que, embora a taxa de espalhamento aumente com o incremento da tensão mecânica, a de decoerência diminui. Isto pode parecer contraditório, mas 


\section{Resultados}

segundo S. Datta, a quebra de fase da função de onda do 2DES é tão frequente quanto mais aleatório — no tempo - for a configuração dos agentes espalhadores (veja a discussão na p. 17 da ref. 43). Isto nos leva à interessante conclusão de que a tensão mecânica "congela" esses agentes espalhadores. As principais fontes de decoerência são, como vimos, as interações intereletrônicas e elétron-fônon. Como excluímos esta última há pouco, podemos concluir que a tensão mecânica "congela" os próprios elétrons do 2DES. Dito de forma mais técnica: o espaço de fase dos elétrons do 2DES é reduzido pela tensão mecânica.

Para finalizar, no detalhe da figura 4.14 vemos $A_{\mathrm{ee}} \times \tau$ para as amostras com e sem pontosquânticos. Embora os valores de $A_{\mathrm{ee}}$ cresçam com $\tau$ em ambos os casos, a inclinação dessa variação é diferente. Nas amostras com pontos-quânticos, há o espalhamento adicional entre os elétrons no sistema bidimensional e aqueles capturados, que incrementa $A_{\mathrm{ee}}$ conforme a densidade de elétrons localizados (de pontos-quânticos) aumenta, resultando na redução da inclinação.

Resumindo esta seção, concluímos que e fenômeno da localização fraca em nossas amostras é dimensionado principalmente pelo tempo de coerência da função de onda dos elétrons do 2DES, que por sua vez é dado pelas interações intereletrônicas e, nas amostras que têm pontos-quânticos, também pelas interações do 2DES com os elétrons aprisionados neles. A tensão mecânica do crescimento epitaxial prejudica as mobilidades do 2DES mas, por outro lado, aumenta o tempo de quebra de fase dos elétrons. Essa influência é distinta para as amostras com e sem pontos-quânticos.

\subsection{Fotodetectores de infravermelho}

A partir de agora, deixamos para trás a física básica em direção à aplicada: os fotodetectores de infravermelho baseados em pontos-quânticos, ou QDIPs (quantum-dots infrared photodetectors), especificamente. A construção de um fotodetector completo não é o nosso objetivo atual, haja vista que isto requer infra-estrutura da qual não dispomos. Alternativamente, objetivamos identificar configurações de heteroestruturas que maximizam os requisitos de um QDIP (capítulo 1).

Conforme vimos na introdução deste trabalho, um QDIP deve ser projetado de modo a apresentar tempo de resposta mínimo e corrente fotogerada máxima, dentre outras características (veja a introdução). A primeira garante não só que a radiação incidente seja detectada, mas que o seja rapidamente (tempo de resposta mínimo significa que o tempo entre a excitação dos elétrons aprisionados nos pontos-quânticos e a detecção deles pelos circuitos externos ao detector seja mínima). A segunda característica provê maior sensibilidade ao dispositivo, permitindo-nos identificar (em meio aos ruídos) a corrente fotogerada para radiações menos intensas.

\subsubsection{Resultados do $1^{\circ}$ conjunto}

Nas medidas de transporte as amostras foram imersas em ${ }^{4} \mathrm{He}$ líquido a 1,4 K em uma região de campo magnético uniforme e perpendicular ao plano de crescimento. Então, fazemos percorrer-lhes uma corrente ac de aproximadamente $1 \mu \mathrm{A}$ e, (I) no escuro, medimos as diferenças de potencial paralela $V$ (efeito Shubnikov-de Haas) e perpendicular $V_{H}$ (efeito Hall) a essa corrente (veja a 


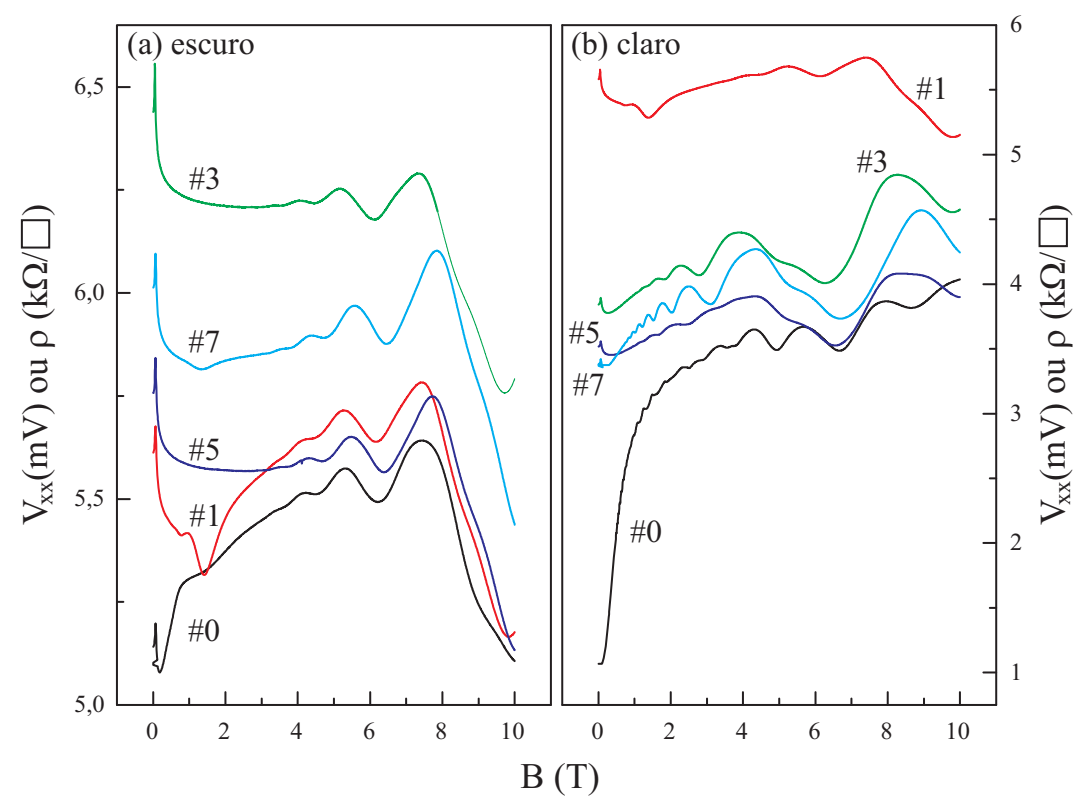

Figura 4.15.: curvas (ou traços) SdH no (a) escuro e no (b) claro das cinco amostras do primeiro conjunto.

figura 3.11) à medida que variamos o campo magnético de zero até dez tesla. Em seguida, (II) iluminamos a amostra através de um LED de $\sim 2 \mathrm{eV}$ por alguns segundos, desligamo-lo e retornamos ao passo (I). Executamos alternadamente os passos (I) e (II) várias vezes até a saturação, situação na qual duas medidas consecutivas não apresentam diferenças apreciáveis.

Levando em conta este procedimento, daqui para frente os termos escuro, antes da iluminação e seus sinônimos referir-se-ão à situação inicial das medidas de transporte, na qual o passo (II) não fora executado nenhuma vez, i.e., na qual a amostra ainda não fora exposta ao LED. Similarmente, com claro, após a iluminação e seus sinônimos referir-nos-emos à situação de saturação. Contudo, note que o uso da palavra claro não significa que a amostra fora exposta à luz enquanto mediamos, mas apenas que fora exposta. Os gráficos de $V$ e $V_{H}$ em função do campo magnético aplicado (B) são chamados de traços $\mathrm{SdH}$ e Hall, respectivamente.

Apenas para simplificar a apresentação dos resultados e das análises a seguir, vamos dividí-la em duas partes: na primeira discutiremos os efeitos da iluminação sobre as amostras e, na segunda, a influência do empilhamento de planos de pontos-quânticos.

\section{Os efeitos da iluminação}

A figura 4.15 apresenta os traços $\mathrm{SdH}$, gráficos de $V \times B$, no escuro e no claro, obtidos diretamente das medidas do efeito Shubnikov-de Haas e sem tratamento algum. Mesmo a partir deles é possível extraír algumas informações qualitativas.

Observamos em primeiro lugar que o valor médio da resistividade decresce ao iluminarmos as 


\section{Resultados}

amostras: no escuro é de $5,7 \mathrm{k} \Omega / \square$ e no claro, de $4,2 \mathrm{k} \Omega / \square$. Mas como a condutividade é proporcional ao produto $n \mu$, podemos concluir que um dos dois (ou ambos) aumentou. Veremos este ponto com maiores detalhes quando analisarmos os resultados das medidas do efeito Hall.

Note agora os três seguintes fatos acerca das oscilações de magnetorresistividade: (i) no escuro o início delas é nítido somente a partir de quatro tesla, mas no claro já as podemos ver em $1 \mathrm{~T}$; (ii) as amplitudes são maiores após a iluminação e, finalmente, (iii) as freqüências das oscilações são maiores no claro.

As duas primeiras observações acima decorrem da redução dos espalhamentos sofridos pelos elétrons: uma das condições necessárias para que observemos as oscilações de magnetorresistividade é que o tempo quântico $\left(\tau_{q} \propto \mu_{q}\right)$, i.e., o tempo de vida do quasi-elétron no nível de Landau, seja maior que o período ciclotrônico $\left(2 \pi / \omega_{c}\right)$ ou, equivalentemente, que $\mu_{q} B \gg 1$. Em palavras, quanto maior for $\tau_{q}$, menor será a intensidade do campo magnético necessário para que as oscilações ocorram. Mas esta condição não é suficiente, pois conforme (2.9) a amplitude das oscilações é dada pela exponencial $\exp \left[-\pi /\left(\mu_{q} B\right)\right]$, o que significa que as oscilações podem não ser visíveis - experimentalmente - para $\mu_{q}$ suficientemente pequena, mesmo que a condição acima valha, ou seja, mesmo que de fato haja oscilação em $\rho$. De qualquer modo, podemos concluir seguramente que as mobilidades quânticas das sub-bandas presentes no claro são maiores que as daquelas presentes no escuro.

A observação (iii) permite-nos concluir que a concentração de portadores da sub-banda que dá origem às oscilações observadas aumenta conforme iluminamos a amostra: veja a equação 2.11 (p. 21).

Resumindo, com base em (i)-(iii), podemos dizer que a iluminação incrementa as concentrações de portadores e aumenta as mobilidades quânticas desses portadores (eventualmente, a iluminação popula sub-bandas antes depopuladas, cf. ref. 45, por exemplo).

O passo seguinte da análise consiste em efetuarmos as transformadas discretas de Fourier dos gráficos de $\rho^{\prime \prime} \times \frac{1}{B}$, sendo $\rho^{\prime \prime}$ a derivada segunda da magnetorresistividade com relação ao recíproco do campo magnético (B) [45]. Fizemos isto através do algorítmo FFT (fast Fourier transform) disponibilizado pelo software de análise de dados Microcal Origin ${ }^{\circledR}$ e obtivemos os espectros de freqüências apresentados na figura 4.16, também nas situações escuro e claro.

Estes espectros são aqueles obtidos com a maior largura da janela Hanning, $\Delta=t_{N}-t_{1}$, onde $t_{1}=1 /(10 \mathrm{~T})$ e $t_{N}$ são os limites inferior e superior da janela, respectivamente. O limite superior da janela Hanning foi fixado em $1 \mathrm{~T}^{-1}$ no escuro e em $0,5 \mathrm{~T}^{-1}$ no claro porque é só a partir destes valores de campo que as oscilações são observáveis (fig. 4.15). O número de pontos utilizados na transformação $(N)$ foi feito igual a $2^{12}=4096$ interpolando linearmente os pontos medidos entre $t_{1}$ e $t_{N}{ }^{10}$

Observando a figura 4.16 notamos que há ao menos duas sub-bandas presentes tanto no escuro quanto no claro: $n_{1}$ e $n_{2}$. Os índices de cada sub-banda são atribuídos da direita para a esquerda

\footnotetext{
${ }^{9} \mathrm{~A}$ notação $\mathrm{k} \Omega / \square$ é uma forma alternativa de escrevermos a resistividade (ou condutividade). Nela o $\square$ representa o fator de forma (ฐ), alertando para o fato de que para se obter a resistividade verdadeira é preciso dividir por $\beth$.

${ }^{10}$ É uma exigência do algorítmo da FFT que $N$ seja uma potência de 2 [110, 111].
} 


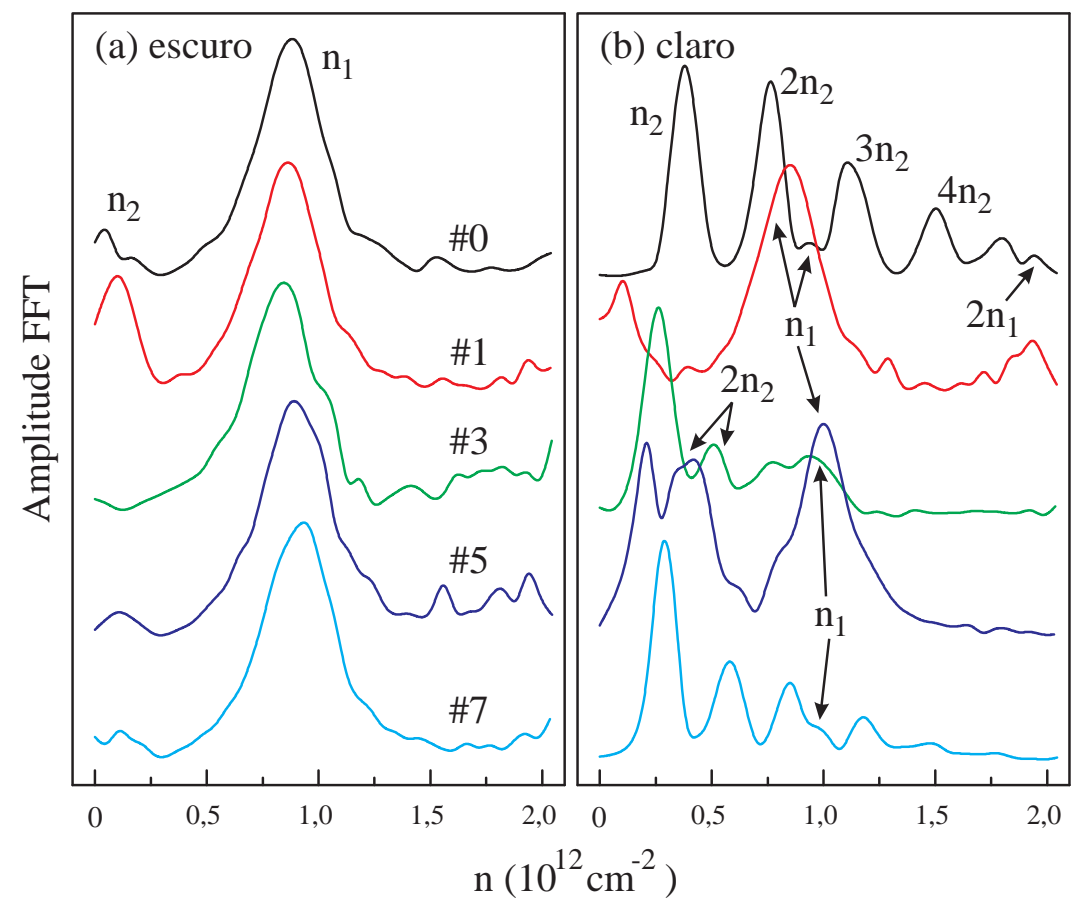

Figura 4.16.: espectros de concentrações no (a) escuro e no (b) claro das oscilações de magnetorresistividade (traços SdH apresentados na figura anterior). Para facilitar a visualização, estes espectros foram normalizados, de modo que suas amplitudes não podem ser comparadas.

no gráfico, i.e., índices menores referem-se a picos com abscissas maiores. Isto porque sub-bandas com índices menores possuem energia de fundo de banda menores e, portanto, são mais populosas (assumindo, como é o caso, que as massas efetivas são parecidas).

No escuro há muita dúvida na identificação desses picos pois há apenas dois, mas no claro a presença de harmônicos (identificados nos espectros por $2 n_{2}, 3 n_{2}$, etc) dificulta a atribuição. Além de serem previstos na dedução de equação de Lifshitz-Kosevich (eq. 2.9) [66], os harmônicos podem também derivar do caráter discreto das transformadas de Fourier com fenômenos espúrios tais como ruídos, flutuações de temperatura, etc [111]. Eles são freqüentemente encontrados e já foram relatados em vários trabalhos [81, 112], mas vamos ignorá-los daqui para frente porque não trazem nenhuma informação adicional.

Podemos também ver pela figura 4.16 que a concentração de portadores de ambas as sub-bandas aumenta ao levarmos as amostras do escuro para o claro. De fato, a concentração média da primeira sub-banda varia de 8,9 (escuro) até $9,3 \times 10^{15} \mathrm{~m}^{-2}$ (claro), enquanto a segunda, de 1,0 a $2,5 \times 10^{15} \mathrm{~m}^{-2}$.

Ao iluminarmos as amostras, os elétrons armadilhados em níveis aceitadores (impurezas residuais de carbono), centros profundos (defeitos estruturais), estados de superfície (ligações químicas insaturadas) e pontos-quânticos (para as amostras que os possuem) absorvem fótons e são transferidos para a banda de condução e, dali, para o 2DES devido à termalização e à presença do campo elétrico gerado pelo desbalanceamento de cargas (band-bending). A contribuição de cada 


\section{Resultados}

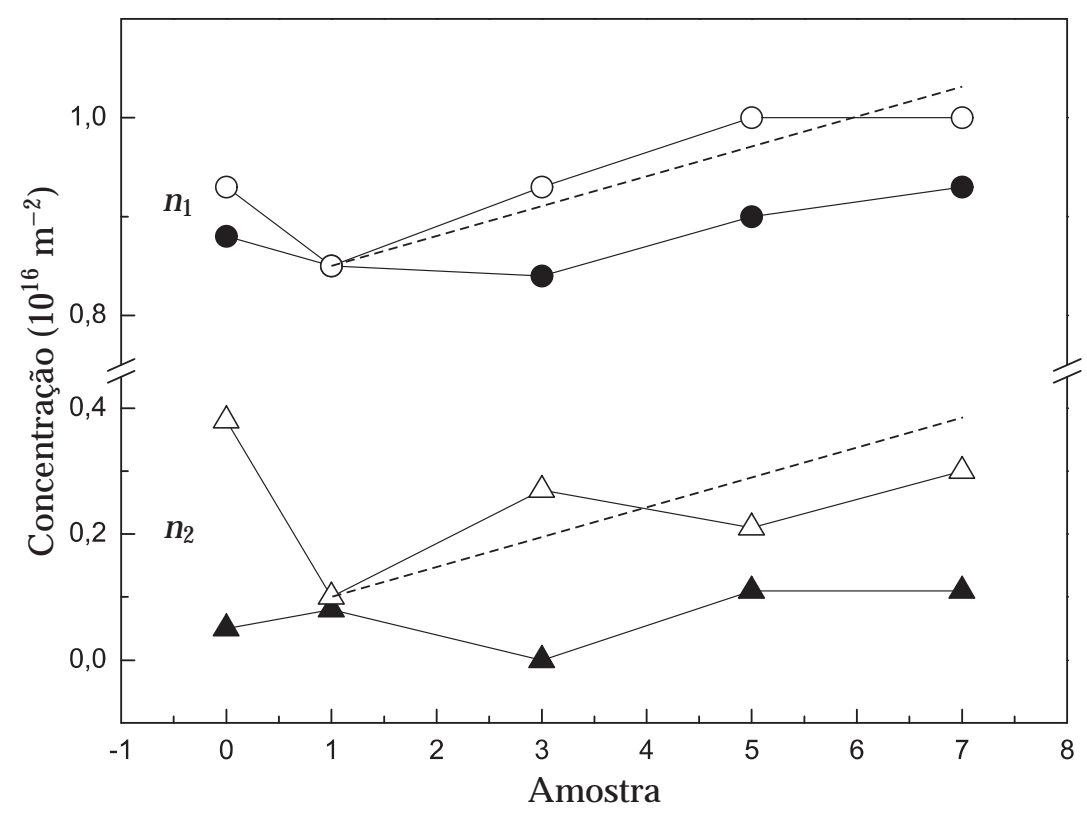

Figura 4.17.: concentração de elétrons na primeira $\left(n_{1}\right)$ e na segunda $\left(n_{2}\right)$ sub-banda do poço-quântico. Os símbolos escuros referem-se ao escuro; os claros, ao claro. O erro na concentração, obtida do efeito Shubnikovde Haas, é da ordem de $10^{10} \mathrm{~cm}^{-2}$.

um desses estados depende das estruturas envolvidas, mas Cavalheiro [91] mostrou que são os centros profundos e os estados de superfície que mais fornecem elétrons para a região-ativa. De fato, ele utilizou cálculos autoconsistentes para mostrar que as impurezas aceitadoras contribuem com não mais do que $\sim 5 \times 10^{14} \mathrm{~m}^{-2}$.

A figura 4.17 ilustra a concentração das duas sub-bandas observadas nos espectros, tanto no escuro (símbolos escuros) como no claro (símbolos claros), em função da quantidade de camadas de pontos-quânticos empilhadas, isto é, em função das amostras. O comportamento médio de ambas as sub-bandas é aumentar a concentração com a iluminação, exceto pela amostra \#1, que não sofreu alteração. Realmente, podemos constatar isso nas figuras 4.15 e 4.16.

No caso da segunda sub-banda esta observação confere com observações anteriores [45], mas não para $n_{1}$, que também deveria aumentar. Acreditamos que isto se deva ao buffer de $170 \mathrm{~nm}$ : por estarem distantes da superfície, os elétrons na camada de pontos-quânticos inibem a ação da iluminação (screening), protegendo o 2DES dela. Naquele trabalho, a camada de pontos-quânticos estava próxima da superfície e, por isso, também era afetada pela iluminação: tornava-se nula. Como conseqüência, a concentração de portadores no 2DES aumentava. Este fenômeno é igual àquele discutido na seção 3.3.3, onde o front-gate só tem influência sobre o poço-quântico mais próximo dele.

Ainda observando os espectros de freqüências, a constatação mais interessante é que a altura do pico referente à segunda sub-banda cresceu muito mais que a daquele referente à primeira. De fato, note que se no escuro o pico $n_{1}$ é mais alto o $n_{2}$, no claro a situação é oposta. Isto significa que, na figura 4.15, as oscilações observadas no escuro devem-se majoritariamente à primeira sub-banda, 

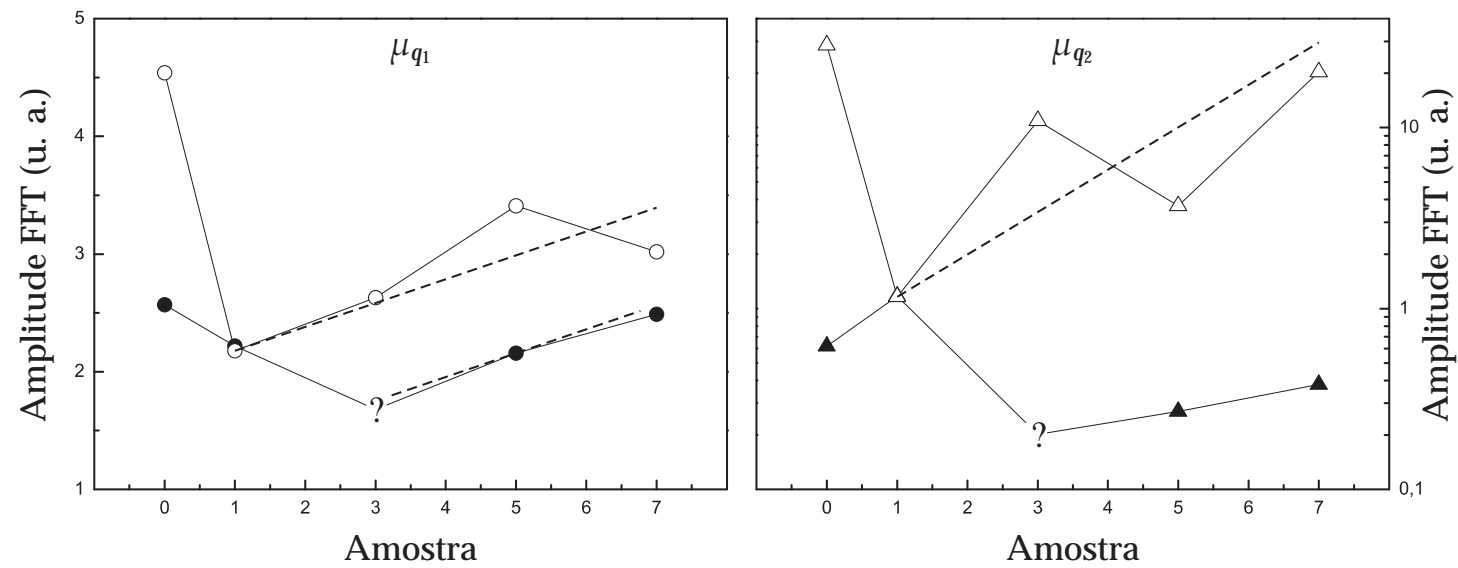

Figura 4.18.: mobilidade quântica dos elétrons na primeira $\left(\mu_{q_{1}}\right)$ e da segunda $\left(\mu_{q_{2}}\right)$ sub-bandas do poçoquântico. Os símbolos escuros referem-se à situação escuro; os claros, à claro. Não há picos nos espectros da amostra \#3 no escuro; os pontos indicados por "?" representam os valores experimentais mais próximos, após 0,76 s de iluminação. (obs.: u.a. = unidades arbitrárias).

enquanto que no claro elas têm origem na segunda sub-banda.

Para determinarmos a mobilidade quântica dessas sub-bandas, precisamos rastrear a dependência da altura dos picos nos espectros com o limite inferior da janela Hanning utilizada na transformada de Fourier [45, p. 45]. Mas este método só é válido quando os picos não se sobrepõem, e isto não é verdade no claro. Alternativamente, podemos comparar as amplitudes dos espectros. Obtemos com isso a figura 4.18 .

O leitor pode eventualmente questionar a validade de estudar a mobilidade quântica, que reflete o tempo de vida do quasi-elétron nos níveis de Landau, não num estado excitado do poço-quântico. Mas ocorre que tanto a mobilidade quântica quanto a de transporte são medidas dos mecanismos de espalhamento existentes [47], o que torna legítimo analisar $\mu_{q}$ para tirar conclusões que visam aplicações eletrônicas.

Agora, observando a figura 4.18 notamos imediatamente que o comportamento é similar ao da figura anterior: todas as mobilidades crescem, exceto (novamente) para a amostra \#1. $\mathrm{O}$ acréscimo na mobilidade ocorre por duas razões: primeiramente, porque há um aumento correspondente de elétrons na região da dopagem (veremos isso ao analisarmos dos dados do efeito Hall clássico), que melhora a blindagem dos íons de silício (screening); segundo, porque como o aumento na concentração de elétrons no 2DES tende a reduzir a extensão da função de onda na direção do crescimento [79], a sobreposição dela com os agentes espalhadores (íons de silício, interface do QW, pontos-quânticos, etc) reduz. O comportamento da amostra \#1 agora condiz com o que já apresentamos.

Observe ainda que de fato, no escuro, os elétrons da primeira sub-banda têm maior mobilidade que os da segunda, enquanto que no claro é o oposto. 


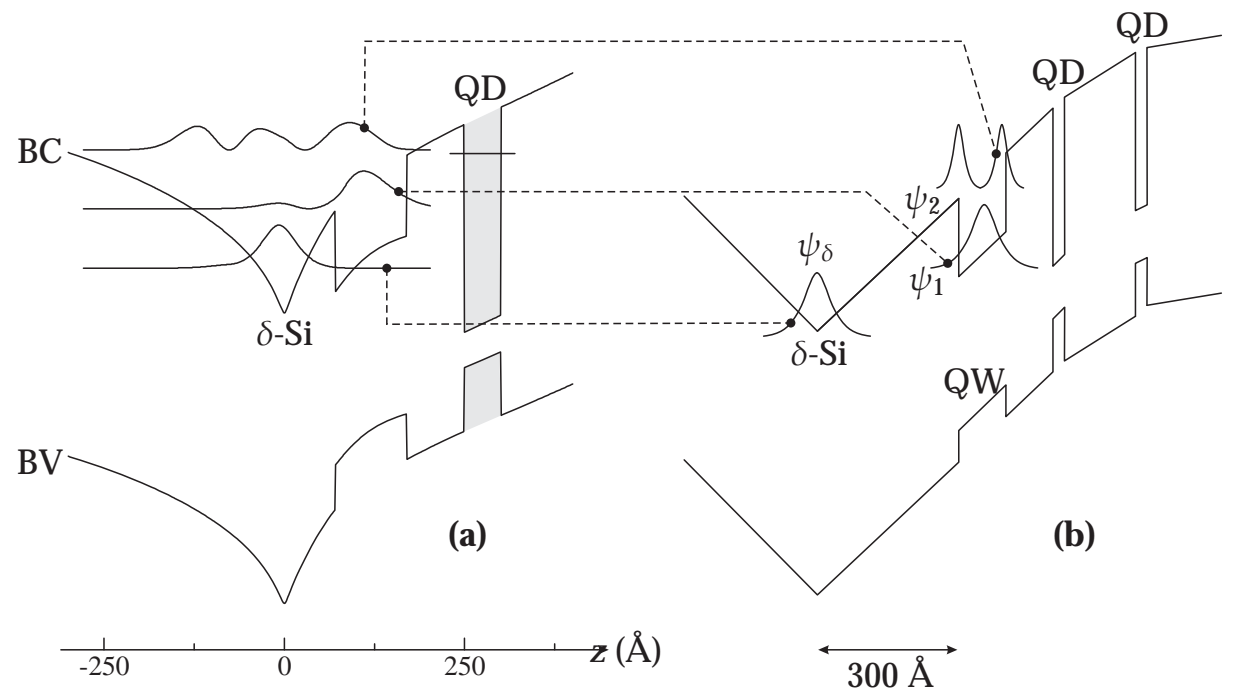

Figura 4.19.: A partir de um (a) cálculo auto-consistente de uma heteroestrutura contendo uma dopagem do tipo delta e um poço-quântico próximo [81] podemos deduzir qualitativamente o (b) perfil das bandas das nossas amostras.

\section{Os efeitos do empilhamento de QDs}

A figura 4.19a mostra um cálculo autoconsistente do trabalho [81] do qual podemos deduzir qualitativamente a distribuição de cargas para as nossas amostras. Nela o poço-quântico está acoplado com o potencial dos íons da dopagem delta e o sistema possui três sub-bandas: a primeira localiza-se sobre o plano da dopagem e tem mobilidade muito baixa devido aos íons de silício; a segunda fica dentro do poço-quântico e a terceira espalha-se por todo o sistema. À medida que afastamos a dopagem do poço-quântico, eles se desacoplam progressivamente, de sorte que a $30 \mathrm{~nm}$ ele estão totalmente desacoplados. Como resultado (fig. 4.19b), a segunda (terceira) sub-banda "torna-se" a primeira (segunda) do poço-quântico.

A primeira sub-banda permanece na dopagem como um canal de condução paralelo de baixa mobilidade que não se manifesta nas oscilações de resistividade, mas que contribui para a condução [dopagem degenerada, onde a distância entre dois átomos de silício $(\sim 5 \mathrm{~nm})$ é menor que o raio de Bohr no GaAs ( $10 \mathrm{~nm})$ ].

A presença dos pontos-quânticos introduz estados localizados nos planos que os contém, conforme fizemos em [45], e podemos representá-los por poços-quânticos, com a ressalva de que não conduzem corrente nas temperaturas utilizadas $(1,4 \mathrm{~K})$.

A figura 4.20a e b apresenta a concentração efetiva $(n)$ e a mobilidade de transporte $(\mu)$, obtidas das medidas do efeito Hall. Com essas medidas mais as do efeito Shubnikov de Haas podemos estimar o comportamento da concentração $\left(n_{\delta}\right)$ e da mobilidade de transporte $\left(\mu_{\delta}\right)$ dos elétrons na dopagem. Basta resolvermos (2.4) para $n_{\delta}$ e $\mu_{\delta}$ :

$$
n_{\delta}=\frac{\left(n \mu-n_{1} \mu_{1}-n_{2} \mu_{2}\right)^{2}}{n \mu^{2}-n_{1} \mu_{1}^{2}-n_{2} \mu_{2}^{2}} \quad \text { e } \quad \mu_{\delta}=\frac{n \mu^{2}-n_{1} \mu_{1}^{2}-n_{2} \mu_{2}^{2}}{n \mu-n_{1} \mu_{1}-n_{2} \mu_{2}},
$$


onde $\mu_{s}$ é a mobilidade de transporte da sub-banda s. Nós não temos $\mu_{s}$, mas sabemos que ela relaciona-se com $\mu_{q_{s}}$ (a mobilidade quântica, obtida do efeito Shubnikov-de Haas) por um fator que depende da distância do 2DES à dopagem [113]. Como as duas sub-bandas localizam-se no poço-quântico, a razão deve ser a mesma e podemos utilizar qualquer valor que resulte em valores não negativos de $n_{\delta}$ e $\mu_{\delta}$. Obviamente os valores absolutos obtidos deste processo não representam a realidade, mas a relação entre eles sim.

Utilizamos $\mu_{s} / \mu_{q, s}=0,06 \mathrm{e}$, como resultado, obtemos as figuras $4.20 \mathrm{c}$ e d. O comportamento de $n_{\delta}$ é similar ao de $n$, enquanto $\mu_{\delta}$ é similar a $\mu$.

Então vejamos as concentrações (fig. 4.17): no escuro tanto $n_{1}$ como $n_{2}$ variam muito pouco à medida que adicionamos mais e mais pontos-quânticos à estrutura. Pouco podemos concluir dessa situação. Mas no claro vemos uma consistente redução entre a \#0 e \#1 e um subseqüente aumento em $n_{s}$. Por outro lado, $n_{\delta}$ aumenta. Acontece que a introdução da camada tensionada de InAs (a presença ou não de pontos-quânticos é irrelevante) eleva o potencial das bandas de condução e de valência, favorecendo a transferência de cargas do 2DES (do poço-quântico) para a dopagem e para a superfície [45].

É importante compreender que o verbo "transferir" acima tem significado didático apenas, já que não existe uma evolução desde a amostra \#0 até a \#7: elas são amostras diferentes e cada qual tem uma distribuição de cargas características que equilibra as cargas na dopagem, no poço-quântico, nos pontos-quânticos e na superfície, dentre outros.

De qualquer forma, a amostra sem pontos-quânticos tem mais elétrons no poço-quântico do que qualquer outra. Contudo, entre \#1 e \#7 essa diferença aumenta à medida que a oferta de elétrons capturados pelos pontos-quânticos aumenta. Na verdade, é preciso analisar a situação através da iluminação, amostra por amostra. Tomemos a \#7, por exemplo. Ela tem 7 camadas de pontosquânticos que, no escuro, estão ocupados por elétrons. Conforme a amostra é iluminada, pares elétron-buraco fotogerados separam-se espacialmente ao longo do eixo de crescimento devido ao campo elétrico estabelecido na heteroestrutura (band-bending). Uma situação possível é a seguinte, ilustrada na figura 4.21: inicialmente os pontos-quânticos mais próximos da superfície transferem elétrons (aqui a transferência é verdadeira) para lá, tornando-se eletricamente neutros (não é necessário chegar a este ponto). Com isso o perfil da banda muda e favorece a depopulação da próxima camada. Mas desta vez é energeticamente mais vantajoso para o elétron migrar para o 2DES e, com isso, $n_{s}$ aumenta.

E como $n_{1}$ (e $n$ ) permanece constante entre \#1 e \#7, somos levados a concluir que o 2DES protege a dopagem desse processo, exatamente da mesma maneira que discutímos anteriormente no caso da amostra \#1. Aliás, com relação a esta amostra, observe que quanto mais longe da superfície estão os pontos-quânticos, menor é a influência da iluminação. É provável que os pares fotogerados próximos à superfície não sobrevivam até chegarem nos pontos-quânticos ou no 2DES.

Finalmente, o comportamento da mobilidade em função da amostra reflete o da concentração. No entanto, este é o resultado mais importante pois, ao contrário do que se poderia pensar, à medida que empilhamos mais e mais pontos-quânticos a mobilidade não é prejudicada. Embora a 

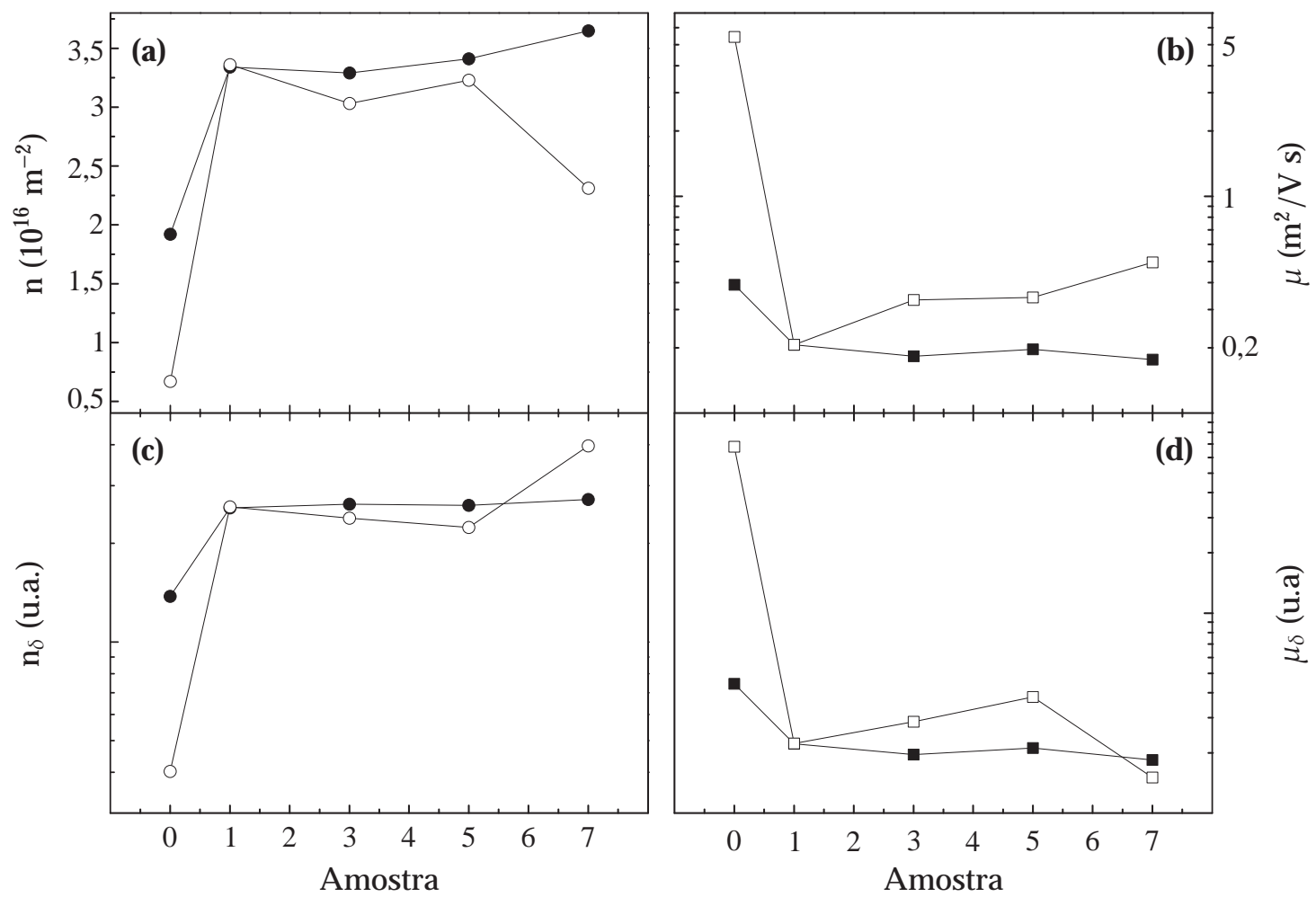

Figura 4.20.: em (a) e (b), concentração e mobilidade efetivas no escuro (símbolos escuros) e no claro (símbolos claros) em função da quantidade de camadas de pontos-quânticos empilhadas, obtidas das medidas do efeito Hall, cf. sec. 2.1. Em (c) e (d), o comportamento da concentração e da mobilidade de transporte dos elétrons sobre a dopagem nas mesmas condições, calculados através da equação 4.7.

formação dos pontos-quânticos libere a tensão mecânica acumulada, isto não ocorre integralmente e o crescimento prossegue sob tensão. O resultado observado sugere que o empilhamento de pontosquânticos pode tanto aumentar (de \#0 para \#1) como reduzir a tensão (de \#1 para \#7), e podemos inclusive conjecturar se a mobilidade apresentaria um comportamento oscilatório, refletindo essas duas tendências.

Independentemente disso, é fato que podemos escolher a quantidade de camadas de pontosquânticos visando maximizar a mobilidade e a corrente fotogerada. Nas nossas amostras, por exemplo, utilizar sete repetições seria a melhor opção. De fato, se ignorarmos toda a análise feita aqui e compararmos apenas os espectros das amostras \#0 e \#7, veremos que são muito parecidos. Eles sugerem que de alguma forma o empilhamento de pontos-quânticos permite à heteroestrutura retomar sua mobilidade inicial (amostra-referência).

\subsubsection{Resultados do $2^{\circ}$ conjunto}

Num fotodetector ideal, o poço-quântico permanece vazio (ou quase) até que se lhe incida uma radiação de comprimento de onda apropriado, levando os elétrons armadilhados nos pontosquânticos para o poço-quântico e permitindo-nos detectá-los através da aplicação de um campo 

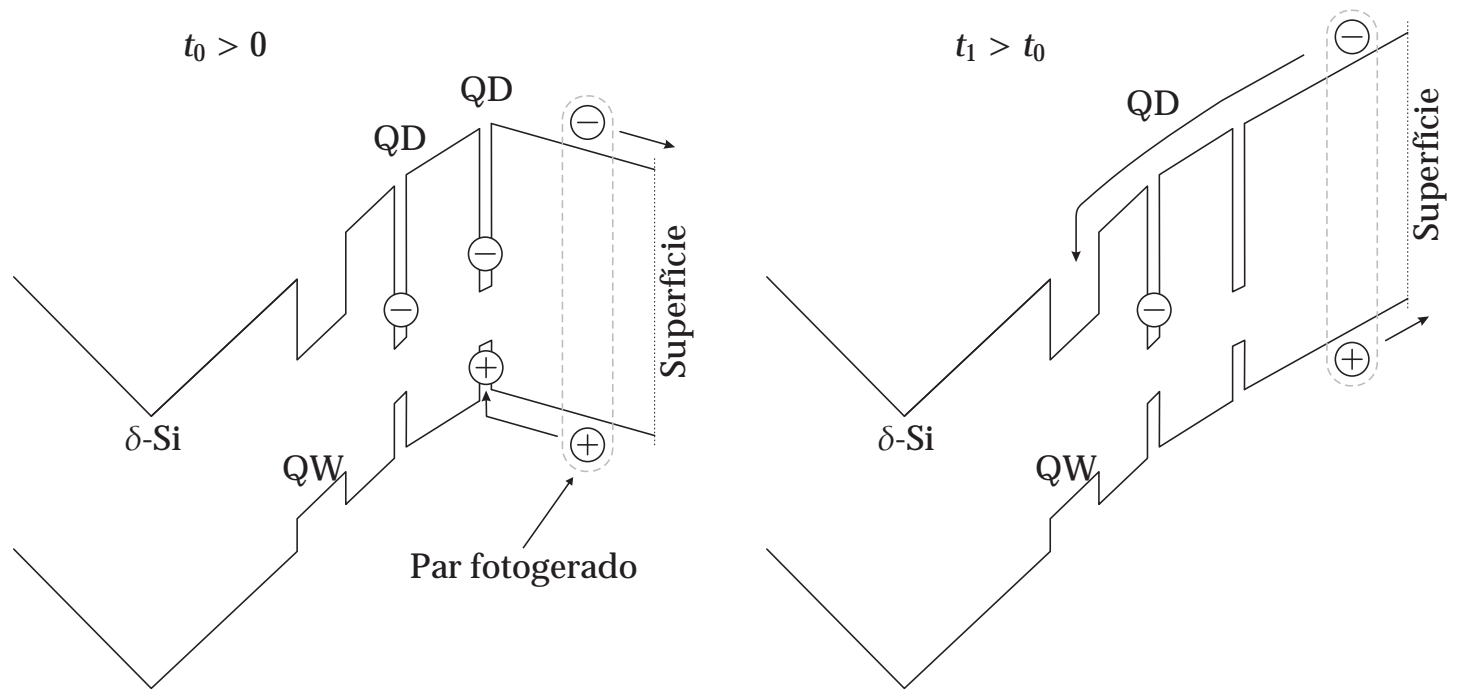

Figura 4.21.: a iluminação promove a transferência de cargas ao longo do eixo do crescimento. À esquerda, após um tempo $t_{0}$ de iluminação, forma-se um par fotogerado. O elétron segue para a superfície e o buraco, para os pontos-quânticos, onde é capturado. Ali ele se recombina com o elétron ali previamente capturado (é como se o ponto-quântico tivesse transferido carga para a superfície). Como resultado, a camada de pontosquânticos torna-se nula e o perfil das bandas muda. Então, num tempo $t_{1}>t_{0}$ (à direita) um novo par é fotogerado. Agora o elétron desloca-se em direção ao 2DES, onde acrescerá a concentração de portadores (se não for capturado pelo ponto-quântico). O buraco, por outro lado, dirige-se para a superfície e lá recombina-se (é como se a superfície transferisse um elétron para o 2DES).

elétrico perpendicular à direção do crescimento. O tempo de vida $\tau$ dos elétrons nesse estado excitado (no poço) está diretamente relacionado com a mobilidade $\left(\mu=e \tau / m^{*}\right)$. Além disso, a mobilidade é uma medida do quão rapidamente um elétron responderá ao campo elétrico aplicado, que também é importante.

Como de costume, fizemos tanto medidas do efeito Shubnikov-de Haas como do Hall, mas devido às baixíssimas mobilidades, não pudemos enxergar nenhuma oscilação em $R_{x x}$. Portanto, contentamo-nos com os resultados do efeito Hall.

A figura 4.22 apresenta a mobilidade Hall em função do gate aplicado para as amostras com 1 e 10 períodos. Analisemos primeiro aquelas com 1 periodo: notamos imediatamente que tensões negativas deslocam a função de onda para cima dos QDs, reduzindo a mobilidade; o contrário para $V_{G S}>0$. Este é um resultado esperado. A primeira novidade, entretanto, é que posicionar os pontos-quânticos no centro do QW é a pior escolha, qualquer que seja $V_{g}$. Pior até que utilizar um poço-quântico triangular, inerentemente rugoso. É mais uma evidência de que a capacidade de espalhamento dos QDs é muito superior que a das imperfeições na interface do QW.

Quando $V_{G S}<0$ o comportamento de qualquer uma das configurações é o mesmo, mas para $V_{G S}>0$ vemos que (i) a mobilidade no QW triangular cresce mais rapidamente, embora sature rapidamente em $0,3 \mathrm{~m}^{2} / \mathrm{Vs}$ para $V_{G S}=0,5 \mathrm{~V}$. (ii) Já o poço-quadrado com os QDs na interface oposta a da dopagem apresenta a melhor mobilidade a partir de $0,75 \mathrm{~V}$, chegando mesmo a triplicar seu valor em $V_{G S}=0 \mathrm{~V}$. 


\section{Resultados}

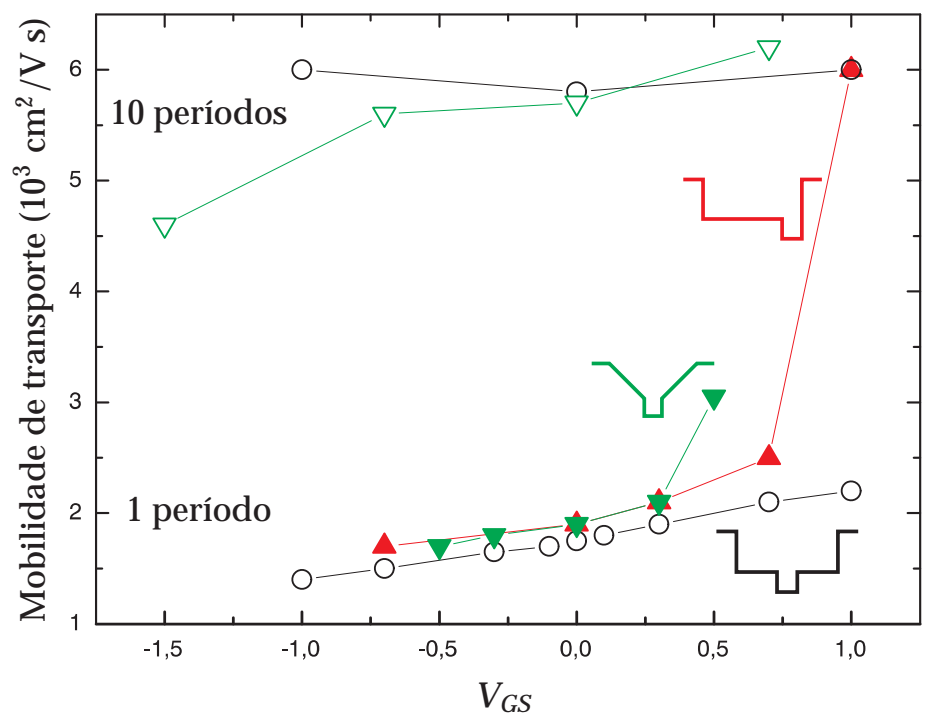

Figura 4.22.: mobilidade de transporte em função do gate. As curvas terminam onde ocorre a saturação. Por exemplo, para a curva verde, $V_{G S}$ pouco maior que $0,5 \mathrm{~V}$ não acarreta alterações na mobilidade. Os desenhos ao lado de cada gráfico são representações do perfil de potencial do QW, que distingue as amostras. Compare-os com a figura 3.9 .

Note que para uma heteroestrutura contendo pontos-quânticos auto-formados, mobilidades de alguns $\mathrm{m}^{2} /$ Vs é razoável [78], embora ainda aquém do que se pode obter.

Quando empilhamos dez períodos, a mobilidade aumenta para todos os valores de $V_{G S}$, mas parece saturar próximo do valor obtido anteriormente para a amostra com pontos-quânticos, $0,6 \mathrm{~m}^{2} /$ Vs. Mais que isso, o resultado sugere que o empilhamento torna a heteroestrutura menos suscetível à aplicação do gate, ao menos no caso da amostra com pontos-quânticos no centro do poço-quântico. Por outro lado, a mobilidade dos elétrons no poço-quântico triangular, embora mantenha a amplitude da variação em função do gate, torna-se nitidamente menos favorável que a primeira para $V_{G S}<0$. A situação se inverte para $V_{G S}>0$. Isto significa que nesta heteroestrutura o deslocamento da função de onda dos elétrons é muito mais suscetível ao gate.

Quanto a amostra de dez períodos com QDs na interface do poço-quântico, não pudemos medí-la porque ela foi destruída pela difusão do ouro do gate, sec. 3.3.3.

Finalmente, concluimos que a melhor opção de região-ativa para QDIPs são poços-quânticos quadrados com pontos-quânticos na interface oposta à da dopagem. Este resultado é verdadeiro desde que não empilhemos as regiões-ativas. Isto porquê se construirmos um QDIP como o da figura 1.1, os íons da camada de dopagem modificariam a banda de condução (conforme ilustrado), favorecendo aos elétrons no poço-quântico aproximarem-se dos pontos-quânticos. Uma opção para contornar isso é alternar dopagens com altas e baixas concentrações, mantendo os pontos-quânticos nas interfaces mais próximas das baixas concentrações. 


\section{5 \\ Conclusões e perspectivas}

Apresentamos neste trabalho três estudos sobre o transporte de cargas em heteroestruturas IIIV contendo pontos-quânticos, utilizando para isso os efeitos Hall clássico e quântico inteiro, o Shubnikov-de Haas e a localização-fraca. Todos os três levaram-nos a conclusões importantes para a para Física Básica e para a Aplicada.

No primeiro deles, observamos pela primeira vez que os platôs do efeito Hall quântico inteiro podem assumir valores distintos daqueles previstos pela regra $R_{K} / v$. Isto acontece quando a condução ocorre através de dois canais de condução paralelos independentes e um deles está sujeito a uma rede de antipontos-quânticos litográficos (hexagonal, no nosso caso). Nesta situação, coexistem estados de borda normais e contra-rotativos (previstos em 1992, mas até então não observados experimentalmente), dando origem a platôs que podem ser determinados através do formalismo de Landauer-Büttiker.

No segundo estudo, observamos que o espaço de fases dos elétrons que compõem um 2DES próximo a uma camada tensionada de InAs (que, eventualmente, contém pontos-quânticos) é reduzido pelo acúmulo da tensão mecânica acumulada durante o crescimento epitaxial. O mecanismo através do qual isto ocorre não está claro.

Finalmente, visando contribuir para o atual desenvolvimento dos fotodetectores de infravermelho baseados em pontos-quânticos, averiguamos que a tensão mecânica acumulada durante o empilhamento de pontos-quânticos de InAs (procedimento este utilizado para maximizar a corrente elétrica fotogerada) não necessariamente prejudica a mobilidade dos portadores (e, com isso, a responsividade do dispositivo). Este resultado pode ser utilizado para determinar a quantidade de 


\section{Conclusões e perspectivas}

camadas de pontos-quânticos que maximiza a mobilidade. É importante observar que o presente estudo, embora vise as aplicações, é de Física Básica. 


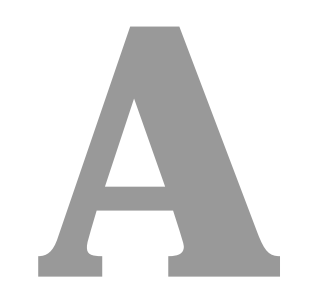

\section{Lista de símbolos}

$A$ Potencial vetor associado ao campo magnético: $B=\nabla \times A$;

$A_{e e} \quad$ Coeficiente angular do gráfico $\tau_{\varphi}^{-1} \times T ;$

$B=|B| \quad$ Campo magnético aplicado;

$b_{\varphi, s o} \quad$ Parâmetro auxiliar de ajuste, definido como $B_{\varphi, s o} / B$;

$B_{\varphi, \text { so }} \quad$ Campo magnético no qual um elétron percorre, por difusão e durante o tempo $\tau_{\varphi}$ $\left(\tau_{\mathrm{so}}\right)$, uma trajetória que encerra uma área tal que contenha aproximadamente um quantum de fluxo magnético $\left(\Phi_{0}\right)$;

$d_{\text {InAs }}$ Espessura nominal da camada de InAs, em monocamadas (MC);

$\delta(x) \quad$ Função delta de Dirac;

$\delta$-Si Camada de dopagem planar

$\delta \sigma$ Correção teórica da condutividade clássica, devido à localização-fraca ou interações entre elétrons;

$\Delta \sigma$ Correção experimental da condutividade clássica, devido à localização-fraca ou interações entre elétrons;

$\Delta(1 / B) \quad$ Período das oscilações de magnetorresistência (efeito Shubnikov-de Haas);

$\Delta_{z} \quad$ Zeeman splitting (gap de spin);

e Carga do elétron $\left(1,602 \times 10^{-19} \mathrm{C}\right)$; 


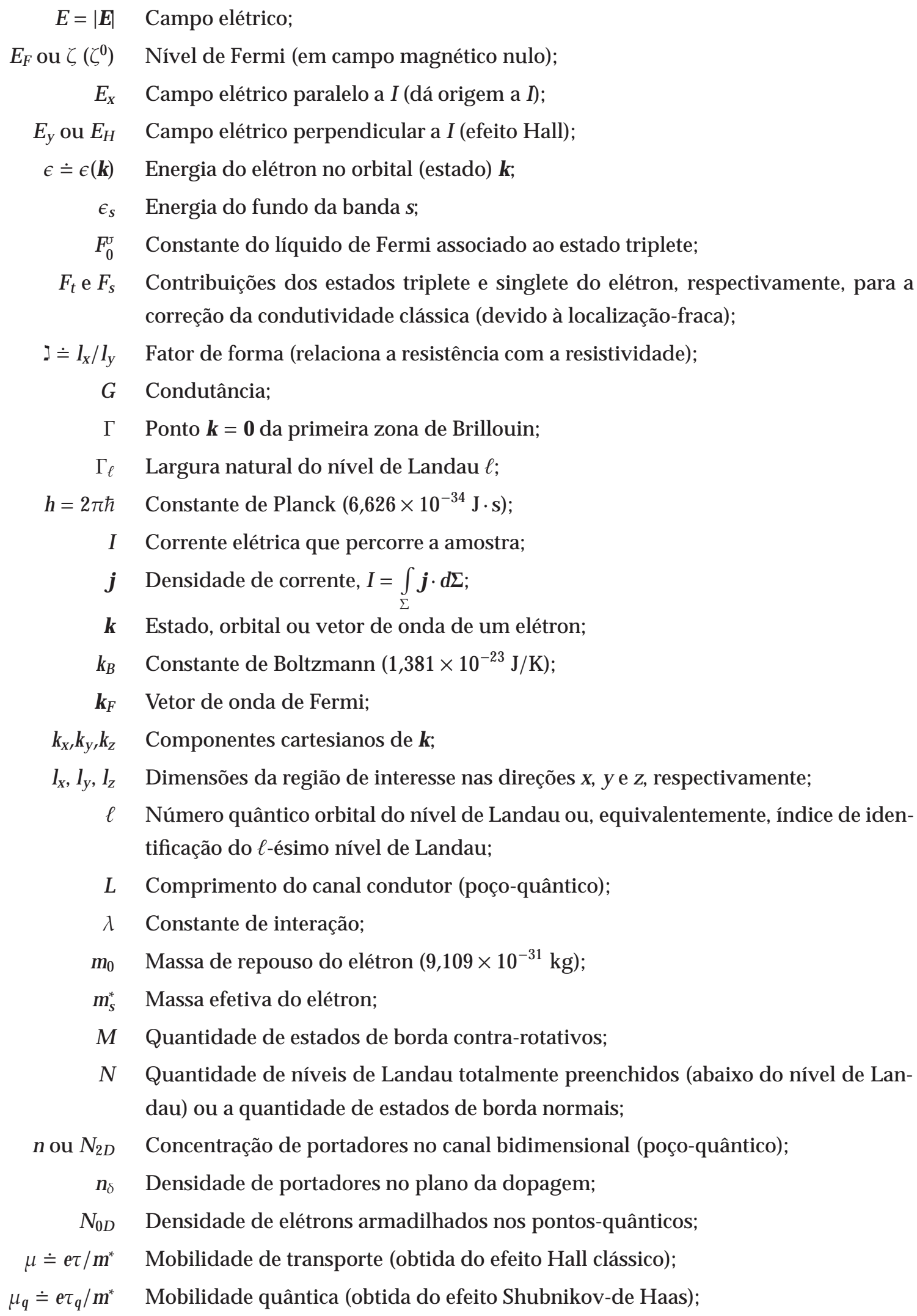




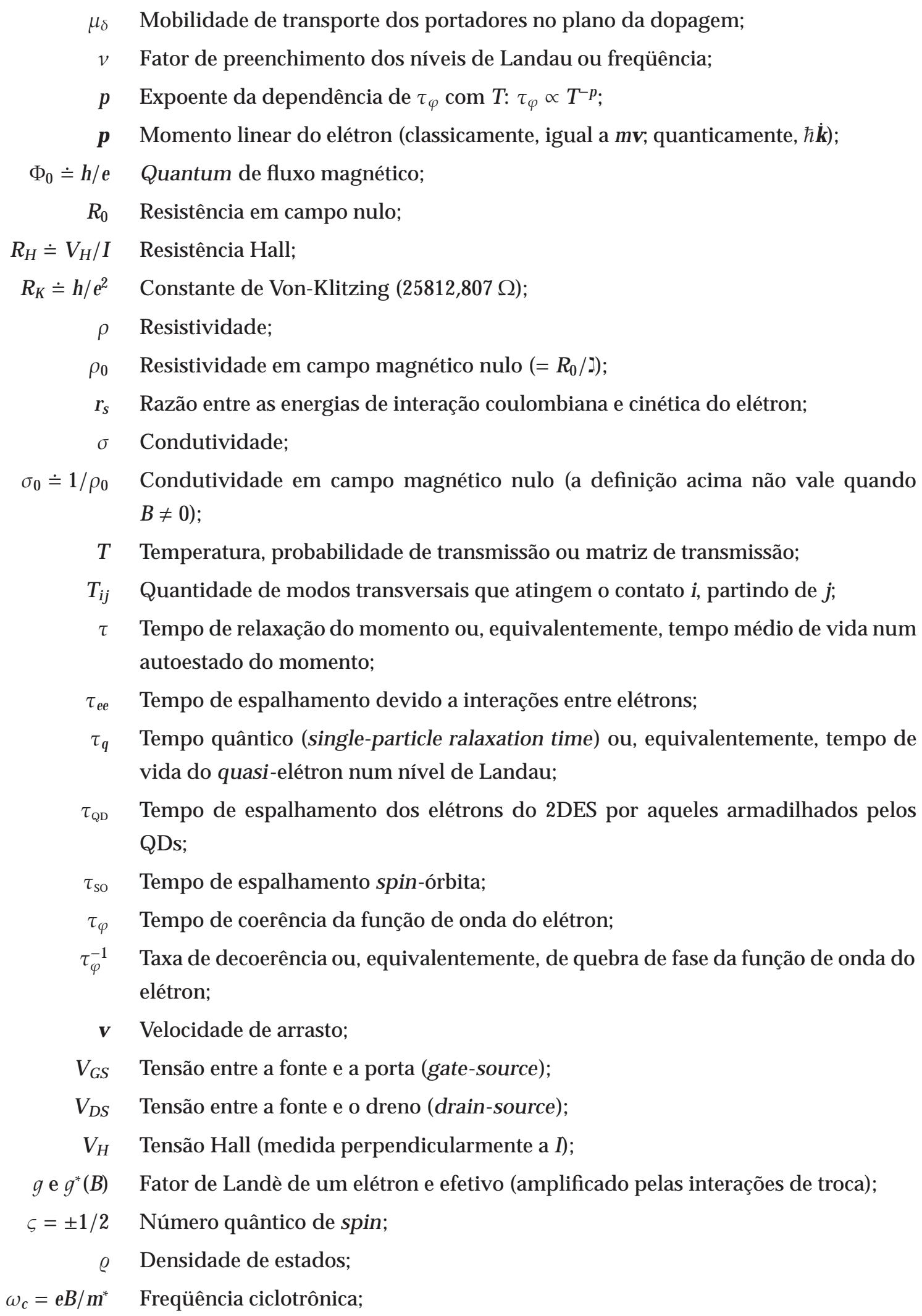




\section{A. Lista de símbolos}

$\psi_{s}$ e $\psi_{\delta} \quad$ Função de onda do elétron na sub-banda s e no plano da dopagem, respectivamente; 


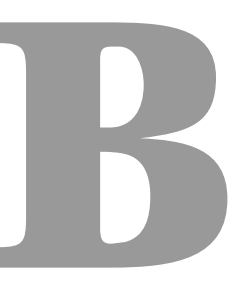

\section{Lista de siglas}

2DES/2DEG Two-dimensional electron system/gas (sistema/gás bidimensional de elétrons);

BC Banda de condução;

BV Banda de valência;

CCS Centro de Componentes Semicondutores;

CNRS Centre National de la Recherche Scientifique (centro nacional de pesquisa científica);

DQW Double quantum-well (poço-quântico duplo);

EEI Electron-electron interaction (interações entre elétrons);

FFT Fast Fourier transform (transformada rápida de Fourier);

HEMT High electron-mobility transistor (transístor baseado em elétron de alta mobilidade);

IF-USP/SP Instituto de Física da Universidade de São Paulo (campus capital);

IQHE Integer quantum Hall effect (efeito Hall quântico inteiro);

LCMI Laboratorie du Champs Magnetics Intenses (laboratório de campos magnéticos intensos);

LNMS Laboratório de Novos Materiais Semicondutores;

LB Equação ou formalismo de Landauer-Büttiker; 
B. Lista de siglas

LL Landau-level (nível de Landau);

LSI Laboratório de Sistemas Integrados;

MC Monocamadas (ou monolayers: ML);

MBE Molecular beam epitaxy (epitaxia por feixe molecular);

PMMA Polimetilmetacrilato (polímero);

QD Quantum-dot (ponto-quântico);

QDIP Quandum-dot infrared photodetector (fotodetector de infravermelho baseado em pontos-quânticos);

QW Quantum-well (poço-quântico);

RHEED Reflection high-energy electron diffraction;

$\mathrm{SdH}$ Shubnikov-de Haas;

SEM Scanning electron microscopy/microscope (microscopia/microscópio de varredura por elétrons);

SQD Self-organized quantum-dots (pontos-quânticos auto-organizados);

WL Weak-localization (localização-fraca) ou wetting-layer. 


\section{C}

Súmula curricular

\section{Artigos}

- I. R. Pagnossin, E. C. F. da Silva, A. A. Quivy, S. Martini e C. S. Sergio, The quantum mobility of a two-dimensional electron gas in selectively doped GaAs/InGaAs quantum wells with embedded quantum dots, J. Appl. Phys. 97, 113709 (2005);

- I. R. Pagnossin, G. M. Gusev, N. M. S. Choque, A. C. Seabra, A. A. Quivy, T. E. Lamas e J.-C. Portal, Quantum Hall effect in bilayer system, Proceedings da International Conference on the Physics of Semiconductors, Austria (2006);

- I. R. Pagnossin, A. K. Meikap, T. E. Lamas e G. M. Gusev, Weak-localization and interaction effects in GaAs/InGaAs heterostructures with nearby quantum-dots, Brazilian Journal of Physics (2008), aguardando publicação;

\section{Eventos}

- 13th Brazilian Workshop on Semiconductor Physics, Weak localization and interaction effects in GaAs/InGaAs heteroestructures with nerby quantum-dots, 2007 (São Paulo);

- 28th International Conference on the Physics of Semiconductors, Quantum Hall effect in bilayer system with array of antidots, 2006 (Áustria);

- 12th Brazilian Workshop on Semiconductor Physics, Scattering processes on a quasi-two- 
dimensional electron gas in GaAs/InGaAs selectively doped quantum wells with embedded quantum dots, 2005 (São José dos Campos);

- 12th Brazilian Workshop on Semiconductor Physics, The influence of strain fields around InAs quantum-dots on the transport properties of a two-dimensional electron gas confined in GaAs/InGaAs wells, 2005 (São José dos Campos);

- XVIII Encontro Nacional de Física da Matéria, The influence of strain fields around InAs quantum-dots on the transport properties of a two-dimensional electron gas confined in GaAs/InGaAs wells, 2005 (Santos);

- XVII Encontro Nacional de Física da Matéria Condensada, A influência de pontos-quânticos de InAs sobre a mobilidade quântica de gases bidimensionais de elétrons confinados em poços-quânticos de GaAs/InGaAs seletivamente dopados, 2004 (Poços de Caldas).

\section{Estágios}

- Estágio de dois meses e meio no LCMI do CNRS, em Grenoble (França). 


\section{Referências Bibliográficas}

[1] B. L. Johnson, C. Barnes, G. Kirczenow, Phys. Rev. B 46, 15302 (1992).

[2] A. J. Severino, Metodologia do trabalho científico (Cortez editora, 2000), 21st edn.

[3] C. A. Duarte, Processos de recombinação em pontos-quânticos em amostras com diferentes espessuras de camadas de inas utilizando a técnica de fotoluminescência, Master's thesis, IFUSP, São Paulo (2002).

[4] P. B. Joyce, et al., Phys. Rev. B 64, 235317 (2001).

[5] M. J. da Silva, et al., Microelec. J. 34, 631 (2003).

[6] M. J. da Silva, et al., Appl. Phys. Lett. 82, 2646 (2003).

[7] S.-F. Tang, S.-Y. Lin, S.-C. Lee, Appl. Phys. Lett. 78, 2428 (2002).

[8] J. D. Phillips, J. Appl. Phys. 91, 4590 (2002).

[9] V. Ryzhii, I. Khmyrova, V. Mitim, M. Stroscio, M. Willander, Appl. Phys. Lett. 78, 3523 (2001).

[10] L. Chu, A. Zrenner, M. Bichler, G. Abstreiter, Appl. Phys. Lett. 79, 2249 (2001).

[11] G. Yusa, H. Sakaki, Appl. Phys. Lett. 70, 345 (1997).

[12] Z. Chen, E.-T. Kim, A. Madhukar, Appl. Phys. Lett. 80, 2490 (2002).

[13] S. Raghvan, et al., Appl. Phys. Lett. 81, 1369 (2002).

[14] S.-F. Tang, S.-Y. Lin, S.-C. Lee, IEEE Transactions on Electron Devices 49, 1341 (2002).

[15] S. Fafard, et al., Science 274, 1350 (1996).

[16] D. Bimberg, M. Grundmann, N. N. Ledentsov (1999).

[17] S.-W. Lee, K. Hirakawa, Y. Shimada, Appl. Phys. Lett. 75, 1999 (1999).

[18] A. J. Shields, et al., Appl. Phys. Lett. 74, 735 (1999).

[19] G. H. Kim, J. T. Nicholls, S. I. Khondaker, I. Farrer, D. A. Ritchie, Phys. Rev. B 61, 10910 (2000). 
[20] B. Dubertret, et al., Science 298, 1759 (2002).

[21] S. Coe, W. K.Woo, M. Bawendi, V. Bulovi, Nature 420, 800 (2002).

[22] S. J. Xu, T. Mei, X. C. Wang, X. H. Zhang, X. G. Xie, Appl. Phys. Lett. 73, 3153 (1998).

[23] X. Su, S. Chakrabarti, A. Stiff-Roberts, J. Singh, P. Bhattacharya, Elletr. Lett. 40, 17 (2004).

[24] V. Ryzhii, Semicond. Sci. Technol. 11, 759 (1996).

[25] S. J. Lee, S. K. Noh, S. C. Hong, J. Lee, Curr. Appl. Phys. 6, 37 (2006).

[26] N. W. Ashcroft, N. D. Mermin, Solid state physics (Saunders College Publishing, 1976).

[27] M. Eshkol, E. Eisenberg, M. Karpovski, A. Palevski, Phys. Rev. B 73, 115318 (2006).

[28] N. Thillosen, et al., Phys. Rev. B 73, 241311 (2006).

[29] W. Desrat, D. K. Maude, Z. R. Wasilewski, R. Airey, G. Hill, Phys. Rev. B 74, 193317 (2006).

[30] S. A. Studenikin, P. T. Coleridge, N. Ahmed, P. J. Poole, A. Sachrajda, Phys. Rev. B 68, 035317 (2003).

[31] G. M. Minkov, et al., Phys. Rev. B 70, 155323 (2004).

[32] R. E. Prange, S. M. Girvin, The quantum Hall effect (Springer-Verlag, 1990), second edn.

[33] B. I. Halperin, Physical Review B 25, 2185 (1982). Halperin introduces the edge states as an explanation to the integer quantum Hall effect.

[34] C. H. W. Barnes, Quantum electronics in semiconductors ((na Internet)).

[35] D. J. Thouless, M. Kohmoto, M. P. Nightingale, M. den Nijs, Physical Reviews Letters 49, 405 (1982).

[36] D. R. Hofstadter, Physical Review B 14, 2239 (1976).

[37] A. H. MacDonald, Physical Review B 29, 6563 (1984).

[38] S. Ishizaka, K. Nakamura, T. Ando, Physical Review B 48, 12053 (1993).

[39] B. L. Johnson, G. Kirczenow, Phys. Rev. Lett. 69, 672 (1992).

[40] M. C. Geisler, et al., Physical Review Letters 92, 256801 (2004).

[41] K. Muraki, T. Saku, Y. Hirayama, Phys. Rev. Lett. 87, 196801 (2001).

[42] K. Takehana, T. Takamasu, G. Kido, M. Henini, L. Eaves, Physica E 34, 148 (2006).

[43] S. Datta, Electronic transport in mesoscopic systems (Cambridge University press, 1995).

[44] L. J. van der Pauw, Phil. Res. Rep. 13, 1 (1958). 
[45] I. R. Pagnossin, Propriedades de transporte elétrico de gases bidimensionais de elétrons nas proximidades de pontos-quânticos de inas, Master's thesis, Instituto de Física da Universidade de São Paulo, São Paulo (2004). Versão digital disponível em http://www.teses.usp.br.

[46] D. C. Look, Electrical characterization of GaAs materials and devices (John Wiley \& Sons, 1992).

[47] G.-Q. Hai, N. Studart, F. M. Peeters, P. M. Koenraad, J. H. Wolter, J. Appl. Phys. 80(10), 5809 (1996).

[48] K. von Klitzing, G. Dorda, M. Pepper, Phys. Rev. Lett. 45, 494 (1980).

[49] S. M. Girvin, Physics Today p. 39 (2000).

[50] A. M. O. de Z. Márquez, Estudo de poços parabólicos largos de AlGaAs em campos magnéticos altos, Master's thesis, Universidade de São Paulo (2007).

[51] R. R. Gerhardts, Zeitschrift für Physik B 21, 275, 278 (1975).

[52] K. Ensslin, et al., Phys. Rev. B 47, 1366 (1993).

[53] B. Huckestein, Reviews of Modern Physics 67, 357 (1995).

[54] M. Weiss, Quantum hall effect in a strongly disordered system, Ph.D. thesis, Universität Konstanz Fachbereich Physik (2004).

[55] G. Gobsch, D. Schulze, G. Paasch, Phys. Rev. B 38, 10943 (1988).

[56] J. P. Sethna, Lectures in Complex Systems (Addison-Wesley, 1992), vol. XV, chap. Order Parameters, Broken Symmetry, and Topology.

[57] J. T. Chalker, P. D. Coddington, Journal of Physics C 21, 2665 (1988).

[58] J. F. Janak, Physical Review 178, 1416 (1969).

[59] B. A. Piot, et al., Phys. Rev. B 72, 245325 (2005).

[60] M. M. Fogler, B. I. Shklovskii, Physical Review B 52, 17366 (1995).

[61] T. Ando, A. B. Fowler, F. Stern, Review of Modern Physics 54, 437 (1982).

[62] T. Jungwirth, A. H. MacDonald, Physical Review B 63, 035305 (2000).

[63] H. A. Fertig, L. Brey, R. Côté, A. H. MacDonald, Physical Review B 50, 11021 (1994).

[64] G. Tsitsishvili, Z. F. Ezawa, Physical Review B 72, 115306 (2005).

[65] I. S. Millard, et al., Journal of Physics: Condensed Matter 11, 3711 (1999).

[66] B. K. Ridley, Quantum processes in semiconductors (Clarendon Press, Oxford, 1993), third edn.

[67] B. J. van Wees, et al., Phys. Rev. Lett. 60, 848 (1988). 
[68] D. Wharam, J. Phys. C 21, L209 (1988).

[69] M. Büttiker, Phys. Rev. Lett. 57, 1761 (1986).

[70] J. Oswald, M. Oswald, J. Phys.: Condens. Matter 18, R101 (2006).

[71] G. Bergmann, Phys. Rep. 107, 1 (1984).

[72] E. Abrahams, P. W. Anderson, D. C. Licardello, T. V. Ramakrishnan, Phys. Rev. Lett. 42, 673 (1979).

[73] M. J. da Silva, Crescimento e caracterização de pontos-quânticos de inas auto-formados, Master's thesis, IFUSP, São Paulo (1999).

[74] A. L. Sperandio, Crescimento epitaxial por feixe molecular de camadas para aplicação em dispositivos, Master's thesis, Instituto de Física da Universidade de São Paulo, São Paulo (1998).

[75] T. R. Ramachandran, R. Heitz, P. Chen, A. Madhukar, Appl. Phys. Lett. 70, 640 (1997).

[76] R. Reitz, et al., Phys. Rev. Lett. 78, 4071 (1997).

[77] T. S. T. N. H. A. Y. K. e. H. N. . . H. Sakaki, G. Yusa, Appl. Phys. Lett. 67, 3444 (1995).

[78] E. Ribeiro, et al., Phys. Rev. B 58, 1506 (1998).

[79] L. W. Höppel, Phase transitions in single layer and bilayer quantum hall ferromagnets, Ph.D. thesis, Fakultät Mathematik und Physik der Universität Stuttgart, Stuttgart (2004).

[80] I. R. Pagnossin, E. C. F. da Silva, A. A. Quivy, S. Martini, C. S. Sergio, J. Appl. Phys. 97, 113709 (2005).

[81] A. Cavalheiro, O efeito da fotocondutividade e a estrutura eletrônica de poços-quânticos de GaAs/InGaAs/GaAs com dopagem planar do tipo n na barreira, Ph.D. thesis, IF-USP/SP (2001).

[82] C. S. Sergio, Transporte quântico em poços-parabólicos largos, Ph.D. thesis, Instituto de Física da Universidade de São Paulo (IFUSP) (2003).

[83] D. Wood, Optoelectronic semiconductor devices (Prentice Hall, 1994).

[84] A. S. Sedra, K. C. Smith, Microelectronic circuits (Oxford University Press, 1997).

[85] K. Muraki, N. Kumada, T. Saku, Y. Hirayama, Jpn. J. Appl. Phys. 39, 2444 (2000). A very simple and instructive article concerning double-quantum-wells.

[86] R. Fletcher, et al., Phys. Rev. B 71, 155310 (2005).

[87] J. Wagenhuber, T. Geisel, P. Niebauer, G. Obermair, Phys. Rev. B 45, 4372 (1992). 
[88] N. M. S. Choque, Estudo da dinâmica de caos no gás tridimensional de elétrons de alta mobilidade, Ph.D. thesis, Instituto de Física da Universidade de São paulo (2002).

[89] G. Kirczenow, Phys. Rev. B 46, 1439 (1992).

[90] Oxford Instruments, England, Practical cryogenics (2000). Oxford's manual on laboratory cryogenics.

[91] A. Cavalheiro, et al., Phys. Rev. B 65, 111 (2002).

[92] G. M. Gusev, et al., Physical Review B 58, 4636 (1998).

[93] C. Lien, Y. Huang, H. Chien, W. Wang, IEEE T Electron Dev 41, 1351 (1994).

[94] B. L. Altshuler, D. E. Khmel'nitskii, A. I. Larkin, P. A. Lee, Phys. Rev. B 22, 5142 (1980).

[95] B. L. Altshuler, A. G. Aronov, A. I. larkin, D. E. Khmel'nitskii, Zh. Eksp. Teor. Fiz 81, 768 (1981). [Sov. Phys. JETP 54, 411 (1981)].

[96] B. L. Altshuler, A. G. Aronov, Modern Problems in Condensed Matter Science (A. L. Efros and M. Pollak, Amsterdam, North-Holland, 1985), chap. Electron-Electron Interactions in Disordered Systems.

[97] G. Zala, B. N. Narozny, I. L. Aleiner, Phys. Rev. B 64, 214204 (2001).

[98] I. V. Gornyi, A. D. Mirlin, Phys. Rev. Lett. 90, 076801 (2003).

[99] E. I. Rashba, Fiz. Tverd. Tela 2, 1224 (1960). [Sov. Phys. Solid State 2, 1109 (1960)].

[100] P. D. Dresselhaus, C. M. Papavassiliou, R. G. Wheeler, R. N. Sacks, Phys. Rev. Lett. 68, 106 (1992).

[101] G. Lommer, F. Malcher, U. Rossler, Phys. Rev. Lett. 60, 728 (1988).

[102] I. Zutic, J. Fabian, S. D. Sarma, Rev. Mod. Phys. 76, 323 (2004).

[103] J. Rammer, A. Schmid, Phys. Rev. B 34, 1352 (1986).

[104] S. Iordanski, Y. Levinson, Phys. Rev. B 53, 7308 (1996).

[105] B. N. Narozhny, G. Zala, I. L. Aleiner, Phys. Rev. B 65, 180202 (2002).

[106] B. L. Altshuler, A. G. Aronov, D. E. Khel'nitskii, J. Phys. C 15, 7367 (1982).

[107] W. E. Eiler, J. Low Temp. Phys. 56, 481 (1984).

[108] Y. Imry, Phys. Rev. B 42, 927 (1990).

[109] T. Kawazu, H. Sakaki, Physica E 29, 593 (2005). 
[110] W. H. Press, W. A. Teukolsky, W. T. Vetterling, B. P. Flannery, Numerical recipes in Fortran 77 (Cambridge University press, 1992).

[111] S. W. Smith, The scientist and engineer's guide to digital signal processing (California Technical Publishing, California, 1999). Disponível em www.dspguide.com.

[112] R. W. Shaw, D. E. Hill, Phys. Rev. B 1, 658 (1970).

[113] S. D. Sarma, F. Stern, Phys. Rev. B 32, 8442 (1985). 